UNIVERSIDADE DE SÃO PAULO

ESCOLA DE ENGENHARIA DE SÃO CARLOS

DEPARTAMENTO DE ENGENHARIA DE TRANSPORTES

MARIANA MARÇAL THEBIT

\title{
RECONSTRUÇÃO DE MATRIZ O/D SINTÉTICA A PARTIR DE DADOS DE TRÁFEGO DISPONÍVEIS NA WEB
}





\section{RECONSTRUÇÃO DE MATRIZ O/D SINTÉTICA A PARTIR DE DADOS DE TRÁFEGO DISPONÍVEIS NA WEB}

Dissertação apresentada à Escola de Engenharia de São Carlos da Universidade de São Paulo, como parte dos requisitos para obtenção do grau de Mestre em Ciências, Programa de Pós-Graduação em Engenharia de Transportes. Área de Concentração: Planejamento e Operação de Sistemas de Transportes.

Orientador:

Prof. André Luiz Barbosa Nunes da Cunha

\section{SÃO CARLOS}

2018

Este documento é a versão corrigida da dissertação. A versão original encontra-se disponível no Serviço de Pós-Graduação da EESC/USP. 
AUTORIZO A REPRODUÇ̃̃O TOTAL OU PARCIAL DESTE TRABALHO, POR QUALQUER MEIO CONVENCIONAL OU ELETRÔNICO, PARA FINS DE ESTUDO E PESQUISA,DESDE QUE CITADA A FONTE.

Ficha catalográfica elaborada pela Biblioteca Prof. Dr. Sérgio Rodrigues Fontes da EESC/USP com os dados inseridos pelo(a) autor(a).

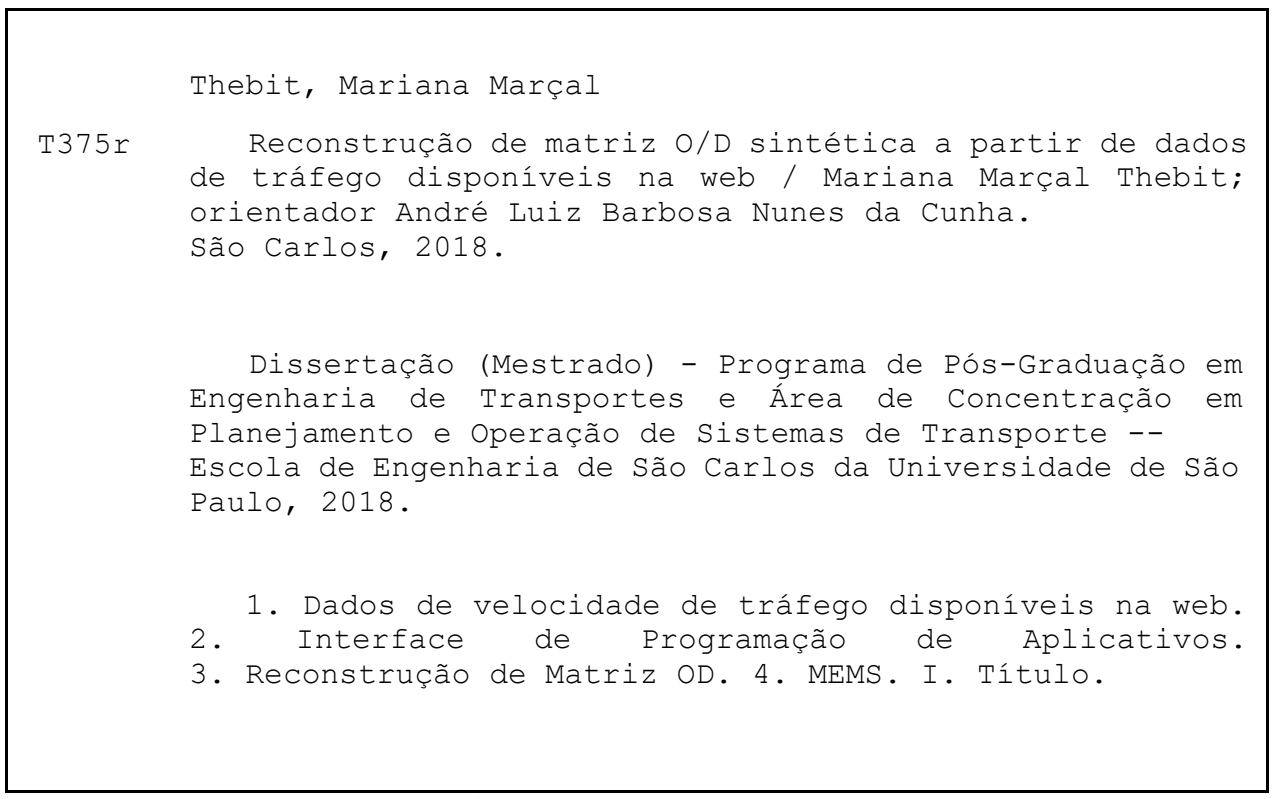

Eduardo Graziosi Silva - CRB - 8/8907 


\section{FOLHA DE JULGAMENTO}

Candidata: Arquiteta e Urbanista MARIANA MARÇAL THEBIT.

Título da dissertaçăo: "Reconstruçăo de matriz O/D sintética a partir de dados de tráfego disponiveis na web".

Data da defesa: 03/09/2018.

Comissão Julgadora:

Resultado:

Prof. Dr. André Luiz Barbosa Nunes da Cunha ADRONADA (Orientador)

(Escola de Engenharia de São Carlos/EESC)

Prof. Dr. Flavio Guilherme Vaz de Almeida Filho

Afrovada

(Escola Politécnica/EP-USP)

Prof. Dr. Bruno Vieira Bertoncini

ADRONADA

(Universidade Federal do Ceará/UFC)

Coordenadora do Programa de Pós-Graduação em Engenharia de Transportes:

Prof ${ }^{\mathrm{B}}$. Associada Ana Paula Camargo Larocca

Presidente da Comissão de Pós-Graduação:

Prof. Associado Luís Fernando Costa Alberto 

Aos meus pais,

Carlos Alberto e Alzira 



\section{AGRADECIMENTOS}

Aos meus pais, Carlos Alberto e Alzira, por tudo que fizeram e ainda fazem por mim. Vocês são meus maiores exemplos!

Aos meus irmãos, Bruna, Marcela e Carlos, meus grandes parceiros em todas as minhas jornadas. Obrigada pelo apoio, pelos puxões de orelha e pela amizade.

Ao meu companheiro Ieside por ter embarcado comigo nessa aventura e ter tido a coragem de largar tudo para também perseguir seus sonhos.

As alegrias da minha vida: minhas sobrinhas Giovanna e Alice e ao meu companheirinho Lock.

Ao meu orientador Prof. André Luís Cunha pelos ensinamentos, contribuições, paciência e por me inspirar por meio de suas aulas a querer ser professora um dia.

Ao Prof. Bruno Vieira Bertoncini (DET-UFC) por ter compartilhado comigo parte de sua pesquisa e ter sido tão solícito as minhas dúvidas.

Aos professores do Departamento de Engenharia de Transportes (STT-EESC-USP) pelos ensinamentos e aos funcionários pelo apoio e atenção. Em especial aos Professores José Reinaldo Anselmo Setti e Cira Pitombo por sempre estarem dispostos a tirar minhas dúvidas, e ao Professor José Leomar Fernandes Junior, pela confiança, carinho e amizade.

Aos amigos que fiz durante essa trajetória e que a tornaram tão especial: Andreza Dornelas, Elaine Ribeiro, Frank Ferreira, Gabriel Oliveira, Lucas Assirati e Natália Panice. Obrigada por me apoiarem, me acolherem e estarem sempre ao meu lado.

Ao meu grupo de pesquisa, por compartilhar comigo os aprendizados: André Morelli, Adriano Belletti, Bruna Kuramoto, Elaine Ribeiro, Gabriel Oliveira, Leandro Marcomini e Natália Panice.

À minha querida amiga Ana Paula Magalhães por ter me motivado a fazer este mestrado na EESC-USP. Obrigada por me incentivar a sempre aprender mais.

À Tectran pelos meus primeiros ensinamentos de Engenharia de Transportes, em especial a Janaina Amorim por ter sido minha primeira mentora. À Barbato Engenharia, em especial a Christiana, por ter me permitido aprofundar minhas práticas na área e a Bruna Sanches pela amizade dedicada.

Ao CNPq - Conselho Nacional de Desenvolvimento Científico pela bolsa de estudos concedida para o desenvolvimento da pesquisa

Agradeço, por fim, a todos aqueles que me incentivaram e torceram por mim. 

Foi o tempo que dedicaste à tua rosa que fez tua rosa tão importante. (Antoine de Saint-Exupéry - O Pequeno Príncipe) 



\section{RESUMO}

\section{THEBIT, M. M. Reconstrução de Matriz O/D Sintética a Partir de Dados de Tráfego}

Disponíveis na Web. 108 p. Dissertação de Mestrado - Escola de Engenharia de São Carlos, Universidade de São Paulo, São Carlos - SP, 2018.

Esta pesquisa apresenta uma proposta de reconstrução de matriz OD a partir de dados de velocidade da corrente de tráfego disponíveis na web. Para tal, foram estabelecidos três objetivos específicos, os quais incluem: obtenção e avaliação dos dados de velocidade de tráfego; construção de um modelo computacional e aplicação desse em uma rede real. A avaliação dos dados foi realizada por meio da comparação dos valores de velocidade média da corrente de tráfego obtidos da web com os valores aferidos por sensores do tipo laço indutivo. Os resultados indicam que, apesar das velocidades extraídas da web apresentarem maior variância e valores mais baixos, a maior parcela dos dados obteve diferença similar ou inferior a $11 \%$. Na construção da rotina computacional foi utilizado o Método das Médias Sucessivas (MEMS) e na sua avaliação foram realizados testes comparativos cujas referências foram os resultados alcançados pelo autor do método utilizado. A rotina desenvolvida apresentou melhor resultado com relação ao número total de viagens da matriz reconstruída, além de exigir menor número de iterações. Por outro lado, com relação às viagens atribuídas a cada par OD seu desempenho foi inferior. Para avaliar a aderência a realidade o método proposto foi aplicado a uma rede real composta por trechos específicos das rodovias Presidente Dutra, Pedro I, Ayrton Senna e Governador Carvalho Pinto. Devido ao fato da entrada principal do MEMS ser o volume de veículos, foi necessário estimar o mesmo a partir da velocidade fornecida pela API. A matriz reconstruída apresentou forte dependência da capacidade atribuída às vias, evidenciando a necessidade de definir de forma mais cuidadosa esse parâmetro. Embora, ainda seja necessário aprimorar o método proposto e a rotina computacional elaborada, bem como, aprofundar os estudos da fonte de dados utilizada, o experimento de caráter exploratório mostra a possibilidade de reconstruir uma matriz OD a partir de dados disponíveis na web.

Palavras-chave: Dados de velocidade de tráfego disponíveis na web, Interface de Programação de Aplicativos, Reconstrução de matriz OD, MEMS. 



\section{ABSTRACT}

\section{THEBIT, M. M. Reconstrução de Matriz O/D Sintética a Partir de Dados de Tráfego}

Disponíveis na Web. 108 p. Master Thesis - São Carlos School of Engineering, University of São Paulo, São Carlos - SP, 2018.

This research presents a proposal for the reconstruction of OD matrix from traffic stream velocity data available on the web. To this end, three specific objectives have been established, which include: obtaining and evaluating traffic speed data; construction of a computational model and application of this in a real network. The data were evaluated by the comparison of the mean values of the traffic current, obtained from the web, with those measured by loop sensors. The results indicate that, although the velocities extracted from the web presented higher variance and lower values, the greater part of the data obtained a difference similar to or lower than $11 \%$. In the construction of the computational routine was used the Method of Successive Averages (MEMS) and in its evaluation were performed comparative tests whose references were the results achieved by the author of the used method. The developed routine presented better results in relation to the total number of trips of the reconstructed OD matrix, besides requiring a smaller number of iterations. On the other hand, in relation to the trips attributed to each OD pair the performance was lower. To evaluate the adherence to reality, the proposed method was applied to a real network composed of specific sections of the Presidente Dutra, Pedro I, Ayrton Senna and Governador Carvalho Pinto highways. Due to the fact that the main input of the MEMS is the vehicles flow, was necessary to estimate it from the speed provided by the API. The reconstructed matrix presented a strong dependence on the capacity attributed to the roads, evidencing the need to define this parameter more carefully. Although it is still necessary to improve the proposed method and the elaborated computational routine, as well as to deepen the studies of the used data source, the exploratory experiment shows the possibility of reconstructing an OD matrix from data available on the web.

Keywords: Traffic speed data available in the web, Application Programing Interface, OD matrix reconstruction, MEMS. 



\section{LISTA DE FIGURAS}

Figura 1 - Organização da proposta.

Figura 2 - Funcionamento de uma API

Figura 3 - Exemplo de saída de dados obtida pelo uso da Here Traffic API............................. 37

Figura 4 - Localização do trecho em estudo no Estado de São Paulo ........................................42

Figura 5 - Trecho da Rodovia Presidente Dutra selecionado para o estudo .............................43

Figura 6 - Localização dos sensores no trecho viário em estudo .............................................43

Figura 7 - Links da Here Traffic API presentes no trecho viário em estudo ............................44

Figura 8 - Sub-trechos de análise da rede em estudo ...............................................................46

Figura 9 - Compatibilização dos dois bancos de dados.......................................................47

Figura 10 - Comparação dos valores de velocidade obtidos por cada fonte para o trecho 1, sentido sul....

Figura 11 - Sobreposição de histogramas obtidos para as duas amostras referentes ao trecho 1, sentido sul.

Figura 12 - Comparação dos valores de velocidade obtidos por cada fonte para trecho 1, sentido norte

Figura 13 - Sobreposição de histogramas obtidos para as duas amostras referentes ao trecho 1, sentido norte. .50

Figura 14 - Comparação dos valores de velocidade obtidos por cada fonte para o trecho 3, sentido sul. .50

Figura 15 - Sobreposição de histogramas obtidos para as duas amostras referentes ao trecho 3, sentido sul.

Figura 16 - Comparação dos valores de velocidade obtidos por cada fonte para o trecho 3, sentido norte. . .51

Figura 17 - Sobreposição de histogramas obtidos para as duas amostras referentes ao trecho 3, sentido norte.

Figura 18 - Comparação dos valores de velocidade obtidos por cada fonte para o trecho 2, sentido sul. 52

Figura 19 - Sobreposição de histogramas obtidos para as duas amostras referentes ao trecho 2, sentido sul.

Figura 20 - Comparação dos valores de velocidade obtidos por cada fonte para o trecho 2, sentido norte.

Figura 21 - Sobreposição de histogramas obtidos para as duas amostras referentes ao trecho 2, sentido norte. 
Figura 22 - Representação visual elaborada para os conjuntos de dados referentes ao sentido norte

Figura 23 - Representação visual elaborada para os conjuntos de dados referentes ao sentido sul.

Figura 24 - Representação visual elaborada para os conjuntos de dados referentes ao sentido norte sem dados do trecho 2 .

Figura 25 - Representação visual elaborada para os conjuntos de dados referentes ao sentido sul sem dados do trecho 2

Figura 26 - Representação visual elaborada a partir dos erros absolutos entre as amostras referente ao dia 23/11/16, quarta-feira, sentido norte 56

Figura 27 - Representação visual elaborada a partir dos erros absolutos entre as amostras referente ao dia 23/11/16, quarta feira, sentido sul. 56

Figura 28 - Representação visual elaborada a partir dos erros absolutos entre as amostras referente ao dia $24 / 11 / 16$, quinta-feira, sentido norte

Figura 29 - Representação visual elaborada a partir dos erros absolutos entre as amostras referente ao dia 24/11/16, quinta-feira, sentido sul .57

Figura 30 - Velocidade obtida pelo sensor x velocidade obtida da web, no trecho 1 sul 59

Figura 31 - Velocidade obtida pelo sensor $\mathrm{x}$ velocidade obtida da web, no trecho 1 norte 59

Figura 32 - Velocidade obtida pelo sensor x velocidade obtida da web, no trecho 2 sul 59

Figura 33 - Velocidade obtida pelo sensor x velocidade obtida da web, no trecho 2 norte 59

Figura 34 - Velocidade obtida pelo sensor $\mathrm{x}$ velocidade obtida da web, no trecho 3 sul. 59

Figura 35 - Velocidade obtida pelo sensor x velocidade obtida da web, no trecho 3 norte 59

Figura 36 - Rede de transporte utilizada para o experimento de implementação do MEMS na linguagem Python 80

Figura 37 - Fluxos alocados aos arcos pelo método das médias sucessivas . .81 Figura 38 - Tempo de deslocamento no fluxo livre e a capacidade viária considerados para cada trecho da rede..... 82

Figura 39 - Relação entre o total de viagens estimadas e o total de viagens "real" para diferentes valores de tolerância .88

Figura 40 - Viagens reais x viagens estimadas por par OD, tolerância 1 ................................. 89

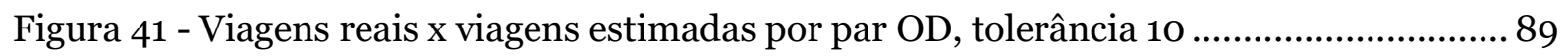

Figura 42 - Viagens reais x viagens estimadas por par OD, tolerância 20 ............................. 89

Figura 43 - Viagens reais x viagens estimadas por par OD, tolerância 30 .............................. 89

Figura 44 - Viagens reais x viagens estimadas por par OD, tolerância 33 ............................... 89

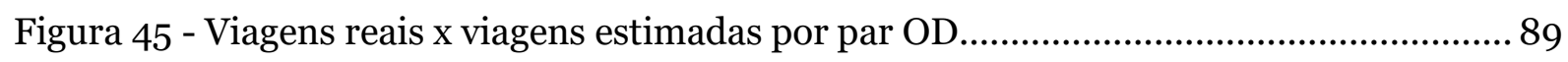

Figura 46 - Distribuição de frequência dos erros absolutos obtidos para o experimento T8 de Bertoncini (2010) e para o código implementado com tolerância 33. .................................... 90 
Figura 47 - Rede real selecionada.........................................................................................93 Figura 48 - Método elaborado para reconstrução da Matriz OD a partir de dados da web. ...94 Figura 49 - Velocidade atribuída a cada link da via ...............................................................96

Figura 50 - Capacidade viária atribuída a cada link da rede...............................................97

Figura 51 - Volumes estimados a partir da velocidade no link fornecida pela API .................97 


\section{LISTA DE TABELAS}

Tabela 1 - Estatísticas descritivas das amostras do sentido sul........................................48

Tabela 2 - Estatística descritiva das amostras do sentido norte .................................... 48

Tabela 3 - Cálculo da variância.................................................................................... 58

Tabela 4 - Resultados obtidos para os testes estatísticos realizados..............................60

Tabela 5 - Matriz OD "real" definida em Bertoncini (2010) .........................................81

Tabela 6 - Matriz OD obtida pela rotina computacional elaborada considerando de nível de tolerância 1 durante processo de otimização .............................................................. 85

Tabela 7 - Matriz OD obtida pela rotina computacional elaborada considerando de nível de tolerância 10 durante processo de otimização......................................................... 85

Tabela 8 - Matriz OD obtida pela rotina computacional elaborada considerando de nível de tolerância 20 durante processo de otimização .......................................................... 85 Tabela 9 - Matriz OD obtida pela rotina computacional elaborada considerando de nível de tolerância 30 durante processo de otimização

Tabela 10 - Matriz OD obtida pela rotina computacional elaborada considerando de nível de tolerância 32 durante processo de otimização 86

Tabela 11 - Matriz OD obtida pela rotina computacional elaborada considerando de nível de tolerância 33 durante processo de otimização ........................................................... 86

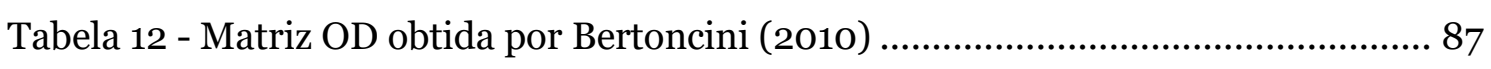

Tabela 13 - Número de iterações necessárias para obtenção de cada matriz................. 87

Tabela 14 - Diferença absoluta média e erro absoluto .................................................. 90

Tabela 15 - Comparação entre os volumes estimados e reais para os trechos da rodovia

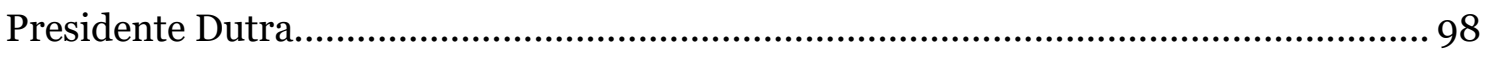

Tabela 16 - Matriz OD obtida para a rede real em estudo............................................ 99

Tabela 17 - Matriz OD obtida para a rede real em estudo considerando capacidade igual a 4.000 veículos/hora para todos os links.

Tabela 18 - Matriz OD obtida para a rede real em estudo considerando a metade da capacidade adotada inicialmente. 


\title{
LISTA DE ABREVIATURAS E SIGLAS
}

\author{
AJAX Asynchronous Javascript and XML \\ API Application Programming Interface (Interface de Programação de \\ Aplicativos) \\ BPR Bureau of Public Roads \\ CPTM Companhia Paulista de Trens Metropolitanos \\ ITS Intelligent Transportation Systems \\ FOLDOC Free Online Dictionary of Computing \\ GLS Generalized Least Squares (Mínimos Quadrados Generalizados) \\ GPS Global Positioning System (Sistema de Posicionamento Global) \\ HCM Highway Capacity Manual \\ JSON Javascript Object Notation \\ MEMS Método das Médias Sucessivas \\ NASA National Aeronautics and Space Administration \\ OD Origem-Destino \\ REST Representational State Transfer (Transferência de Estado \\ Representacional) \\ SKD Software Development Kit \\ SLSQP Sequential Least Square Programming \\ SOAP Simple Object Access Protocol (Protocolo Simples de Acesso a Objetos) \\ XML Extensible Markup Language
}




\section{SUMÁRIO}

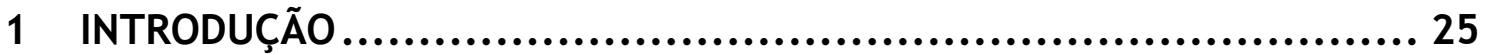

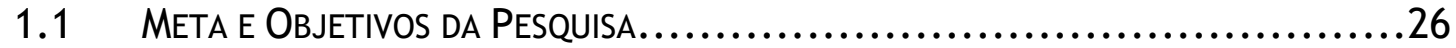

1.2 Justificativa Para a Pesquisa Proposta...............................26

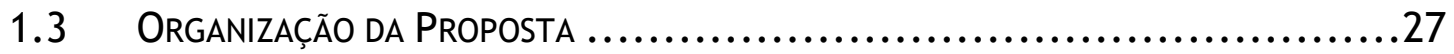

2 DADOS DE TRÁFEGO DISPONÍVEIS NA WEB .......................... 29

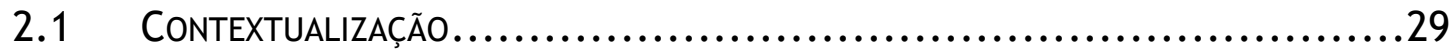

2.1.1 Sensores de monitoramento do tráfego.........................29

2.1.2 Application Programming Interface (API)........................30

2.1.3 APIs de tráfego disponíveis ...................................32

2.1.4 Uso de APIs no monitoramento e estudo do tráfego ...............38

2.1.5 Velocidade média da corrente de tráfego ........................40

2.2 MATERIAIS ....................................................... 42

2.3 MÉTOdo PROPOSTO ..............................................44

2.3.1 Obtenção dos dados .......................................... 45

2.3.2 Compatibilização dos bancos de dados...........................44

2.3.3 Comparação entre as fontes de dados ..........................47

2.4 RESULTADOS .......................................................48

2.4.1 Medidas estatísticas..........................................48

2.4.2 Frequência e comparação das velocidades ........................49

2.4.3 Erro absoluto................................................54

2.4.4 Relação entre velocidade no espaço e no tempo ..................57

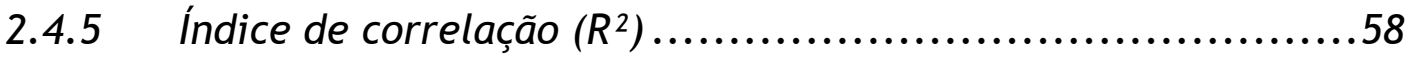

2.4.6 Testes estatísticos..............................................60

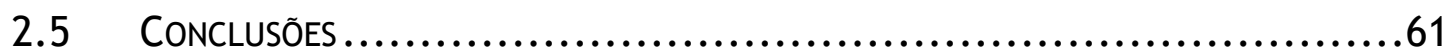

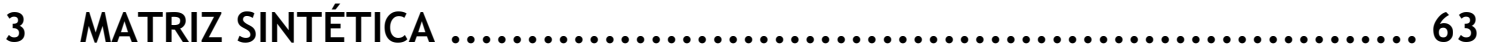

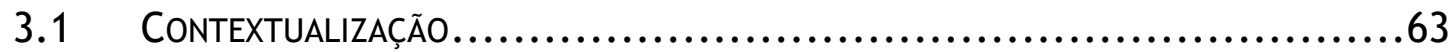

3.1.1 Modelo gravitacional..........................................65

3.1.2 Inferências estatísticas ......................................66

3.1.3 Modelos entrópicos.........................................69

3.1.4 Método das médias sucessivas ................................75

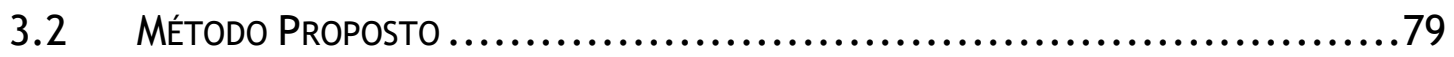

3.2.1 Implementação do MEMS .....................................8 80

3.2.2 Validação do método MEMS implementado.......................84

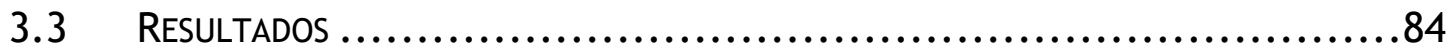


3.3.2 Total de viagens estimadas ................................. 87

3.3.3 Viagens estimadas em cada par OD ........................... 88

3.3.4 Diferença absoluta ......................................... 90

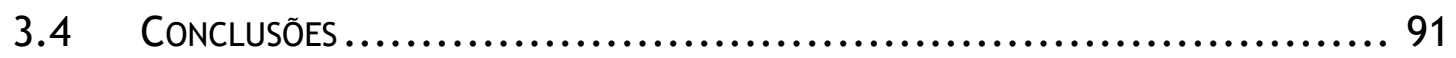

4 MATRIZ SINTÉTICA A PARTIR DE DADOS DA WEB ....................... 93

4.1 ESTUDO DE CASO................................................ 93

4.2 MÉTOdo Próosto .................................................... 94

4.2.1 Etapa 1: Coleta de dados de tráfego da web.................... 94

4.2.2 Etapa 2: Estimação do fluxo a partir da velocidade ............ 95

4.2.3 Etapa 3: Reconstrução da matriz OD sintética.................. 98

4.3 RESULTADOS ........................................................ 98

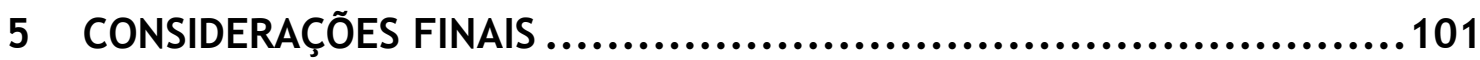

5.1 CONCLUSÕES .................................................... 101

5.2 Sugestões de Trabalmos Futuros ................................... 103

REFERÊNCIAS BIBLIOGRÁFICAS ..........................................105 


\section{INTRODUÇÃO}

A Matriz Origem-Destino (OD) é fonte essencial para o planejamento e operação do tráfego, sendo um dos principais dados de entrada para maioria dos programas de estimativa de viagens e simulação do tráfego.

Sua estimativa é objeto de diversos estudos. De modo geral, uma matriz OD para veículos pode ser estimada de duas formas: por amostragem ou por métodos sintéticos. Na amostragem, as abordagens mais tradicionais utilizam pesquisas manuais, tais como: pesquisa domiciliar, imagens aéreas, controle de placas de veículos, dentre outros procedimentos. No entanto, essas abordagens consomem muito tempo e recursos financeiros, o que as tornam inviáveis em determinadas ocasiões. Além disso, as estimativas realizadas por esses métodos possuem alto potencial para erros, tanto da amostra como no registro dos dados.

Os métodos sintéticos consistem em, a partir de qualquer fonte de dados secundários ou indiretos como, por exemplo, contagens de veículos, estimar uma Matriz OD por meio de um método inverso ao da atribuição do tráfego. Na literatura especializada, os modelos matemáticos elaborados para esse tipo de estimativa buscam solucionar a indeterminação do problema por meio de métodos como Mínimos Quadrados Generalizados (do inglês, Generalizes Least Squares - GLS), máxima verossimilhança, maximização da entropia, filtro de Kalman e inferência Bayesiana.

As contagens de tráfego utilizadas nesse processo usualmente possuem diferentes propósitos como estudos de acidentes, planos de manutenção e melhorias em interseções e os custos de sua obtenção são relativamente baixos (VAN ZUYLEN; WILLUMSEN, 1980) comparado com as entrevistas.

O processo de contagem de veículos pode ser realizado de diferentes maneiras com a utilização de pesquisadores em campo, equipamentos de monitoramento de tráfego, como detectores do tipo laço indutivo e câmeras de vídeo, dentre outras opções. Nos últimos anos, algumas tecnologias de posicionamento, como GPS e telefones celular, começaram a ser utilizadas para monitorar o tráfego em tempo real, fornecer informações de viagens e estimar demanda de tráfego (ZHANG et. al., 2010). 
Com a popularização dos smartphones e a consequente presença desses aparelhos em inúmeros locais da rede de tráfego, utilizar dados provenientes desses equipamentos tem se mostrado uma estratégia pouco onerosa e que permite a obtenção de grande quantidade de informações em tempo real. Diversos estudos como Caceres et al. (2007), Herrera et al. (2009), Becker et al. (2011), Calabrese et al. (2011) e Wang et al. (2012) apresentam propostas de metodologias para a utilização de dados provenientes de telefones celular no estudo de sistemas de tráfego e na elaboração de matrizes OD.

\subsection{Meta e Objetivos da Pesquisa}

O objetivo desta pesquisa é extrair e explorar os dados de tráfego disponíveis na web e avaliar a possibilidade de se reconstruir uma matriz OD sintética de determinada região a partir desses dados. Sendo assim, o presente estudo busca testar a seguinte hipótese: $E$ possível reconstruir uma matriz OD a partir de dados de velocidade disponíveis na web?

São propostos os seguintes objetivos específicos:

I. Comparar as velocidades obtidas a partir da web com as aferidas por sensores fixos do tipo laço indutivo;

II. Construir um modelo de reconstrução de matriz OD;

III. Implementar o modelo e verificar sua aderência a realidade.

\subsection{Justificativa Para a Pesquisa Proposta}

A obtenção e validação dos dados de velocidade fornecidos em tempo real por meio de APIs (do inglês, Application Programming Interface - Interface de Programação de Aplicativos) apresentam a vantagem de não exigirem gastos com a contratação de pesquisadores, serem de fácil acesso e estarem disponíveis em tempo real e para boa parte da malha viária nacional.

A importância de implementar um método de reconstrução de matrizes OD é o fato de serem elementos de grande importância para o adequado planejamento e operação do tráfego em qualquer sistema viário, seja ele urbano, rural ou interurbano.

A utilização de dados reais permite observar as dificuldades que um gestor de transportes enfrenta/enfrentará durante a reconstrução de uma matriz OD como, por exemplo, a 
limitada disponibilidade de dados e a elevada complexidade das redes de tráfego. Por outro lado, o uso de um cenário teórico apresenta como vantagem o controle das operações, o que permite avaliar de forma mais aprofundada o desempenho do método propriamente dito, sem as interferências do ambiente, da fonte de dados, das ferramentas disponíveis, dentre outros fatores.

\subsection{OrganizaÇão da Proposta}

A proposta está organizada em cinco partes, conforme mostrado na Figura 1: esta introdução, seguida por três capítulos de experimento e pelas considerações finais. A introdução traz de forma sintética a proposta da pesquisa e as justificativas para sua realização. Optou-se por subdividir o conteúdo da pesquisa em três capítulos, por tratarem de ideias independentes, podendo ser entendidos e aplicados individualmente. Cada um desses três capítulos apresenta método, resultados e conclusões. A revisão bibliográfica, aqui indicada como contextualização, está presente no Capítulo 1 e no Capítulo 2, os quais apresentam temas independentes que se unem apenas na aplicação apresentada no Capítulo 4. Por fim, é apresentado o capítulo de conclusões (Capítulo 5) onde são expostas as observações acerca do trabalho em sua totalidade.

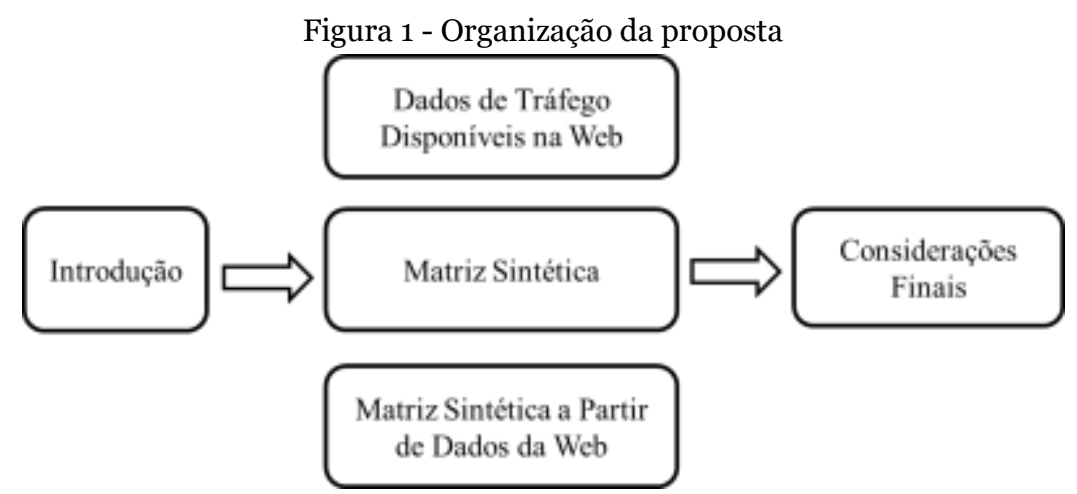

Fonte: A autora 


\section{DADOS DE TRÁFEGO DISPONÍVEIS NA WEB}

Conforme exposto no Capítulo 1, o presente capítulo está organizado em três seções centrais, as quais possuem objetivos, materiais, métodos e resultados. Este capítulo tem por objetivo comparar dados de tráfego extraídos da web com os obtidos por meio de sensores físicos dispostos na via.

\subsection{CONTEXTUALIZAÇÃo}

\subsubsection{Sensores de monitoramento do tráfego}

O monitoramento do tráfego usualmente tem sido realizado por duas abordagens distintas. Uma dessas são as tecnologias com base nas vias, as quais podem ser realizadas por meio de detectores instalados no pavimento, como laços indutivos, magnetômetros e detectores piezoeléctricos, tubos pneumáticos; ou por meio de detectores instalados ao lado da via, como, por exemplo, detectores por imagens de vídeos e sensores dos tipos micro-ondas, radar, ultrassónicos e passivo acústicos (MORGUL et al., 2014).

Outra abordagem bastante utilizada são as tecnologias com base no veículo, as quais podem fazer uso de veículo de sondagem, sistemas automáticos de localização de veículos, sistemas automáticos de identificação de veículos, como reconhecimento de placas, smartphones, dentre outras. Embora as tecnologias com base no veículo obtenham medidas de tempos de viagem adequadas, não é frequente a adoção das mesmas devido, entre outras questões, ao elevado custo de implementação (MORGUL et al., 2014).

Os detectores de tráfego podem ser categorizados em três grupos: detector de ponto único disposto ao lado da via, detectores dispostos em diversos pontos na lateral da via e sensores móveis de ampla cobertura. É importante ressaltar que a coleta de dados de tráfego, com ampla cobertura, por meio de sensores de monitoramento dispostos ao lado da via, requer elevados custos de implantação e manutenção (MORGUL et al., 2014).

Alternativas de baixo custo como os ID transponders de rádio frequência, bluetooth, e sensores sem fio apresentam a desvantagem do baixo número de veículos transmitindo a informação em uma rota de interesse, juntamente com outras dificuldades em detectar veículos em movimento. 
Cada tecnologia apresentará pontos positivos e negativos e exigirá distintos processos de tratamento de dados (MORGUL et al., 2014).

Veículos sonda equipado com GPS (do inglês, Global Positioning System - Sistema de Posicionamento Global) como, por exemplo, táxis, ônibus urbanos ou veículos comerciais oferecem fluxo de dados de ótima qualidade para o monitoramento do tráfego e com praticamente nenhum custo adicional. Embora alguns dos dados coletados por esse tipo de fonte não estejam disponíveis para acesso público, devido a questões de segurança e privacidade, existem fontes de dados abertas fornecendo informações de tráfego em tempo real como o NextBus ${ }^{1}$ (MORGUL et al., 2014).

No Brasil, aplicativos de ônibus como Moovit ${ }^{2}, \mathrm{CittaMobi}^{3}$, Cadê o ônibus $?^{4}$, Vá de ônibus ${ }^{5}$, dentre outros, já estão presentes em praticamente todas as capitais e em diversas cidades do interior. Em geral, os aplicativos de ônibus presente no país oferecem dados sobre a posição geográfica de ônibus municipais e intermunicipais em tempo real e o itinerário completo das linhas, com horários de partida e os pontos mais próximos. Em alguns casos, como no do Cadê o Ônibus? é possível obter também informações sobre o trânsito e alertas com notícias da autarquia responsável pela gestão do transporte público de São Paulo, a SPTrans, do Metrô e da Companhia Paulista de Trens Metropolitanos (CPTM) além de avisos relacionados a greves e manifestações na cidade (CANALTECH, 2018).

\subsubsection{Application Programming Interface (API)}

Uma nova maneira de monitoramento de transporte tem surgido devido ao desenvolvimento tecnológico na área dos sistemas inteligentes de transporte. $\mathrm{O}$ processamento de grandes quantidades de dados de tráfego em tempo real tem se tornado cada vez mais viável em operações de controle de tráfego e disponibilização de informações para os motoristas. O uso de mapas online se tornou amplamente popular com o uso de aplicativos como GoogleMaps ${ }^{6}$ e Waze $^{7}$.

\footnotetext{
${ }^{1}$ https://www.nextbus.com/

${ }^{2}$ https://moovit.com/

${ }^{3}$ https://www.cittamobi.com.br/home/

${ }^{4}$ http://www.cadeoonibus.com.br/

${ }^{5}$ http://www.vadeonibus.com.br

${ }^{6} \mathrm{https}: / / \mathrm{www} . g o o g l e . c o m . b r / m a p s$

${ }^{7} \mathrm{https} / / / \mathrm{www}$.waze.com/pt-BR
} 
A Google foi a primeira empresa a lançar, em 2005, uma Interface de Programação de Aplicativos para obtenção de dados e elaboração de mapas online. A API é uma ferramenta que facilita a troca de dados e recursos entre diversas fontes virtuais de informação ao estipular os meios em que a aquisição, manipulação e apresentação dessas informações deve ocorrer (BRUS, J.; VONDRAKOVA, A.; VOZENILEK, V., 2015).

Segundo o FOLDOC (do inglês, Free Online Dictionary of Computing), as APIs são desenvolvidas em nível de código fonte e permitem um grau de abstração entre o aplicativo e a parte essencial do sistema operacional, de modo a garantir a portabilidade do código. Essas ferramentas permitem a comunicação entre componentes de softwares distintos viabilizando assim a extração de dados em diferentes formatos como i.e., XML (do inglês, Extensible Markup Language) e JSON (do inglês, Javascript Object Notation). A Figura 2 expõe o funcionamento de uma API.

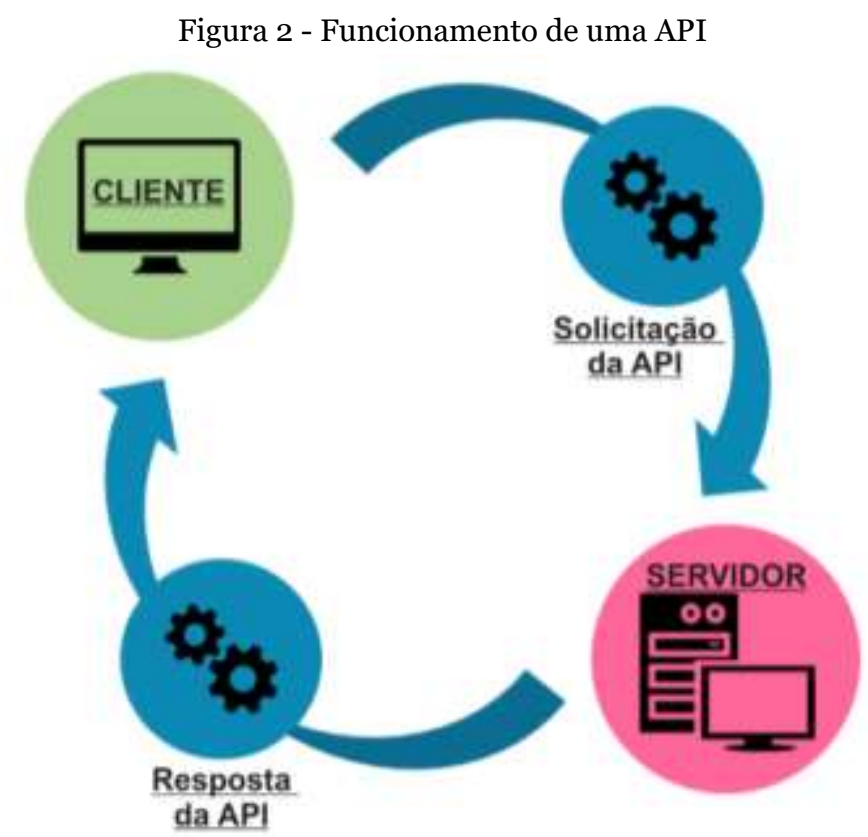

Fonte: A autora

Publicar APIs permitiu que desenvolvedores criassem ambientes abertos para compartilhar dados internamente e com outros aplicativos. Além do Google, diversas empresas fornecedoras 
de mapas online possuem APIs disponíveis na internet, como Bing Maps $^{8}$, MapQuest ${ }^{9}$, NextBus, TomTom ${ }^{10}$ e Here ${ }^{11}$.

\subsubsection{APls de tráfego disponíveis}

Atualmente existem diversas APIs de tráfego que fornecem informações de tráfego por meio de dados e mapas. As APIs de mapeamento pela web fornecem diferentes tipos de serviço como mapas estáticos, direções, matrizes de distância, altitudes, geocodificação e locais. Esse tipo de ferramenta oferece métodos eficientes de visualização de grandes quantidades de dados, como a apresentação de dados em tempo real para os usuários. As interfaces de programação de aplicativo geralmente viabilizam seus dados nos formatos XML ou JSON, os quais podem ser processados facilmente em praticamente qualquer linguagem computacional.

\subsubsection{Google Maps}

A API do Google Maps foi a primeira interface de programação de aplicativo a tornar conveniente para os desenvolvedores, mesmo aqueles com pouco conhecimento de programação, a incorporação de mapas em aplicativos para web. A API do Google Maps é uma das mais populares bibliotecas em Java Script da web, apresentando 1 bilhão de usuários ativos por mês. Suas fontes de dado são: MAPIT, TeleAtlas, DigitalGlobe e MDA Federal (GOOGLE MAPS, 2018; MORGUL et al. 2014).

A API em JavaScript do Google Maps permite que o usuário insira mapas em páginas web externas e sobreponha qualquer tipo de dado no mapa. A API fornece diversas funções para controlar e adicionar informações aos mapas por meio de uma variedade de serviços (GOOGLE MAPS, 2018).

Em suas últimas atualizações a API do Google Maps passou a permitir a estilização personalizada de mapas para dispositivos móveis. A estilização personalizada multiplataforma

\footnotetext{
${ }^{8}$ https://www.bing.com/maps

${ }^{9} \mathrm{https} / / / \mathrm{www} . \mathrm{mapquest} . \mathrm{com} /$

${ }^{10} \mathrm{https}: / /$ www.tomtom.com/pt_br/

${ }^{11} \mathrm{https}: / /$ wego.here.com/
} 
permite que o usuário altere a paleta de cores dos mapas, oculte etiquetas, varie a densidade das vias e alterne os pontos de interesse.

A Google oferece cursos online de treinamento para o uso de suas APIs. Conforme exposto na documentação fornecida pela empresa em seu site ${ }^{12}$, suas interfaces de programação são gratuitas para uma grande variedade de situações. Para os casos em que é preciso pagar pelo serviço, a empresa oferece pacotes com limites de preços e extrações previsíveis e contratos anuais para implantações empresariais.

No site da empresa são apresentados dois planos: Padrão e Premium. O plano padrão permite a extração, de forma gratuita, de até 2.500 solicitações por dia, com taxa adicional de US $\$ 0,50$ a cada 1.000 solicitações extras, sendo permitido um total de 100.000 solicitações diárias. O plano premium apresenta recursos aprimorados e seu preço é estabelecido com base no volume de dados necessário. Não é apresentado um limite de solicitações.

\subsubsection{Microsoft Bing Maps}

A Bing Maps foi lançada em 2005 pela Microsoft como uma "Virtual Earth" para o programa de mensagens MSN. Oferece produtos como serviços de localização, escolha de rotas, obtenção de imagens, dados de tráfego, bem como georeferenciamento e busca. Suas fontes de dados são: Navteq, Intermap, Pictonetry International e NASA (do inglês, National Aeronautics and Space Administration) (MORGUL et al. 2014).

A Bing Maps utiliza três protocolos de API. As do tipo AJAX/JavaScript são destinadas a navegadores e aplicativos da web, similares a outros serviços em que não são necessários plugins adicionais ou aplicativos além do navegador de internet. No entanto, a API em JavaScript não apresenta recursos avançados como design gráfico, transparência e animações. Já a API do tipo SOAP (do inglês, Simple Object Access Protocol)/XML é uma server-side calls, em que os desenvolvedores podem criar aplicativos do tipo .NET que suportam XML e que fazem uso de funcionalidades avançadas como designs gráficos mais elaborados. As APIs Silverlight rodam dentro do navegador do usuário, mas utilizam APIs baseadas em .NET.

\footnotetext{
${ }^{12} \mathrm{https}: / /$ cloud.google.com/maps-platform/pricing/?hl=pt-br
} 
Atualmente o site ${ }^{13}$ da empresa apresenta cinco possibilidades de serviços a serem adquiridos: V8 web Control, Windows 10 plataform, REST (do inglês, Representational State Transfer Transferência de Estado Representacional), Spatial Data e WPF. Dentre os serviços ofertados, o V8 web Control é o que apresenta maior quantidade de informações e funções. Apresenta compatibilidade com navegadores PC e Mac e com diversas plataformas de aparelhos celulares. Com relação ao sistema viário e ao tráfego, é possível obter informações como sentido de direção das vias, cálculo das rotas com base nas vias principais, elaboração de mapas viários e, para algumas localidades, informações sobre o transporte público e a ocorrência de incidentes de tráfego. A Bing Maps não apresenta limite de extrações diárias para seus planos.

\subsubsection{MapQuest}

A MapQuest tem fornecido mapas na web por aproximadamente 15 anos $e$ é a única empresa a oferecer dados licenciados e abertos simultaneamente e assim permitir que seus usuários escolham a versão que quiserem. Suas fontes são: Navteq e OpenStreetMap ${ }^{14}$ (MORGUL et al., 2014)

Dados licenciados fornecem recursos para empresas e desenvolvedores os quais incluem ferramentas para a elaboração de mapas, aplicativos para web e desktop, e ferramentas para desenvolvedores. Os dados, incluindo os de tráfego, são automaticamente atualizados para os proprietários de dados licenciados. Os usuários podem baixar e buscar dados customizados. Os dados abertos fazem uso de informações de satélites de livre acesso, de dados antigos e do OpenStreetMap, um serviço gratuito de mapeamento atualizado diariamente por seus usuários.

Segundo a Map Quest ${ }^{15}$, todas as porções do mapa são atualizadas 15 minutos após a edição ter sido realizada por um usuário do OpenStreetMap. A empresa oferece separadamente distintos tipos de JavaScript, Flash ou Flex APIs para diversos tipos de dados. As opções de geoprocessamento, serviços de tráfego e busca estão disponíveis apenas na forma de dados licenciados. A extração de dados é ilimitada para os dados abertos, porém para os dados licenciados há limite diário de extração de acordo com o dado que se deseja obter.

\footnotetext{
${ }^{13} \mathrm{https}: / /$ www.microsoft.com/en-us/maps/choose-your-bing-maps-api

${ }^{14} \mathrm{https} / / /$ www.openstreetmap.org/\#map=4/-15.13/-53.19

15 https://www.mapquest.com/
} 


\subsubsection{TomTom}

As APIs da TomTom Maps permitem que o desenvolvedor elabore aplicativos para celulares e computadores com dados georreferenciados. São ofertadas uma variedade de plataformas do tipo REST APIs e SDKs (do inglês, Software Development Kits - Kits de Desenvolvimento de Software) que permitem incorporar ao aplicativo em desenvolvimento ferramentas de roteamento, mapeamento, trafego e navegação (TOMTOM, 2018). Suas fontes são: TomTom International BV e Whereis.

A API de roteirização da TomTom permite o planejamento de uma rota entre dois pontos considerando dados de trafego históricos e em tempo real. Como resultado a ferramenta pode fornecer tempos de viagens, atualização em tempo real das informações do trânsito e instruções de rotas para diversos modos como carros, caminhões, bicicletas e pedestres (TOMTOM, 2018).

A API de tráfego da TomTom permite a obtenção de dados como informações detalhadas da velocidade média da corrente de tráfego em cada link da rede viária em estudo. Informações sobre congestionamentos, bloqueios de vias e demais incidentes relacionados ao tráfego (TOMTOM, 2018).

A TomTom não oferece integração com o sistema de transporte coletivo, como observado em algumas APIs para determinadas localidades. Além disso, também não são fornecidas matrizes de distância. É possível a obtenção de uma chave de API para avaliação mediante contato com a empresa. Não há limite de extrações diárias.

\subsubsection{Here - Nokia Maps}

A fabricante de celulares Nokia, atualmente uma unidade da Microsoft, lançou em 2002 seu serviço de tráfego o qual tinha por objetivo fornecer um aplicativo de mapas independente para seus aparelhos. Por meio do uso de um extenso arquivo de mapas armazenado na memória dos telefones, os usuários eram capazes de gerar mapas sem a necessidade de estarem conectados à Internet.

Após a compra da empresa de sistemas embarcados de navegação, Navteq, uma gigante na área de mapas, em 2007, a Nokia se tornou um dos maiores fornecedores de dados online baseados em mapas. A empresa voltou suas atenções para a Internet com o lançamento do OviMaps em 
2007, renomeado Nokia Maps em 2011 e em seguida para Here em 2012, o qual, também foi disponibilizado na forma de aplicativo em sua última versão. Em 2012, a Nokia assumiu o controle da Yahoo Maps, uma grade fornecedora da área de posse de seus próprios mapas e APIs (BRUS, J.; VONDRAKOVA, A.; VOZENILEK, V., 2015).

Em 2011, a Nokia começou a fornecer dados de tráfego para a Yahoo Maps e em 2012 para Bing Maps. Apesar da Nokia fornecer APIs para navegadores de internet, seu foco está em fornecer dados de tráfego para diversos consumidores em diferentes indústrias e canais, incluindo motoristas, aparelhos de navegação, empresas de telefonia móvel e agências de setores públicos.

Atualmente as informações fornecidas pelas APIs da Here Maps são coletadas por meio de dispositivos, infraestruturas, veículos sonda, dentre outras fontes (HERE, 2018). Nos Estados Unidos, a Nokia possui e gerencia milhares de sensores em rodovias ao longo de todo o país. Os dados extraídos a partir de veículos sonda podem ser obtidos de usuários dos aplicativos da empresa, como o Here WeGo, de aplicativos construídos a partir das APIs da Here ou mesmo de veículos com tecnologias embarcadas. Nesse último caso, a Here se destaca como empresa líder no fornecimento de mapas para veículos, sendo responsável, por exemplo, pelos mapas de veículos de diversas linhas da Volvo.

As APIs de desenvolvedores da Nokia são disponibilizadas em três categorias: Java Script, REST e HTML5. A API em Java Script permite que o desenvolvedor crie aplicativos para web e consiste em uma biblioteca de classes e métodos de diferentes funcionalidades. A API de imagem da Nokia ou REST API, é uma API de serviço web que permite acesso rápido e fácil a mapas e imagens. A interface de HTML5, para aparelhos móveis, também é em Java Script e foi desenvolvida para criar aplicações da web baseadas em aparelhos celulares, incluindo renderização em tempo real, roteirização, e disponibilização de informações de tráfego.

A Here fornece um total de 24 APIs para diferentes objetivos, linguagens e sistemas operacionais. No caso específico de dados de tráfego, a Here disponibiliza a ferramenta Traffic API, atualmente na versão 6.0.27.0, a qual é completamente baseada em REST e fornece informações e mapas sobre o fluxo de veículos na corrente de tráfego. (HERE, 2014). 
A Here Traffic API ${ }^{16}$ fornece quatro tipos de dados de incidentes, mapas de tráfego, disponibilidade de informações de tráfego e dados de fluxo de veículos, as quais são atualizadas a cada 60 segundos. Os dados de incidentes de tráfego são fornecidos de forma agregada. As informações concedidas são a localização, se o evento está ocorrendo naquele momento ou não, instante de início e fim, dentre outros dados relevantes. Os mapas de tráfego podem ser elaborados com layers pré renderizados e se basearem em dados históricos de uma área específica ou em dados em tempo real. A disponibilidade de informação de tráfego, permite ao elaborador do aplicativo, que utiliza a API, determinar em qual região do mapa devem ser apresentadas informações de tráfego ou não.

Com relação aos dados de fluxo de veículos, é possível obter informações como limite de velocidade, velocidade na via e fator de congestionamento por meio da API. Caso seja solicitado durante o pedido de dados, também é possível obter dados adicionais como informações acerca da geometria do trecho de via em questão. A empresa também realiza testes de veracidade para assegurar que a velocidade fornecida é tão precisa quanto possível. A Figura 3 apresenta um exemplo de dados obtidos pelo uso da Here Traffic API.

Figura 3 - Exemplo de saída de dados obtida pelo uso da Here Traffic API

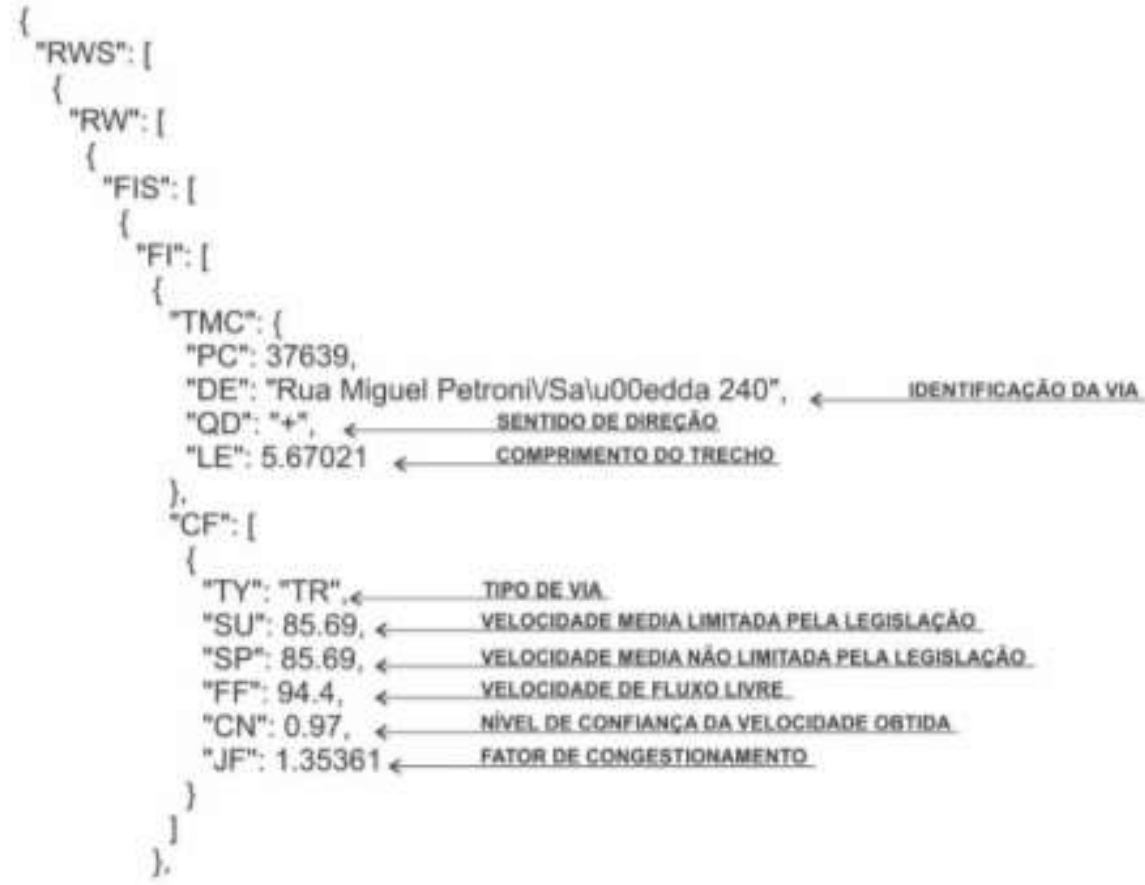

Fonte: A autora

\footnotetext{
${ }^{16} \mathrm{https}: / /$ developer.here.com/documentation/traffic/topics/request-constructing.html
} 
O item "CF", que se refere a confiança dos dados, é estabelecido com base na porcentagem de dados obtidos em tempo real incluída no cálculo da velocidade. Seus resultados podem ser subdivididos em 3 categorias. $0,7<\mathrm{CF} \leq 1,0$ indica velocidades obtidas em tempo real, $0,5<\mathrm{CF} \leq 0,7$ indica que a velocidade fornecida se baseia no histórico da via e $0,0<\mathrm{CF} \leq 0,5$ que ocorre quando a velocidade fornecida corresponde ao limite de velocidade da via. Caso não tenha sido possível calcular o "CF", o valor a ele atribuído será de -1. Para utilizar apenas velocidade obtidas em tempo real é recomendado pelo desenvolvedor da API utilizar somente os dados cujos valores de "CF” são superiores a 0,7 (HERE, 2014).

\subsubsection{Uso de APIs no monitoramento e estudo do tráfego}

Flammia e Rabinowicz (2003) citaram o uso de aplicativos baseados na web como uma promissora fonte de dados para departamentos de trânsito e agência de planejamento. Atualmente, essa já é uma realidade que ocorre por meio de parcerias como a Conected Citizens ${ }^{17}$ da Waze, segundo a qual a empresa se dispõe a fornecer dados e informações a prefeituras, concessionárias de rodovias, dentre outros, em troca também de informações.

Flammia e Rabinowics (2003) propuseram um aplicativo de mapas baseado na web com competência para implementar funções capazes de apresentar de maneira gráfica e interativa resultados de estudos de tráfego. O site desenvolvido pelos autores mostra o fluxo por motivo trabalho entre os condados americanos, por meio de linhas além de fornecer as informações na forma de tabelas.

Welch et al. (2007) apresentaram um sistema que permite o acesso universal a dados de tráfego baseados em localização de forma simples e rápida. O sistema por eles apresentado era composto por um aplicativo online que permitia a visualização, a inserção e o gerenciamento de dados de tráfego. Para que os usuários pudessem buscar dados de tráfego e acessar os registros solicitados, seria necessário apenas um navegador de internet. Os dados podem estar salvos em qualquer local contanto que sejam acessíveis por meio de um navegador.

Thomas et al. (apud Morgul et al., 2014) criaram o sistema denominado T.R.A.F.F.I.C. que auxilia os usuários a evitarem atrasos devido ao tráfego, fornece rotas alternativas e apresenta notificações de trânsito. O grupo de pesquisa utilizou a API do MapQuest para obter as direções

\footnotetext{
${ }^{17}$ https://www.waze.com/pt-BR/ccp
} 
detalhadas de rota e dados da TRANSCOM e assim localizar eventos e retenções no tráfego. A TRANSCOM consiste na aliança entre 16 agências de transportes e segurança pública na região metropolitana de Nova York-Nova Jersey-Connecticut, criada em 1986. A estrutura apresentada pelo estudo se mostrou promissora no uso de big data na detecção de congestionamentos, porém não foi apresentado pelo estudo o resultado de sua implementação.

O tempo de viagem depende inerentemente da tipologia da rede de transportes, o que consistem em um conjunto de links e nós. Procedimentos de estimativa do tempo de viagem são implementados principalmente com base na determinação do menor caminho entre um nó origem e um nó destino. Além disso, diversos elementos da rede devem ser definidos como presença de via de sentido único de circulação, restrições de movimentos ou tempos semafóricos.

Fontes online, como Google Maps, Here Maps e MapQuest, fornecem opções úteis para solucionar problemas de escolha do caminho mais curto por meio de mapas atualizados frequentemente e baseados em condições de tráfego em tempo real. Embora informações sobre o cálculo do tempo de viagem não sejam disponibilizadas devido a questões comerciais e de confidencialidade, pesquisadores tem tentado medir a acurácia desses dados de tempo de viagem.

Pouco após o Google liberar sua API, Wang e Xu (2011) utilizaram dados de rede de transporte juntamente com o algoritmo de escolha de rota do Google e compararam o tempo de viagem obtido com o calculado pelo módulo de análise de rede do ArcGIS. Os autores destacaram diversas vantagens em utilizar a API do Google Maps na estimação de tempos de viagem, como a menor necessidade de preparação dos dados da rede e de conhecimentos de GIS.

Alguns dos primeiros estudos nessa área focaram na utilização dos dados provenientes dos GPS instalados nos telefones celulares. Desenvolvido por Pesquisadores da Universidade Berkeley na Califórnia, o projeto Mobile Century buscou validar o conceito de monitoramento do tráfego por meio de dados provenientes de telefones celulares. A proposta consistiu em rastrear alguns veículos por meio do GPS do telefone celular em seus interiores. Os resultados obtidos foram comparados com os provenientes de sensores fixos (laço indutivo) (HERRERA et al., 2008).

No entanto, é importante destacar que o estudo não considerou os dados provenientes do sensor como verdade absoluta. Para avaliar a adequação de ambas as fontes de dados o projeto Mobile Century optou por extrair a velocidade no trecho em estudo por meio de câmeras de alta 
definição com sistema de reconhecimento de placas. O tempo de viagem obtido por meio de cada uma das fontes de dados foi analisado, sendo observada uma subestimação do tempo de viagem por parte da fonte de dados de laço indutivo, o que indicou também uma superestimação da velocidade em questão. Por fim, o estudo mostrou que com uma penetração de aparelhos celulares com GPS inferior a 5\%, é possível obter, de maneira precisa, a velocidade do fluxo de tráfego ( HERRERA et al., 2008).

Com base nos dados de GPS proveniente dos táxis de Beijing, Wang, Zengh e Xue (2014) modelaram o tempo de viagem de diversos motoristas, em diferentes segmentos de vias e diferentes intervalos de tempo, e propuseram um modelo para estimar o tempo de viagem em qualquer caminho. Pan et al. (2013) utilizaram dados de GPS de táxis, referentes a um período de três meses, juntamente com um banco de dados de tweets coletados pelo WeiBo para elaborar um sistema de sensoriamento coletivo das anomalias do tráfego. As anomalias eram identificadas com base no comportamento dos taxistas em relação a escolha de rotas.

Os dados provenientes de GPS de aparelhos celulares também são importante fonte de dados para a elaboração de softwares aplicados ao trânsito. Por exemplo, os softwares de chamada de táxi amplamente utilizados atualmente como Uber $^{18}$, 99Taxi ${ }^{19}$ e Easy $\mathrm{Taxi}^{20}$, foram todos elaborados com base em dados reais oriundos de GPS dos telefones de taxistas.

Atualmente parte dos dados armazenados por dispositivos móveis e seus aplicativos pode ser extraído por meio de APIs, algumas das quais disponíveis gratuitamente. No caso específico de dados de tráfego, existem no mercado diversas APIs que permitem a obtenção de informações referentes a situação do trânsito naquele instante, conforme os exemplos apresentados anteriormente.

\subsubsection{Velocidade média da corrente de tráfego}

A velocidade é uma grandeza que descreve a relação entre o espaço percorrido e o tempo gasto para percorre-lo. No caso de uma corrente de tráfego, a velocidade pode ser compreendida como a média das velocidades individuais dos veículos que compõem a corrente. Essa velocidade média pode ser obtida em função do tempo e do espaço.

\footnotetext{
${ }^{18} \mathrm{https}: / / \mathrm{www} \cdot$ uber.com/pt-BR/

${ }^{19} \mathrm{https}: / / 99$ app.com/

${ }^{20} \mathrm{http} / / / \mathrm{www}$.easytaxi.com/br/
} 
A velocidade média no tempo refere-se a um ponto específico da via e pode ser calculada pela média aritmética da velocidade individual dos veículos que passam naquele local por determinado intervalo de tempo (equação [2.1]). Um exemplo de velocidade média no tempo é a obtida por meio da média das velocidades aferidas por sensores do tipo laço indutivo em determinado ponto de uma rodovia ao longo de um determinado intervalo de tempo.

$$
u_{t}=\frac{1}{n}{ }_{i=1}^{n} \sum u_{i}=\frac{1}{n}{ }_{i=1}^{n} \sum \frac{d}{t_{i}}
$$

em que,

$u_{t}: \quad$ velocidade média no tempo;

$n$ : número de veículos;

$u_{i}$ : velocidade instantânea do $i$-ésimo veículo;

$d$ : comprimento do trecho;

$t_{i}$ : tempo gasto pelo $i$-ésimo veículo para percorrer o trecho.

A velocidade média no espaço (equação[2.2]) refere-se a um segmento de via. Seu cálculo é realizado por meio da média harmónica das velocidades individuais dos veículos que passam em determinado segmento da via, por determinado tempo. Pode ser calculada pelo somatório das distâncias percorridas pelos veículos sobre o somatório do tempo gasto por cada um deles.

$$
u_{s}=\frac{n \cdot d}{{ }_{i=1}^{n} \sum t_{i}}=\frac{n}{{ }_{i=1}^{n} \sum \frac{1}{u_{i}}}
$$

A relação entre a velocidade no tempo e no espaço pode ser descrita pela equação[2.3], (GERLOUGH e HUBER, 1976).

$$
u_{t}=u_{s}+\frac{\sigma^{2}}{u_{s}}
$$

Em que $\sigma^{2}$ corresponde a variância das velocidades instantâneas dos veículos. Sendo assim, de modo geral, a velocidade média no tempo apresentará valores mais elevados do que a velocidade média no espaço. 


\subsection{MATERIAIS}

Para realizar a comparação entre a velocidade média do tráfego disponível na web e a aferida por meio de sensores fixos foi necessário selecionar um trecho viário para o qual fosse possível obter a velocidade média do fluxo a partir das duas fontes de dados em estudo.

Devido a existente parceria entre o grupo de pesquisa e a Concessionária CCR Nova Dutra, optou-se por delimitar como rede de estudo o trecho específico da Rodovia Presidente Dutra (BR-116), localizado entre os municípios de Santa Isabel e Jacareí, no estado de São Paulo (Erro! Fonte de referência não encontrada.).

Figura 4 - Localização do trecho em estudo no Estado de São Paulo

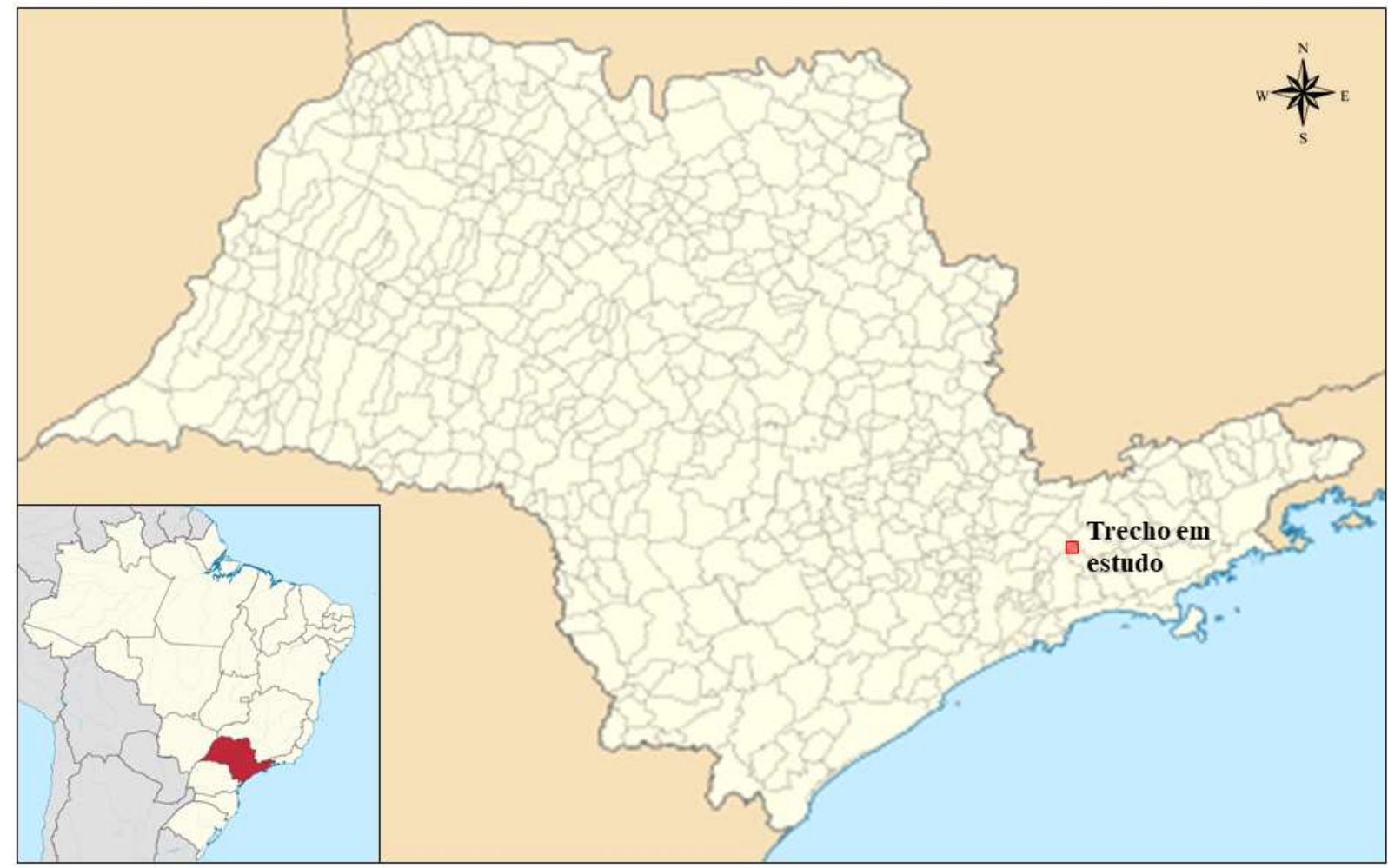

Fonte: A autora sobre imagem da Wikipedia

A BR-116 é a principal rodovia do país e estabelece a ligação entre os municípios de Fortaleza-CE e Jaguarão-RS, na fronteira com o Uruguai. A rodovia possui traçado longitudinal o qual passa por 10 estados brasileiros. Sua extensão é de aproximadamente $4.513 \mathrm{~km}$.

No trecho em estudo (Figura 5) a estrutura da rodovia é composta por pista dupla, segregadas por barreira de concreto do tipo New Jersey, com duas faixas de circulação por sentido e acostamento a direita. A velocidade regulamentada no local é $90 \mathrm{~km} / \mathrm{h}$. 
Figura 5 - Trecho da Rodovia Presidente Dutra selecionado para o estudo

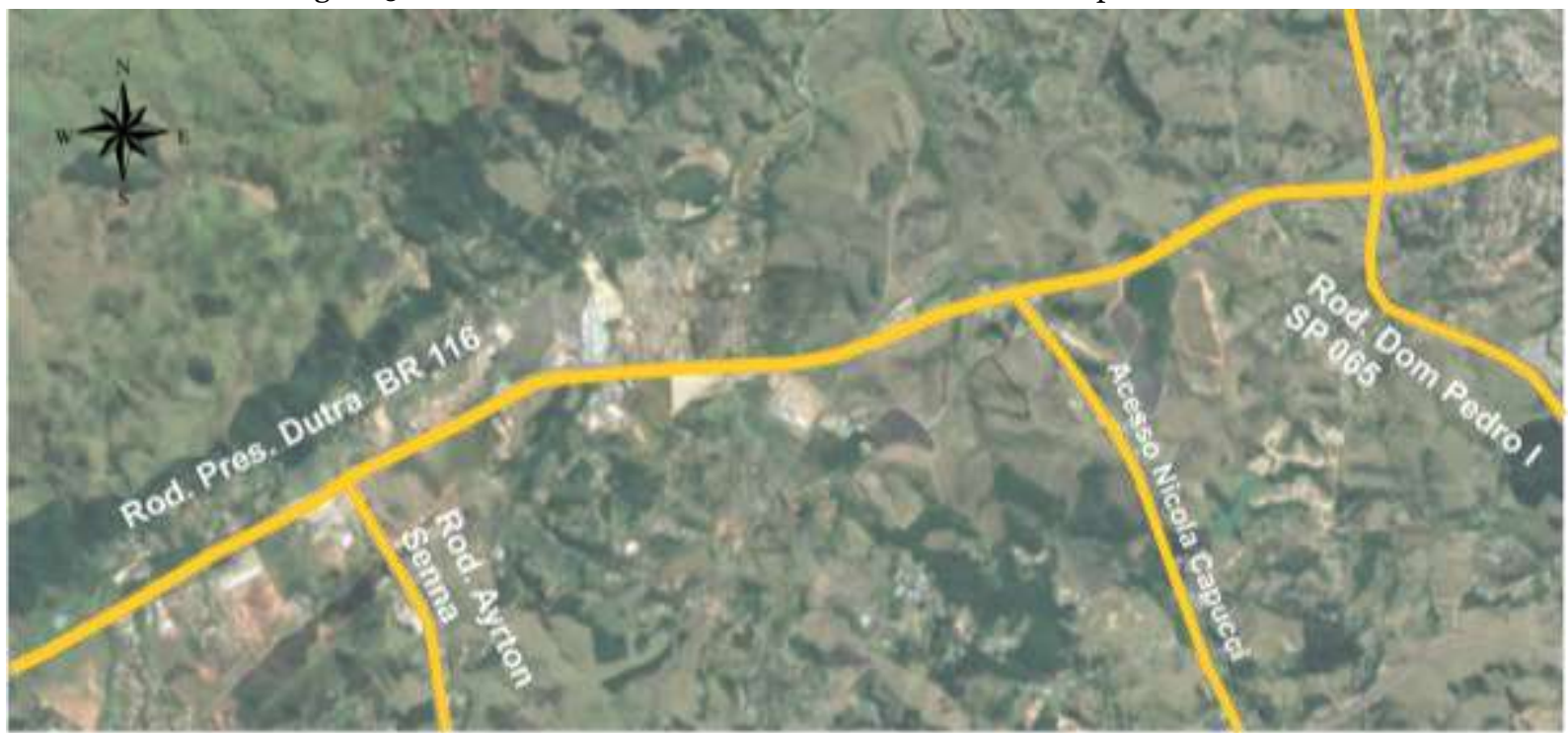

Fonte: A autora sobre imagem do Google Earth

Em seguida foram realizadas as coletas dos dados necessários ao estudo. Os dados oriundos dos sensores fixos foram fornecidos pela concessionária e são referentes a cinco sensores (Figura 6) e ao período do dia 22 a 27 de novembro de 2016. As informações obtidas a partir dos sensores e cedidas pela concessionária foram o volume, a velocidade e a taxa de ocupação, todos agrupados em intervalos de 6 minutos. Os dados são referentes a corrente de tráfego como um todo e em função do tipo de veículo. Foram obtidas informações de ambos os sentidos de circulação. O presente estudo optou por avaliar apenas a variável velocidade da corrente de tráfego considerando a presença de todos os tipos de veículos.

Figura 6 - Localização dos sensores no trecho viário em estudo

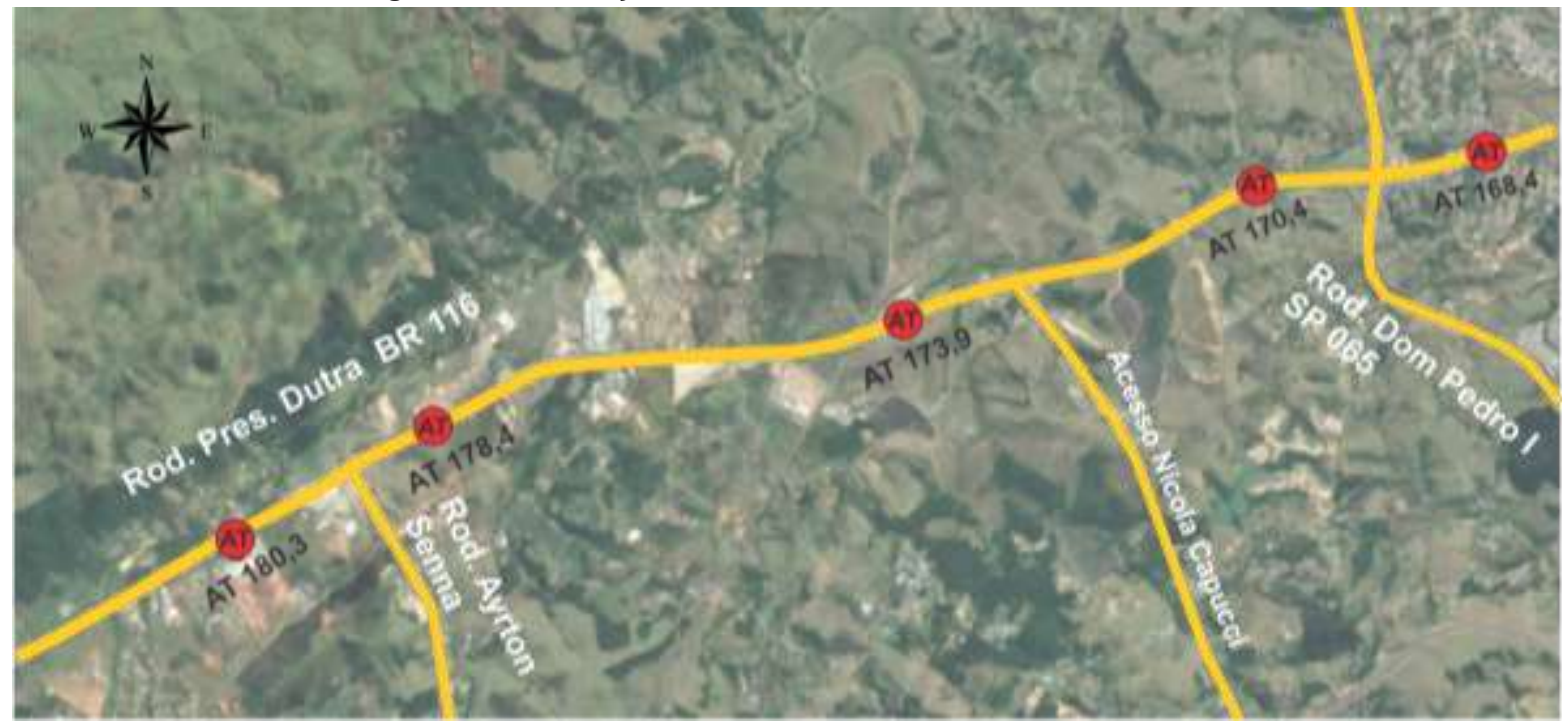

Fonte: A autora sobre imagem do Google Earth 
Os sensores fixos existentes no local são os do tipo laço indutivo, uma tecnologia amadurecida. Embora melhorias nas técnicas de instalação e acondicionamento tenham levado ao aumento da acurácia, esses sistemas de detecção ainda sofrem devido à pouca confiabilidade. Dentre os fatores que contribuem para o baixo desempenho do sistema estão as más conexões feitas nas caixas de pressão, falhas nos pares de fio de torção e o uso de selante defeituoso. Essas questões se agravam quando os laços indutivos são instalados em pavimentos ruins (KLEIN, 2001).

Para extração dos dados de tráfego disponíveis na web, optou-se por utilizar a API da Here Maps devido a liberação de dados de tráfego em formato numérico, contínuo e não apenas de forma visual ou discreta e ao plano de avaliação com duração de três meses sem custos financeiros ou limites de extração. Foi utilizada a versão 6.0.27.0 da Traffic API e extraídos dados referente ao mesmo período e trecho viário. Embora a ferramenta permita a extração de diversas informações, este estudo tem como foco apenas a utilização da variável identificada pela API como "velocidade média não limitada pela legislação". É importante ressaltar que os dados obtidos são referentes a links e não pontuais como ocorre no caso dos dados fornecidos pela concessionária. No trecho viário em estudo foram obtidas informações de quatro links distintos (Figura 7).

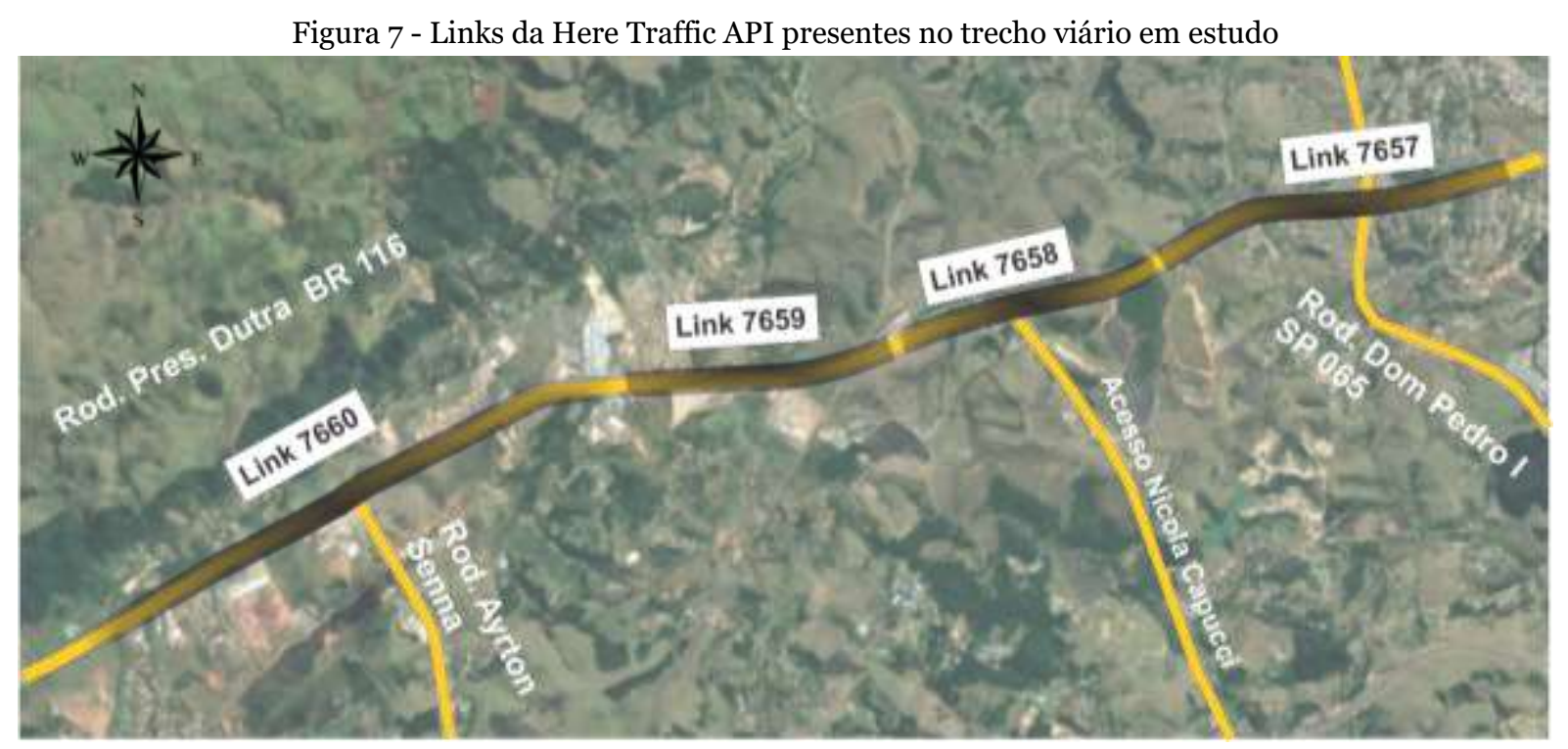

Fonte: A autora sobre imagem do Google Earth

\subsection{MÉTOdo PROPOSTO}

Uma vez que o objetivo central do presente estudo é explorar os dados de tráfego disponíveis na web, mais especificamente a velocidade da corrente de tráfego. Sendo objeto deste capítulo a comparação entre as velocidades obtidas por essa fonte de dados e os aferidos por sensores 
fixos, foi desenvolvido um método composto por três etapas principais. A primeira delas consiste na extração dos dados e foi apresentada no item anterior. Em seguida, foi necessário compatibilizar os dados obtidos pelas duas fontes, para então serem realizadas as comparações entre as amostras.

\subsubsection{Obtenção dos dados}

Foi elaborada uma rotina computacional na linguagem Python para realizar a solicitação de dados pela Here Traffic API de forma ininterrupta para o período de 00:00 do dia 22 de novembro às 23:59 do dia 27 do mesmo mês. As informações foram coletadas em formato JSON e imediatamente armazenadas em documentos no formato TXT nomeados em função do dia e do minuto extraído. Todo este processo foi implementado de forma automática no código elaborado.

Uma segunda rotina computacional foi criada para acessar os documentos no formato texto e extrair desses apenas as variáveis relevantes para o estudo, as quais foram salvas em seguida em planilhas digitais, em que cada linha continha as informações referentes a cada minuto de extração e cada arquivo continha os dados referentes a um dia e um link.

Devido a problemas técnicos a extração foi interrompida em determinados horários os quais foram: dia 22/11/16 das $9 \mathrm{~h} 48 \mathrm{~min}$ às $12 \mathrm{~h} 12 \mathrm{~min}$ e dia 25/11/16 das $00 \mathrm{~h} 12 \mathrm{~min}$ às $16 \mathrm{~h} 12 \mathrm{~min}$.

\subsubsection{Compatibilização dos bancos de dados}

Para comparar as amostras obtidas pelas duas fontes de dados foi necessário tratar o banco de dados elaborado a partir dos extraídos por meio da API para compatibiliza-lo com o fornecido pela concessionária.

O banco de dados fornecido pela concessionária apresenta as observações agregadas em intervalos de 6 minutos para todo o período de coleta. Por outro lado, o banco de dados obtido a partir da API possui observações referentes a cada minuto, sem alguns horários do período estudado. A ausência dessas informações se deve a problemas técnicos durante a extração e ao tempo gasto pelo programa para rodar uma extração, que embora seja de segundos, ao agregar o atraso de várias extrações leva a perda de uma observação. 
A primeira etapa do tratamento do banco de dados consistiu em agrupar as observações em intervalos de 6 em 6 minutos em função da média das observações coletadas para esse período. Em seguida foram retiradas do banco de dados fornecido pela concessionária as observações referentes aos horários não coletados por meio da API.

Após ajustar as questões relacionadas a compatibilização dos intervalos de tempo foi necessário observar a relação entre os links da API e os pontos de AT da concessionária. Como pode ser observado na Figura 8, os links 7660 e 7657 da API agregam dois sensores cada, ATs 180,3 e 178,4 no link 7660 e ATs 170,4 e 168,4 no link 7657. Por outro lado, o AT 173,9 encontra-se no limite dos links 7659 e 7658 . Por essa razão, optou-se por dividir a rede em estudo em três sub-trechos (Figura 8).

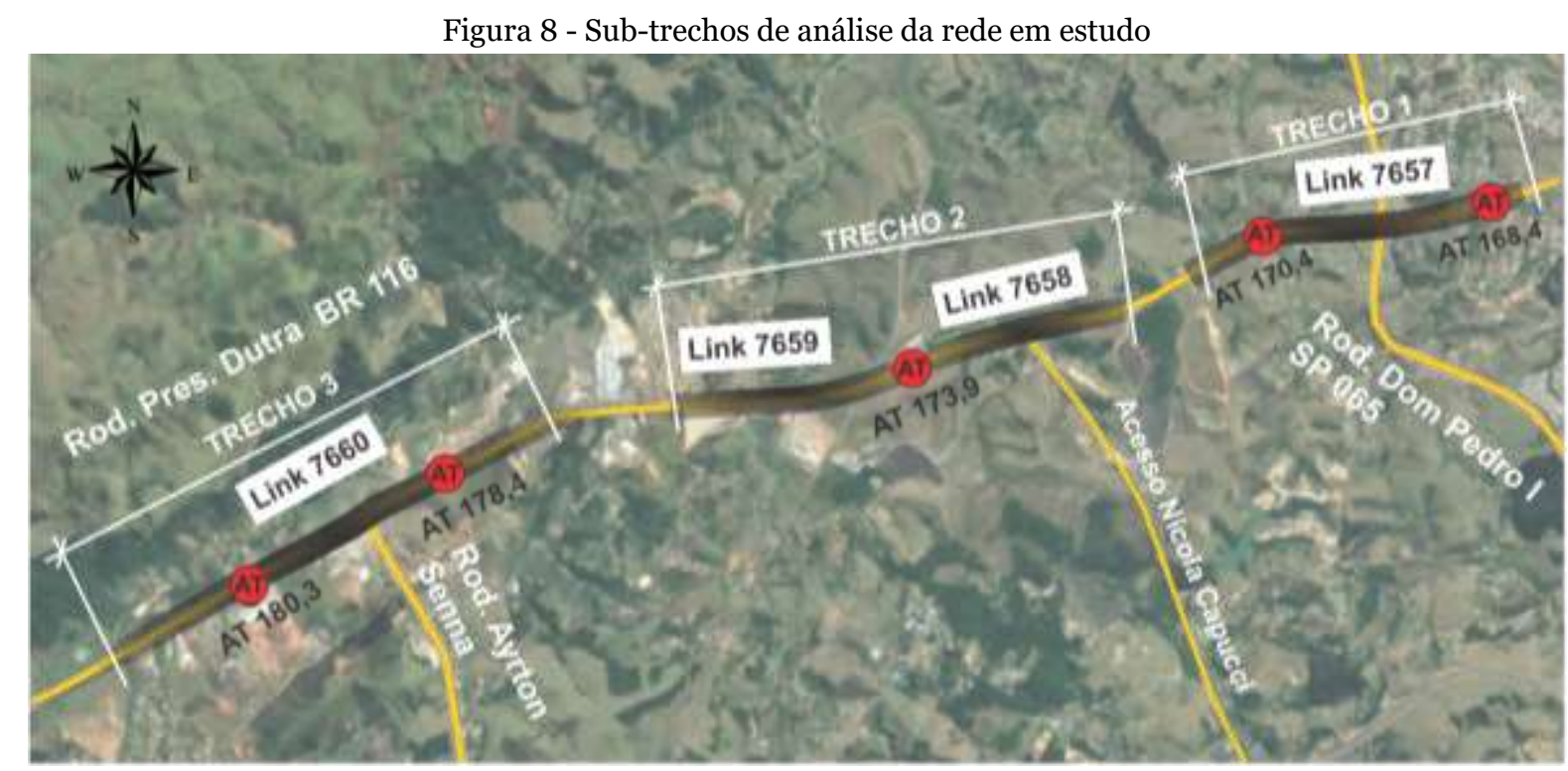

Fonte: A autora sobre imagem do Google Earth

Para os casos em que um link continha mais de um sensor, trechos 1 e 3, foi adotada a estratégia de obter a média dos valores referentes a cada sensor. Com relação ao trecho 2 , não foram observadas grandes distinções entre os dados provenientes dos links 7658 e 7659, desse modo, foi selecionado apenas os dados provenientes do link 7658 para a análise. O banco de dados final foi composto por 950 pares de observações para cada trecho analisado. 


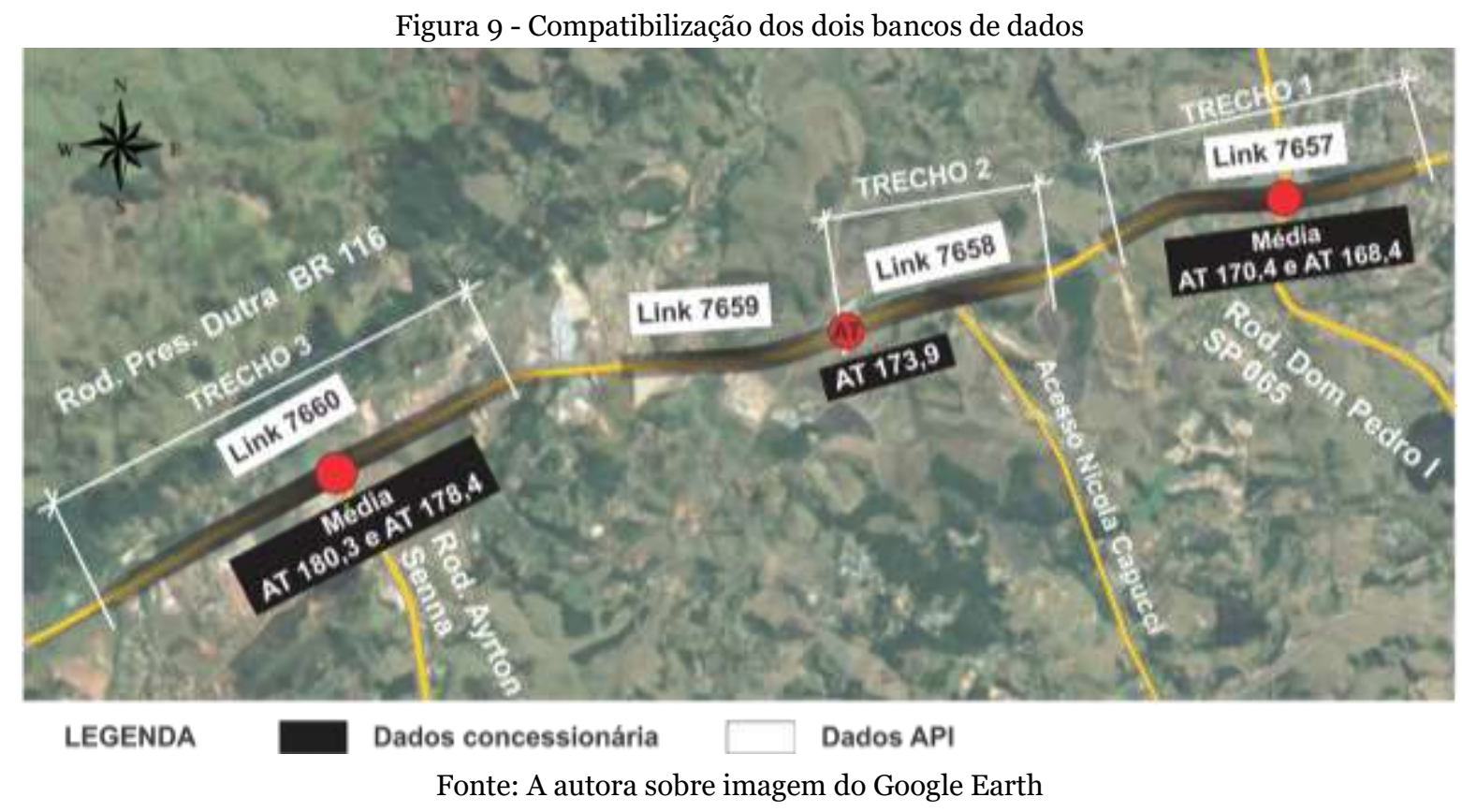

\subsubsection{Comparação entre as fontes de dados}

A comparação entre as duas amostras foi realizada por meio de quatro abordagens distintas. Em um primeiro momento foram observadas as medidas estatísticas de cada amostra, as quais são apresentadas na Tabela 1 e Tabela 2. Em seguida, foi avaliada a relação entre as amostras por meio da elaboração de histogramas e gráficos de comparação dos valores de velocidade obtidos da Web e por meio dos sensores de laço indutivo, ao longo da semana em estudo. O passo seguinte consistiu na obtenção do erro absoluto entre cada um dos pares de observação válidos, os quais foram organizados por meio de formatação condicional, o que permite observar em quais pontos e horários ocorreram maior discrepâncias entre os valores extraídos da web e os fornecidos pela concessionária. O passo seguinte consistiu no cálculo do $\sigma^{2}$ por meio da relação entre a velocidade no tempo, obtida pelo sensor do tipo laço indutivo, e no espaço, obtida da web, conforme a equação 2.3. Também foi calculado o coeficiente de correlação $\mathrm{R}^{2}$ e obtida a linha de tendência. Por fim, foram realizados os testes estatísticos de Kolmogorov-Smirnov e Qui-quadrado $\left(X^{2}\right)$, com o intuito de avaliar a aderência entre as amostras oriundas das duas fontes de dados. 


\subsection{RESULTADOS}

\subsubsection{Medidas estatísticas}

A Tabela 1 e a Tabela 2 apresentam as medidas estatísticas das amostras para cada sensor, link e sentido de direção.

Tabela 1 - Estatísticas descritivas das amostras do sentido sul

\begin{tabular}{|c|c|c|c|c|c|c|}
\hline & \multicolumn{2}{|c|}{ Trecho 1} & \multicolumn{2}{|c|}{ Trecho 2} & \multicolumn{2}{|l|}{ Trecho 3} \\
\hline & $\begin{array}{c}\text { Média sensores } \\
\text { km } 168,4 \mathrm{e} \\
\text { km } 170,4\end{array}$ & Link 7657 & $\begin{array}{c}\text { Sensor } \\
\mathrm{km} 173,9\end{array}$ & Link 7658 & 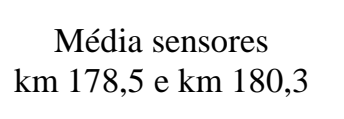 & Link 7660 \\
\hline Média & 95,34 & 90,26 & 64,04 & 87,96 & 85,54 & 83,17 \\
\hline Mediana & 95,62 & 89,88 & 64,33 & 87,83 & 85,84 & 82,89 \\
\hline Erro padrão & 0,11 & 0,25 & 0,12 & 0,29 & 0,12 & 0,20 \\
\hline Desvio padrão & 4,12 & 8,80 & 4,40 & 10,43 & 4,46 & 7,21 \\
\hline Variância & 16,96 & 77,40 & 19,34 & 108,75 & 19,91 & 52,02 \\
\hline Mínimo & 67,04 & 59,74 & 24,59 & 25,46 & 64,87 & 59,74 \\
\hline Máximo & 107,13 & 117,71 & 74,95 & 123,72 & 96,07 & 104,33 \\
\hline
\end{tabular}

Tabela 2 - Estatística descritiva das amostras do sentido norte

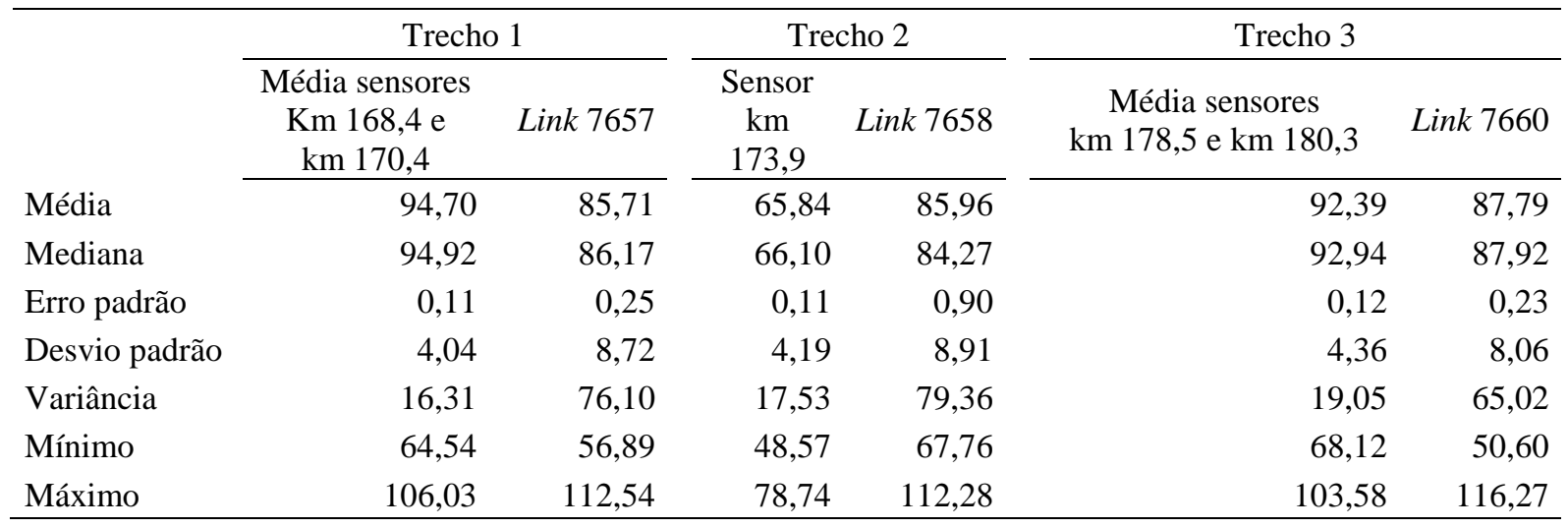

Fonte: A autora

Com exceção das amostras referentes aos dois sentidos do trecho 2 é possível observar uma mesma relação entre as amostras oriundas da Here Maps e as obtidas por meio dos sensores fixos.

De modo geral, as amostras oriundas da Here Maps apresentaram maiores valores de variância e desvio padrão o que indica maior dispersão dos dados em relação as amostras obtidas pelos sensores. Além disso, os valores de média e mediana obtidos para a amostra da Here Maps são inferiores aos obtidos para as amostras oriundas dos sensores. Essa questão pode estar relacionada ao fato do aplicativo fornecer uma média das velocidades no espaço, enquanto os sensores obtêm a média das velocidades no tempo. Conforme explicitado anteriormente, a 
velocidade no espaço tende a ser inferior a velocidade no tempo o que justifica a distinção entre os dados obtidos por cada uma das fontes em estudo.

\subsubsection{Frequência e comparação das velocidades}

Devido ao comportamento distinto da amostra obtida pelo sensor para ambos sentidos do trecho 2 optou-se por analisar seu comportamento separadamente e analisar em conjunto as amostras referentes aos trechos 1 e 3 , as quais possuem características similares.

\subsubsection{Trechos 1 e 3}

Com objetivo de analisar a adesão entre as amostras das duas fontes de dados para cada trecho de via foram elaborados gráficos de comparação dos valores de velocidade obtidos em cada amostra e a sobreposição de seus histogramas (Figura 10 a Figura 17).

Figura 10 - Comparação dos valores de velocidade obtidos por cada fonte para o trecho 1, sentido sul

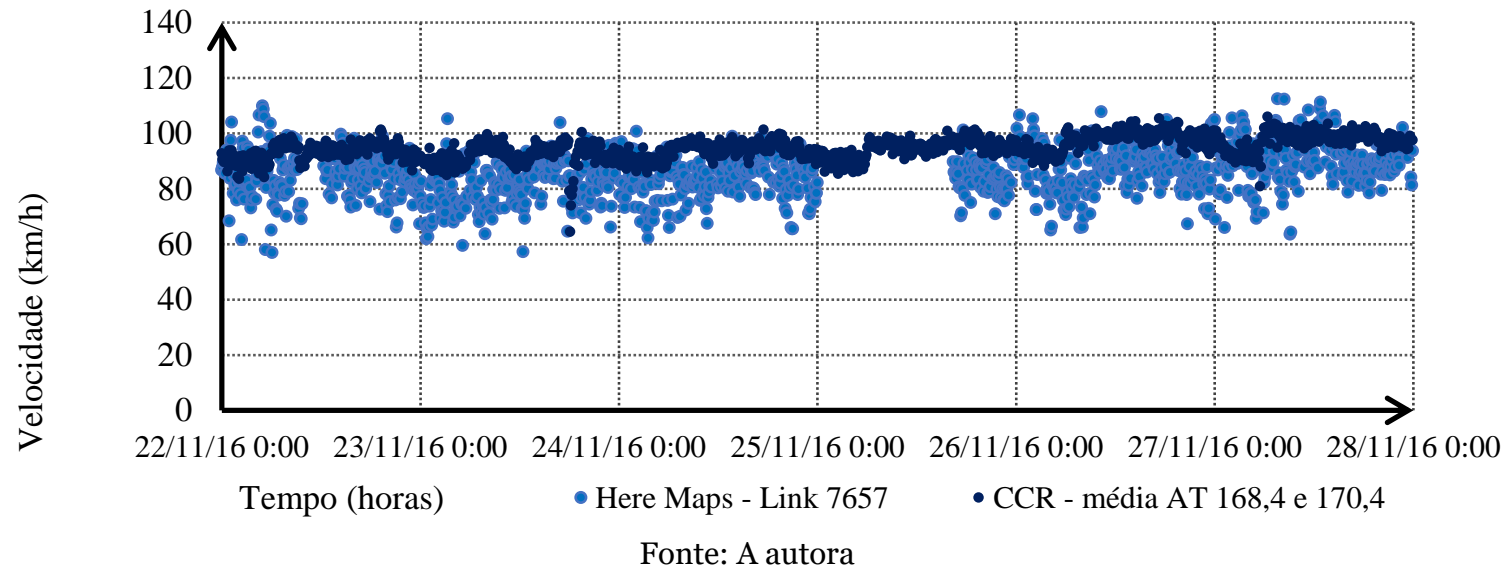

Figura 11 - Sobreposição de histogramas obtidos para as duas amostras referentes ao trecho 1, sentido sul

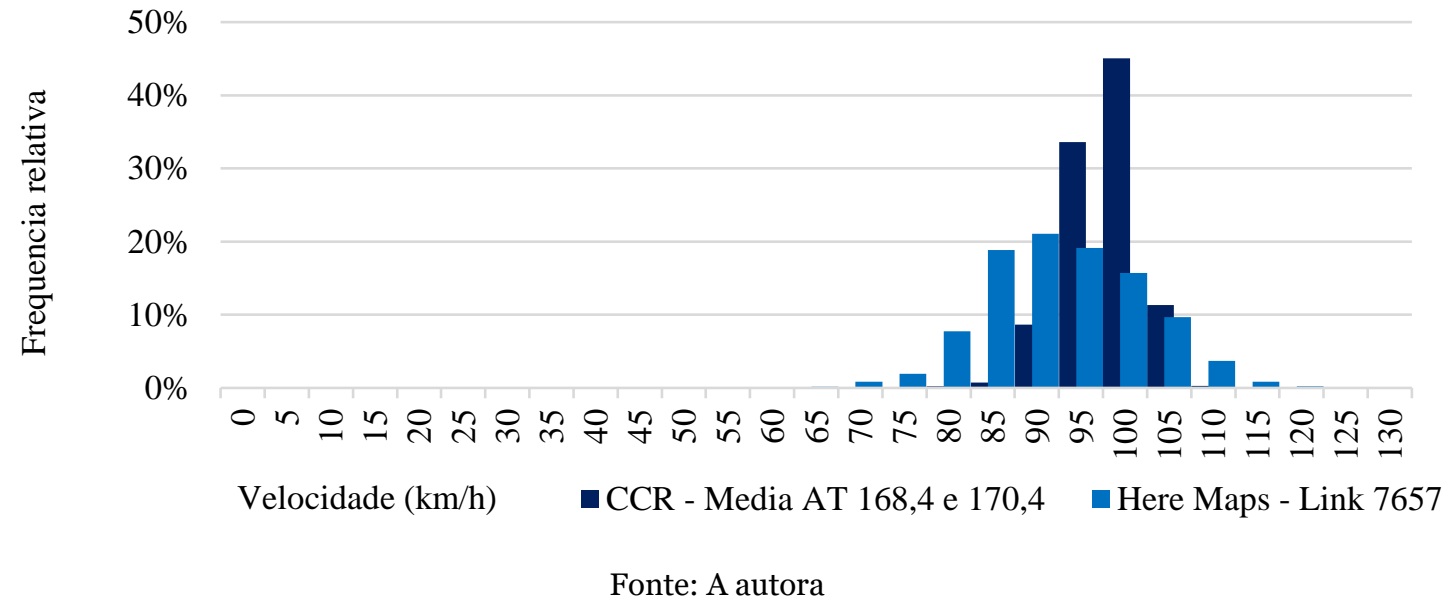


Figura 12 - Comparação dos valores de velocidade obtidos por cada fonte para trecho 1, sentido norte

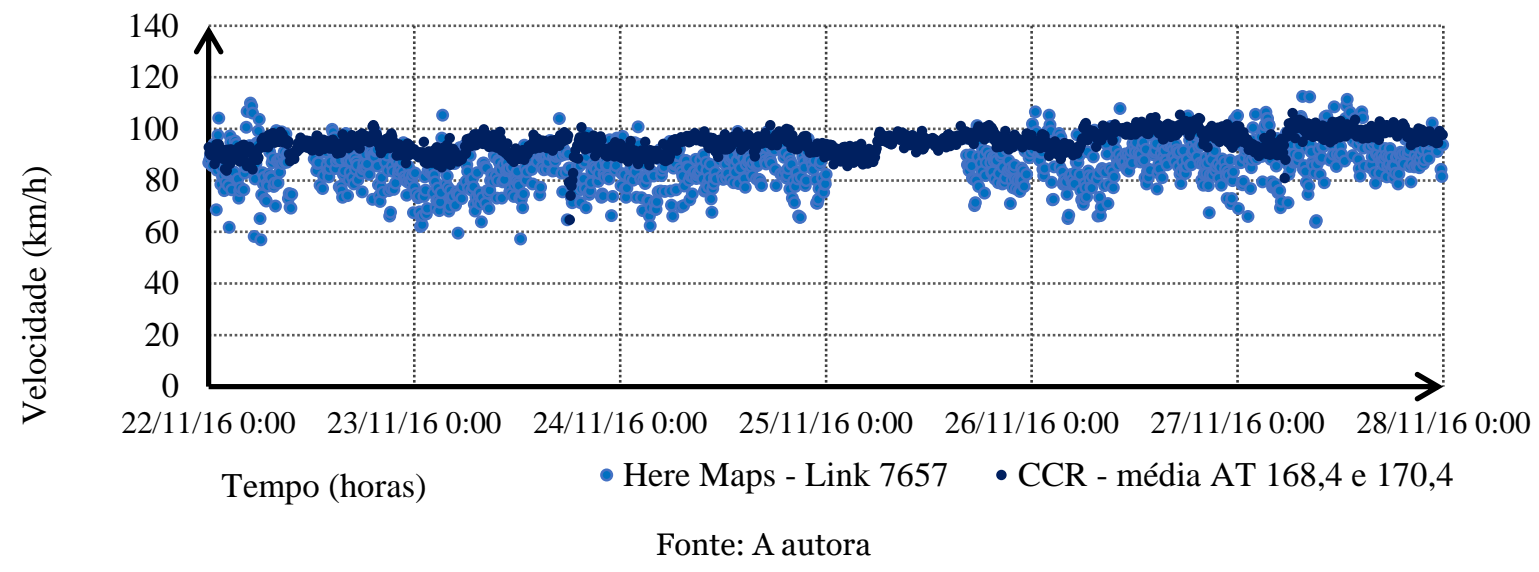

Figura 13 - Sobreposição de histogramas obtidos para as duas amostras referentes ao trecho 1, sentido norte

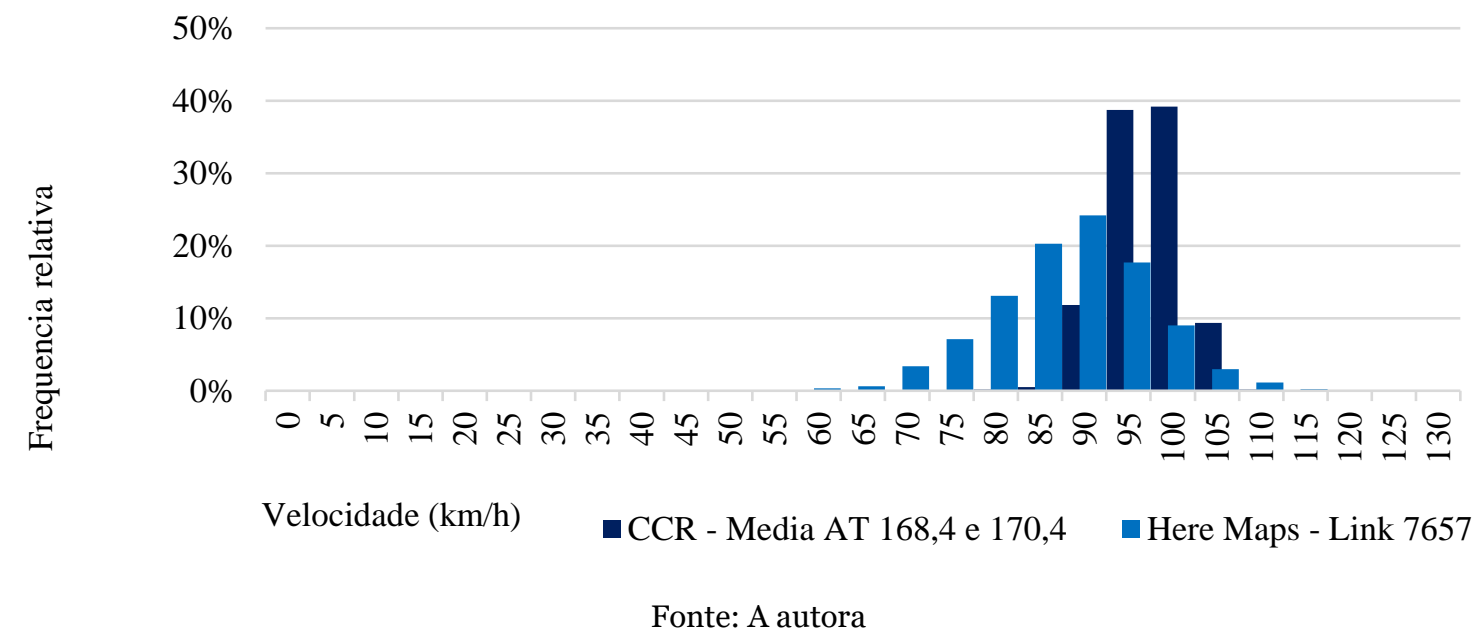

Figura 14 - Comparação dos valores de velocidade obtidos por cada fonte para o trecho 3, sentido sul

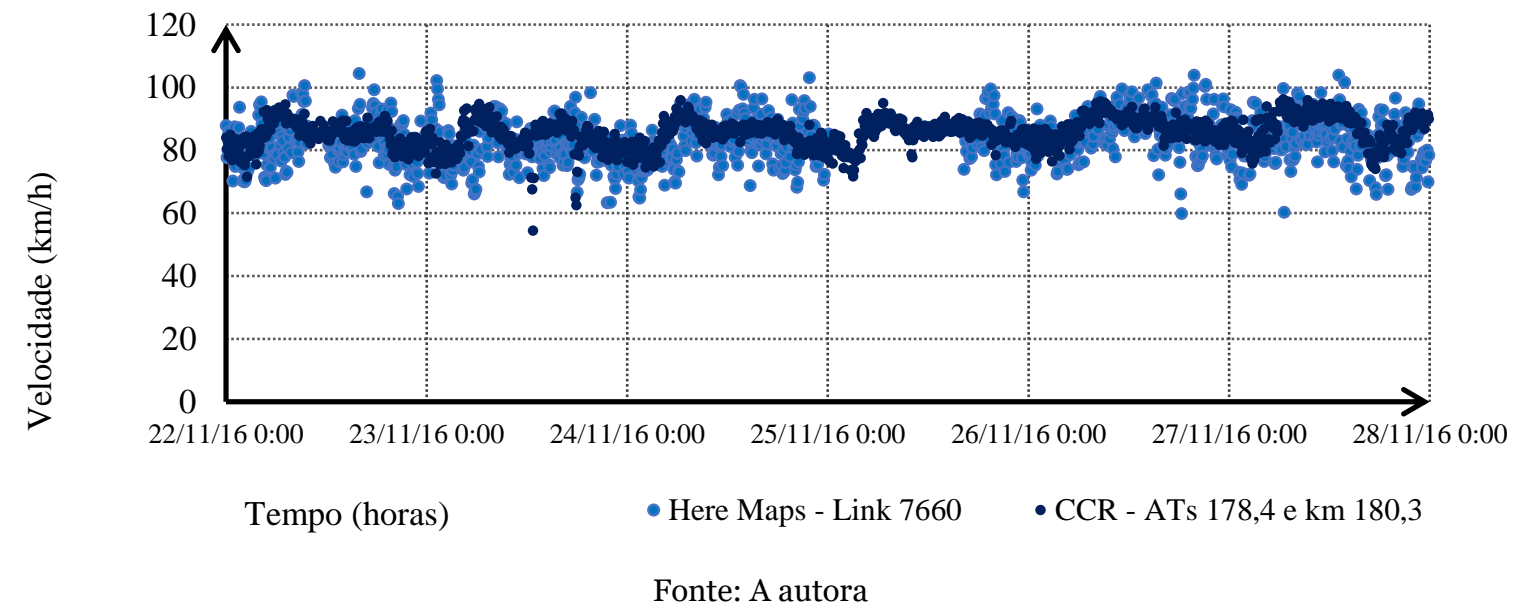


Figura 15 - Sobreposição de histogramas obtidos para as duas amostras referentes ao trecho 3, sentido sul

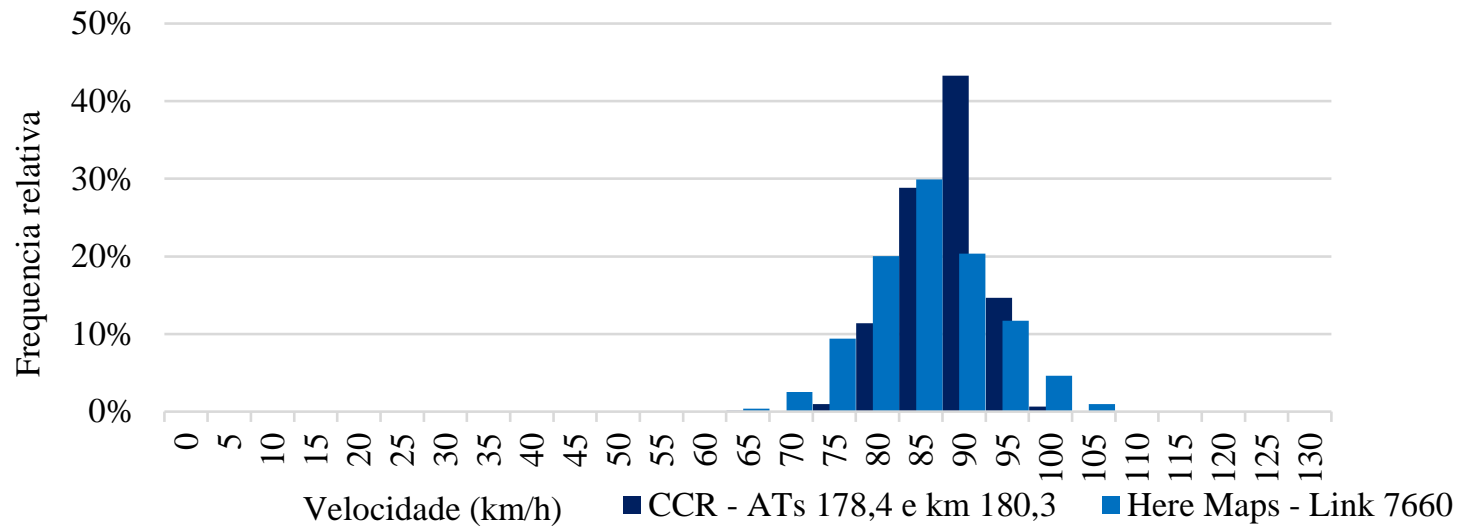

Fonte: A autora

Figura 16 - Comparação dos valores de velocidade obtidos por cada fonte para o trecho 3, sentido norte

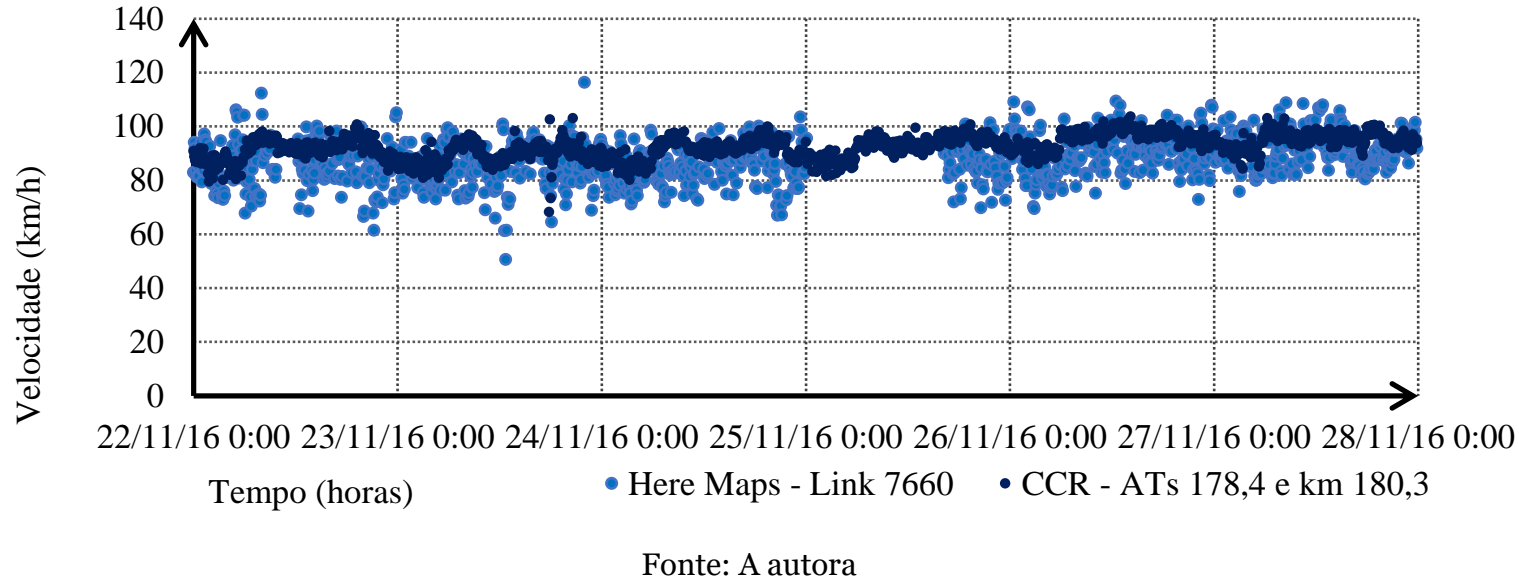

Figura 17 - Sobreposição de histogramas obtidos para as duas amostras referentes ao trecho 3, sentido norte

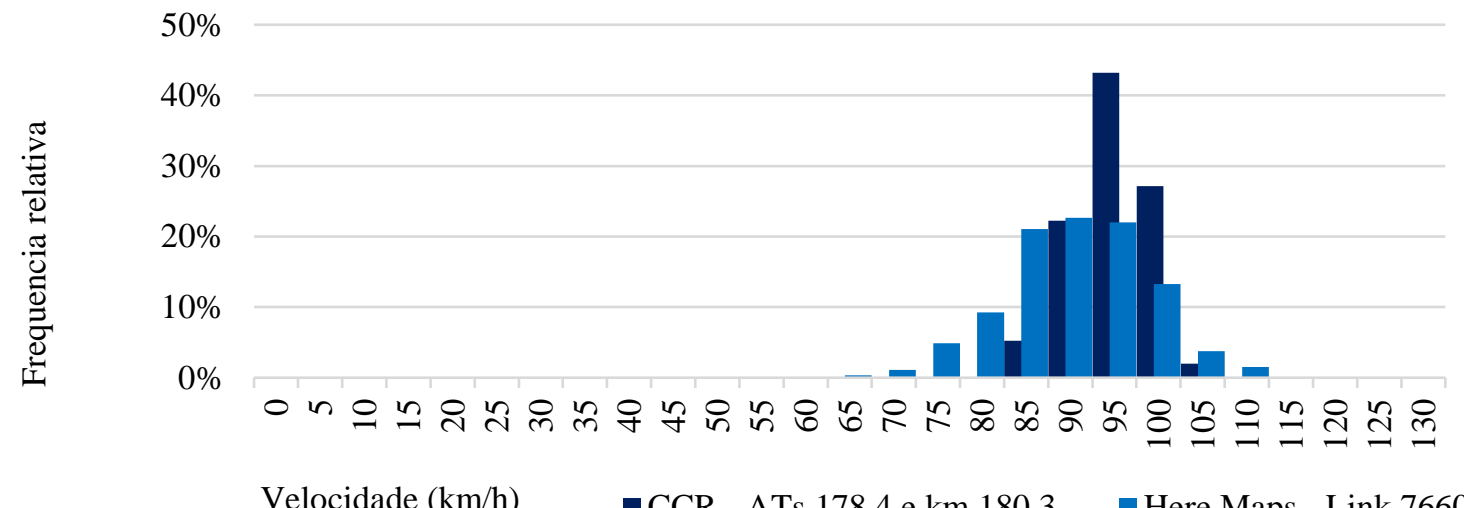

Fonte: A autora

Nos gráficos de comparação dos valores de velocidade obtidos por cada fonte é possível observar os períodos em que a extração dos dados provenientes da web foi interrompida devido a questões técnicas externas. 
Conforme observado na análise das medidas estatísticas, as amostras provenientes da web apresentam maior dispersão dos dados e valores inferiores aos obtidos pelos sensores fixos. Com relação a aderência entre as amostras, é possível observar, por meio dos histogramas elaborados, que as amostras referentes aos dois sentidos do trecho 3 apresentam maior aderência do que as demais amostras obtidas. A Erro! Fonte de referência não encontrada. e a Figura 17 evidenciam que a distribuição das frequências das amostras provenientes dos sensores fixos encontra-se completamente interna as classes obtidas pelas amostras provenientes da web.

\subsubsection{Trechos 2}

Conforme explicitado, o trecho 2 apresentou comportamento atípico, com os valores obtidos pelos sensores fixos significativamente inferiores aos obtidos pela mesma fonte para os trechos a jusante e a montante o que indica uma possível falha do sensor fixo no local ou a presença de algum elemento externo que influencie o comportamento do tráfego apenas no ponto em questão, como por exemplo radares e demais redutores de velocidade, sem ocasionar grande impacto na velocidade média do trecho como um todo.

A Figura 18 até Figura 21, apresentam a dispersão das amostras referentes ao trecho 2 e evidenciam o valor significativamente inferior dos dados obtidos pelos sensores fixos em comparação aos obtidos pela Here Maps. Os histogramas apresentados na Erro! Fonte de r

eferência não encontrada. e na Figura 21 evidenciam elevada distinção entre as amostras em questão com as classes de frequência completamente deslocadas.

Figura 18 - Comparação dos valores de velocidade obtidos por cada fonte para o trecho 2, sentido sul

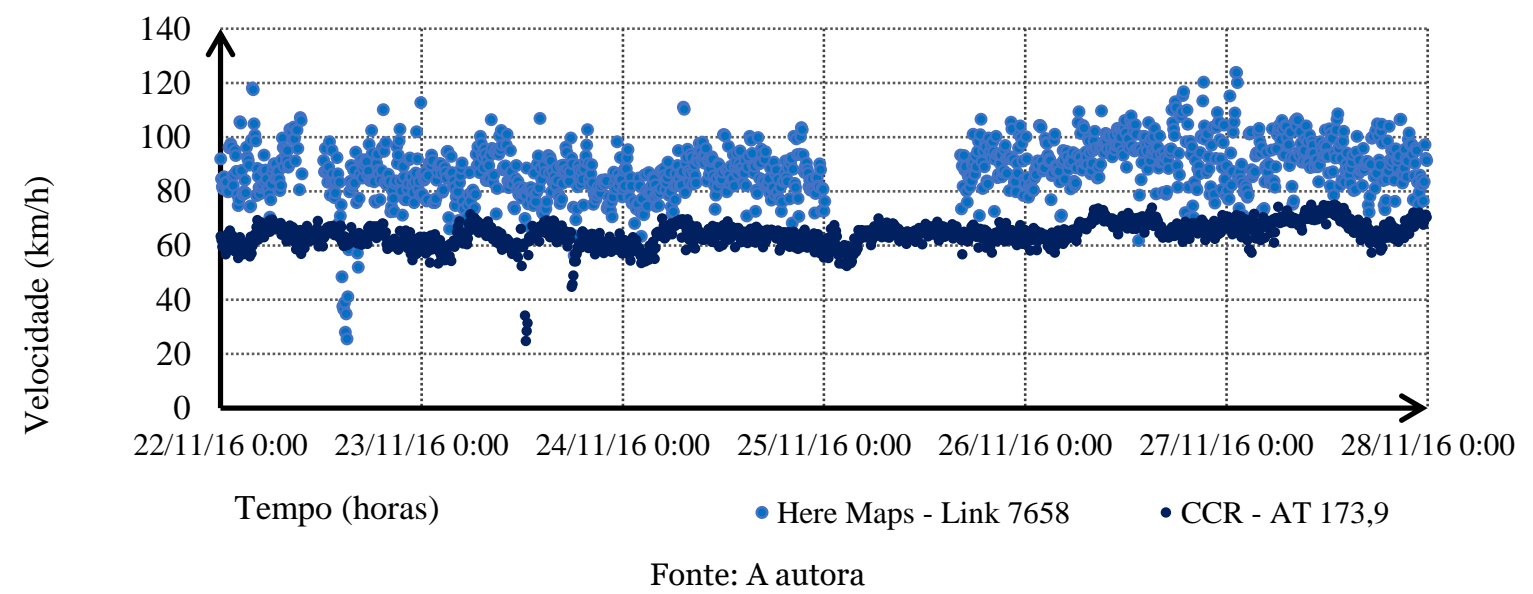


Figura 19 - Sobreposição de histogramas obtidos para as duas amostras referentes ao trecho 2, sentido sul

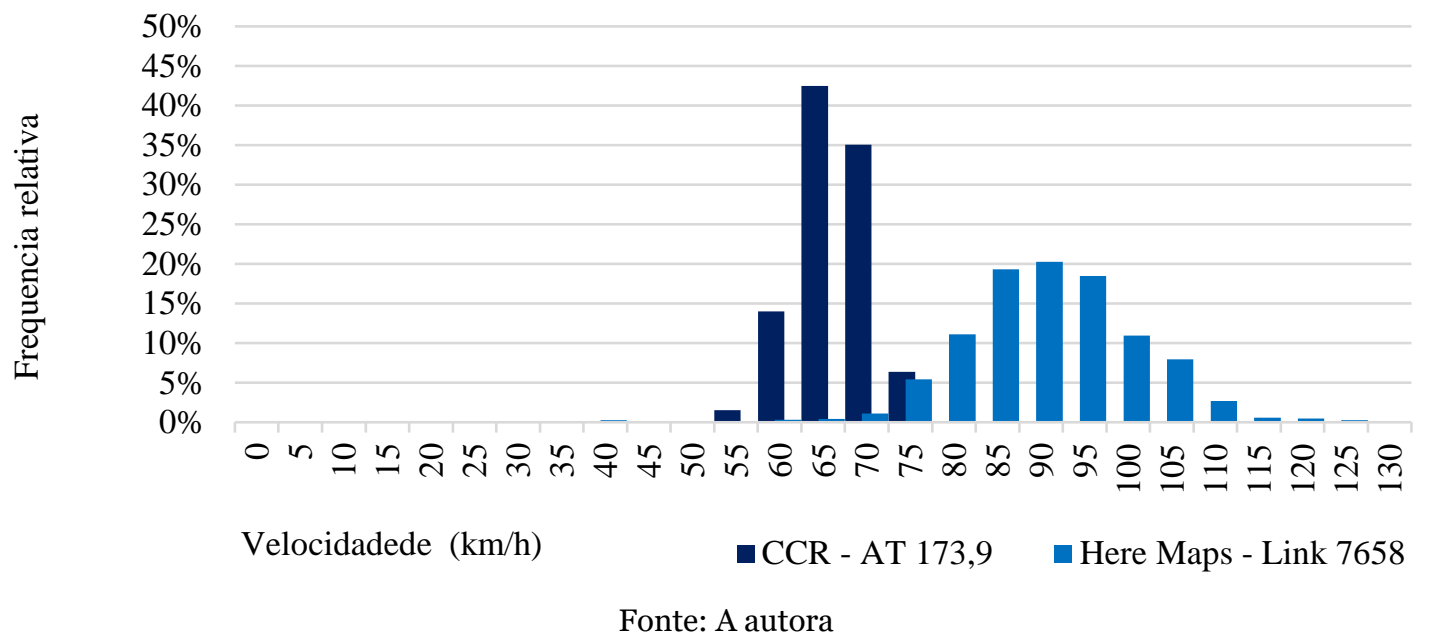

Figura 20 - Comparação dos valores de velocidade obtidos por cada fonte para o trecho 2, sentido norte

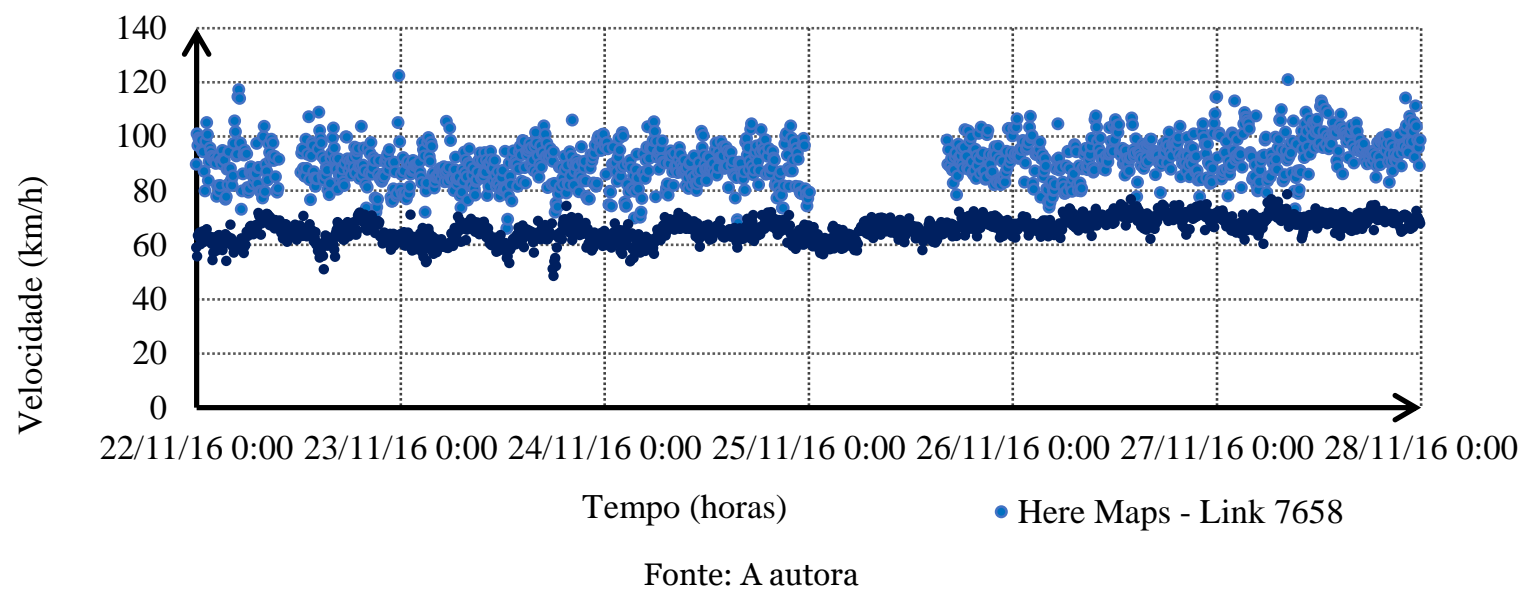

Figura 21 - Sobreposição de histogramas obtidos para as duas amostras referentes ao trecho 2, sentido norte

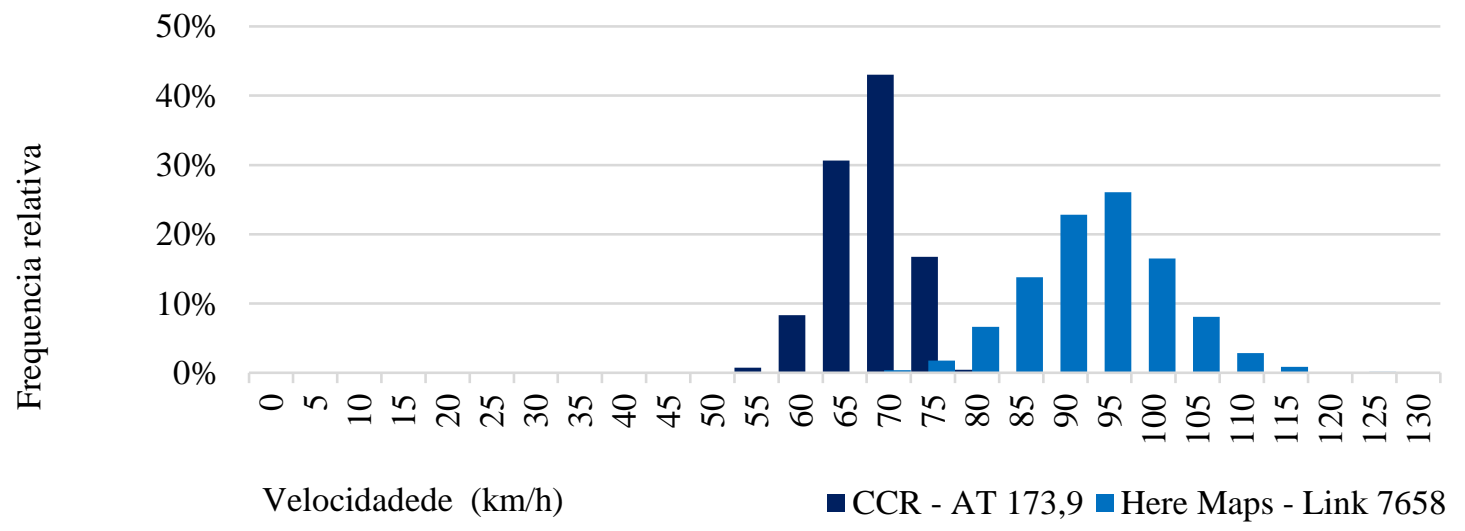

Fonte: A autora 


\subsubsection{Erro absoluto}

Com objetivo de avaliar a confiabilidade dos dados provenientes da web foi elaborada uma representação visual em que foi aplicada uma formatação condicional a diferença absoluta entre as velocidades obtidas a partir da web e a partir dos sensores para cada intervalo de 6 minutos. Os parâmetros considerados na formatação condicional foram:

- Diferença adequada - até $10 \mathrm{~km} / \mathrm{h}$ - cor verde;

- Diferença aceitável - até $20 \mathrm{~km} / \mathrm{h}$ - cor amarela;

- Diferença inaceitável - valores acima de $20 \mathrm{~km} / \mathrm{h}$ - cor vermelha; e

- Dados faltantes - cor cinza.

A Figura 22 e a Figura 23 apresentam os resultados obtidos para cada sentido de circulação e para os três trechos de via em estudo. É possível observar que, conforme esperado, o trecho 2 foi o que apresentou maiores ocorrências de erros acima de 10 e $20 \mathrm{~km} / \mathrm{h}$ o que reforça a inadequação dos dados fornecidos pelos sensores fixos presentes em ambos os sentidos nesse trecho.

Figura 22 - Representação visual elaborada para os conjuntos de dados referentes ao sentido norte

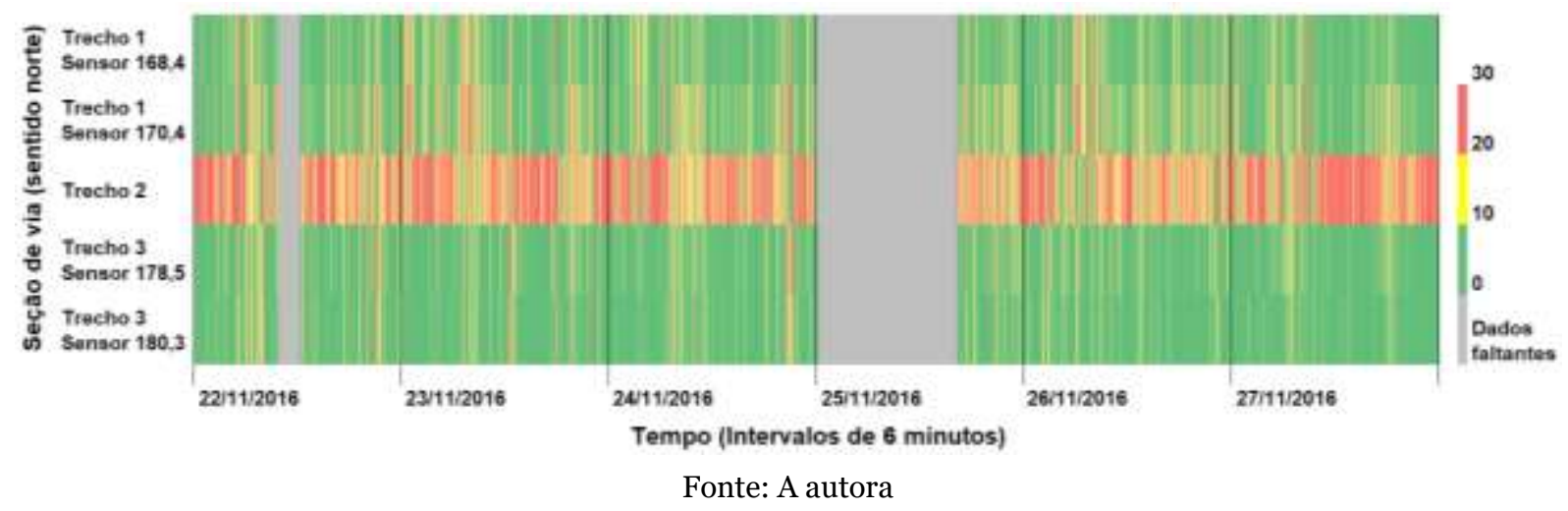

Figura 23 - Representação visual elaborada para os conjuntos de dados referentes ao sentido sul

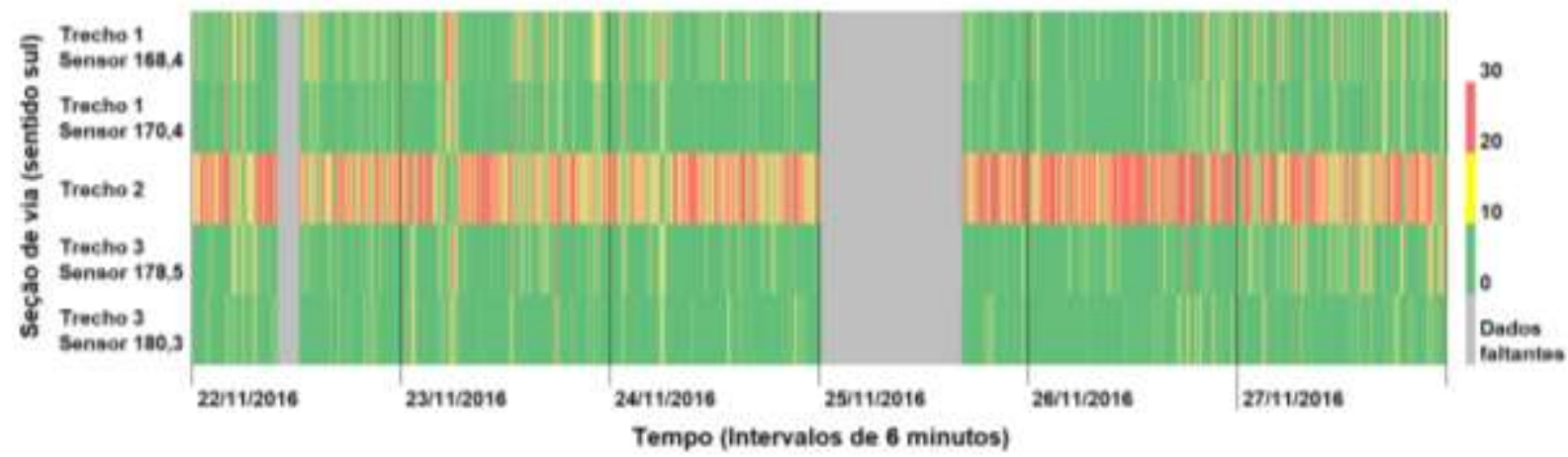

Fonte: A autora 
Devido ao caráter atípico dos dados referentes ao trecho 2 optou-se por desconsiderá-los e aplicar novamente a formatação condicional, porém apenas com os sensores dos trechos 1 e 3 .

Conforme descrito anteriormente os links da API referentes aos trechos 1 e 3 apresentam mais de um sensor por trecho. Com objetivo de avaliar qual dos sensores apresenta maior proximidade com os dados fornecidos para cada link, foi realizada a comparação, de forma separada, entre os dados obtidos por cada sensor e os obtidos para o link.

A Figura 24 expõe que, considerando o conjunto total dos dados obtidos para o sentido norte de circulação, o sensor localizado no km 168,4 da rodovia apresenta valores mais próximos aos fornecidos para o link da API referente ao trecho 1. Essa maior relação pode ser verificada por meio da menor ocorrência de trechos amarelos e vermelhos na primeira linha da Figura 24. Para o link referente ao trecho 3 sentido norte, o sensor que apresentou resultados mais próximos ao dos dados da web foi o localizado no $\mathrm{km} 180,3$ da rodovia.

Figura 24 - Representação visual elaborada para os conjuntos de dados referentes ao sentido norte sem dados do trecho 2

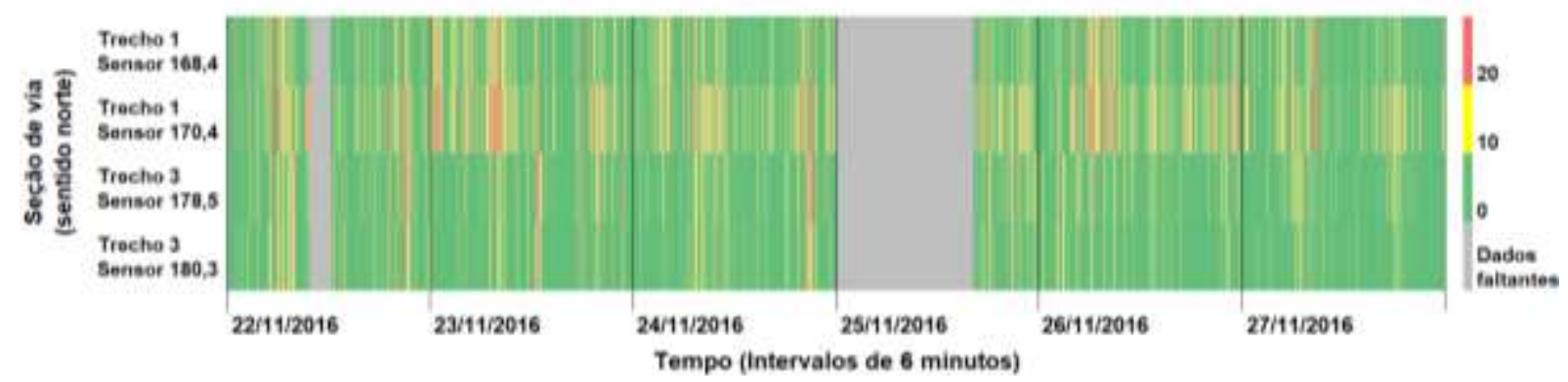

Fonte: A autora

No sentido sul (Figura 25), a melhor aproximação com relação aos dados da web, para o trecho 3, também foi obtida pelo sensor locado no $\mathrm{km} \mathrm{180,3} \mathrm{da} \mathrm{rodovia.} \mathrm{No} \mathrm{trecho} \mathrm{1,} \mathrm{no} \mathrm{entanto,}$ o sensor que obteve resultado mais próximo foi o disposto no km 170,4 e não o localizado no km 168,4 como observado para o sentido norte de circulação.

Figura 25 - Representação visual elaborada para os conjuntos de dados referentes ao sentido sul sem dados do trecho 2

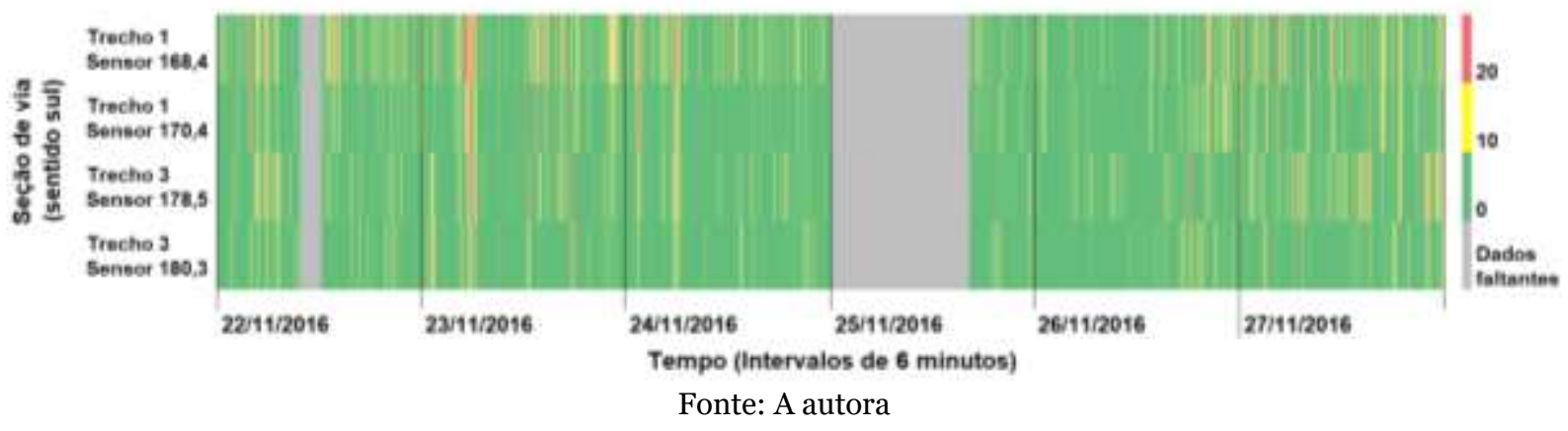


De modo geral, os dados referentes ao sentido de circulação sul apresentaram menores erros absolutos do que os referentes ao sentido norte. Analisando a relação entre o dia da semana e a diferença entre os valores das amostras é possível observar que, para o sentido de circulação sul, o final do dia 26/11/2016 (sábado) e toda a extensão do dia 27/11/2016 (domingo) apresentam maiores ocorrências de erro absoluto acima de $10 \mathrm{~km} / \mathrm{h}$. A quarta-feira, dia 23/11/2016, apresentou uma maior ocorrência de erro, acima de $20 \mathrm{~km} / \mathrm{h}$, entre as amostras.

No sentido norte não é possível observar uma forte relação entre o dia da semana e o erro absoluto obtido. O que se nota é a maior ocorrência de erros acima de 10 e $20 \mathrm{~km} / \mathrm{h}$ na comparação entre os dados obtidos da web com os coletados por meio do sensor localizado no $\mathrm{km} 170,4$.

Para avaliar uma possível relação entre a ocorrência de erros mais elevados e o horário do dia foram elaborados mapas de calor apenas dos dias 23 e 24/11/2016 (respectivamente Figura 26 e Figura 27, e Figura 28 e Figura 29), os quais correspondem a uma quarta e quinta-feira, dias que tendem a apresentar comportamento típico conforme exposto por Ribeiro e Cunha (2016).

Figura 26 - Representação visual elaborada a partir dos erros absolutos entre as amostras referente ao dia 23/11/16, quarta-feira, sentido norte

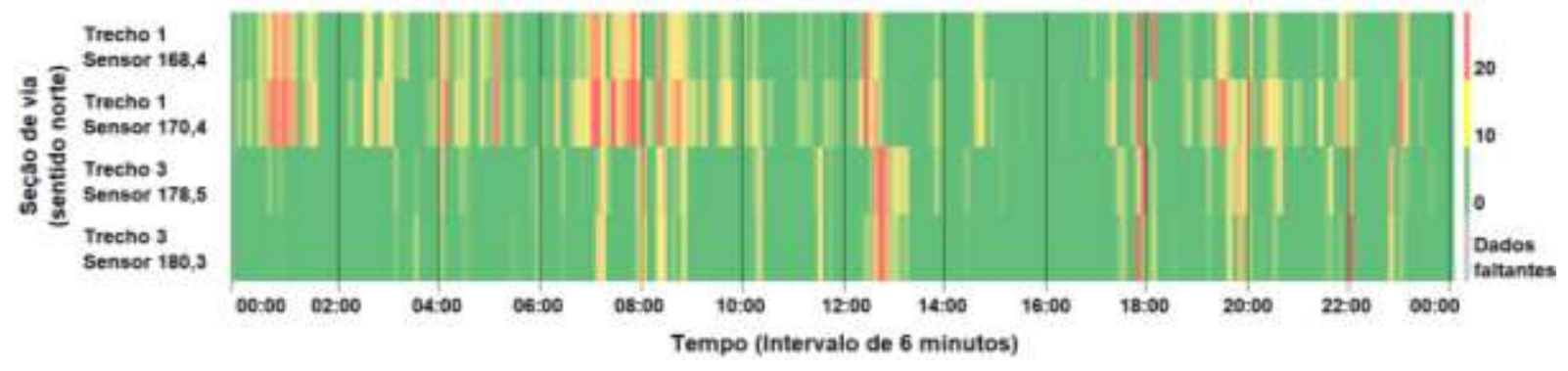

Fonte: A autora

Figura 27 - Representação visual elaborada a partir dos erros absolutos entre as amostras referente ao dia $23 / 11 / 16$, quarta feira, sentido sul

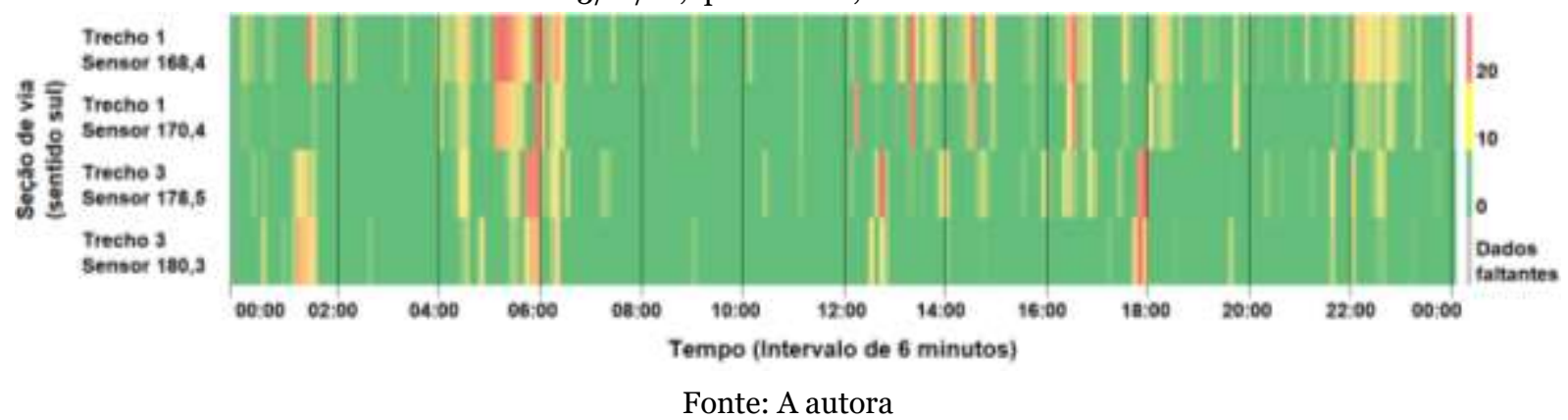

As Figura 26 e Figura 27 evidenciam uma maior concentração de erros acima de 10 e 20 km/h no horário em torno de $8 \mathrm{~h}$ da manhã para o sentido norte e $6 \mathrm{~h}$ da manhã para o sentido sul. 
2 Dados de Tráfego Disponíveis na Web

Figura 28 - Representação visual elaborada a partir dos erros absolutos entre as amostras referente ao dia 24/11/16, quinta-feira, sentido norte

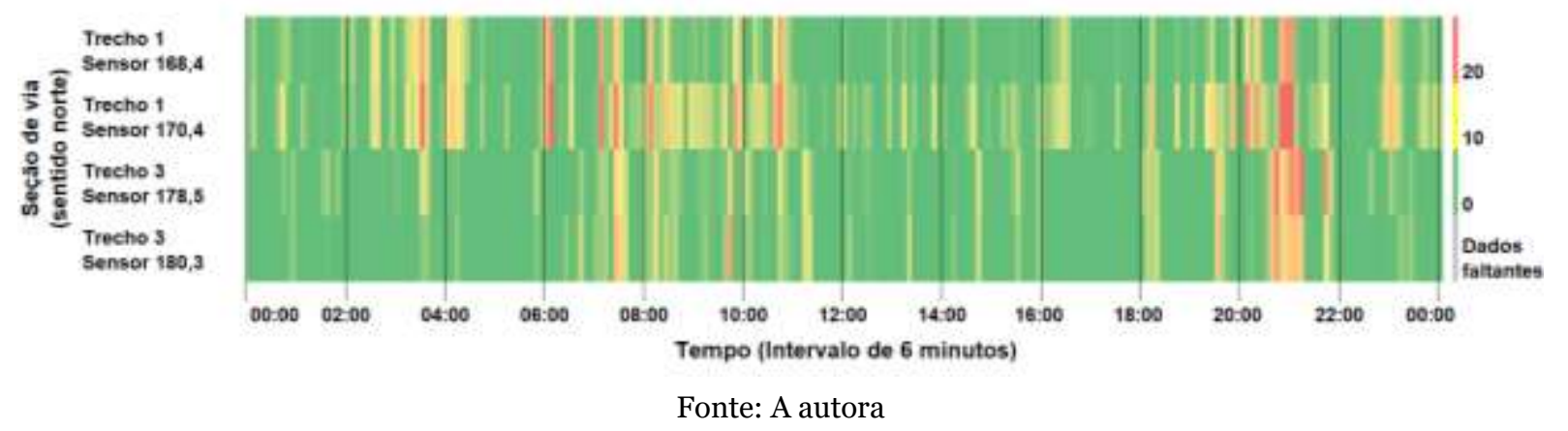

Figura 29 - Representação visual elaborada a partir dos erros absolutos entre as amostras referente ao dia 24/11/16, quinta-feira, sentido sul

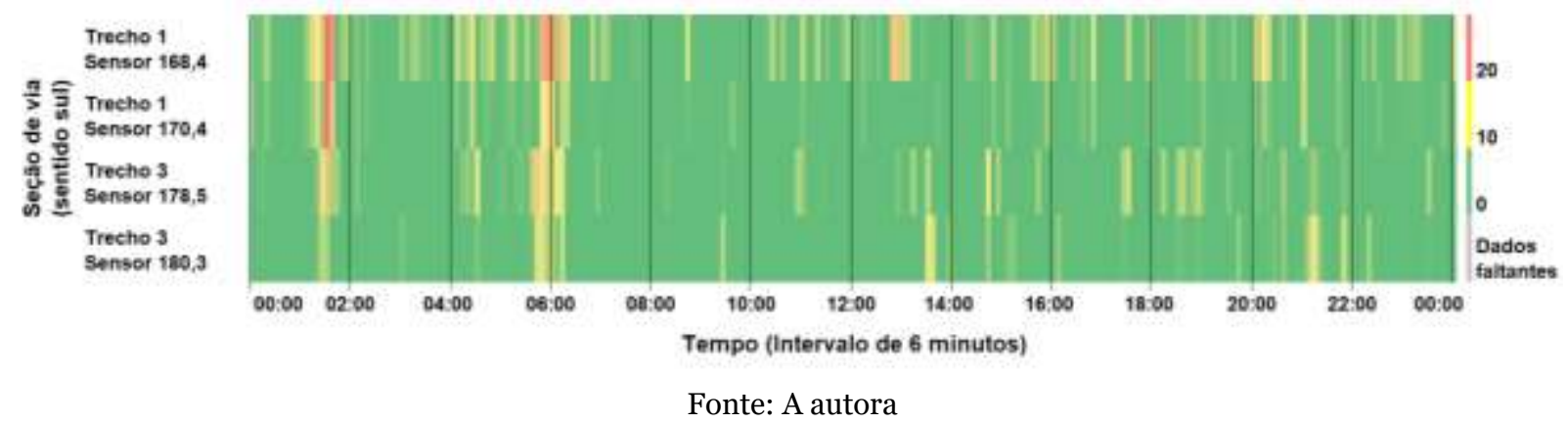

A observação dos erros referentes a comparação dos dados do dia 24/11/2016, quinta-feira, permite notar maior ocorrência de erros acima de 10 e $20 \mathrm{~km} / \mathrm{h}$ no sentido de circulação norte (Figura 28). Também é possível notar a concentração de erros acima de $20 \mathrm{~km} / \mathrm{h}$ no horário entre as $20 \mathrm{~h}$ e $22 \mathrm{~h}$.

No sentido sul de circulação (Figura 29) a faixa de horário que apresentou maior concentração de erros elevados foi em torno das $6 \mathrm{~h}$ da manhã. Sendo que os erros obtidos foram menos pronunciados do que os obtidos para o sentido norte.

\subsubsection{Relação entre velocidade no espaço e no tempo}

Conforme exposto na seção 2.1.5 há diferença entre os valores de velocidade no tempo e no espaço, sendo a primeira um pouco superior a segunda. Para avaliar se as amostras em estudo atendem essa relação foi realizado o cálculo da variância $\left(\sigma^{2}\right)$ por meio da relação entre a velocidade no tempo, obtida pelo sensor do tipo laço indutivo, e no espaço, obtida da web, conforme a equação 2.3 , para posterior comparação com a variância da amostra de velocidades instantâneas obtidas. 
Ambos os sentidos do trecho 2 foram desconsiderados para esta análise devido a não adequação dos dados em questão, em que a velocidade obtida pelo sensor obteve valores significativamente inferiores quando comparada a velocidade aferida pelos próprios sensores nos outros trechos e as obtidas a partir da web.

A Tabela 3 apresenta a comparação dos valores de variância obtidos a partir da amostra total de dados em cada trecho e sentido e os calculados a partir da equação 2.3. Pode-se observar que os valores de variância calculados foram significativamente superiores aos obtidos para o conjunto de dados em estudo, o que demonstra que a diferença entre a velocidade obtida pelo sensor e pela web não se deve apenas ao fato da primeira corresponder a velocidade no tempo e a segunda a velocidade no espaço.

\begin{tabular}{|c|c|c|c|c|}
\hline Trecho & Média sensor & Média web & $\begin{array}{l}\text { Variância calculada } \\
\text { pela equação } 2.3\end{array}$ & $\begin{array}{l}\text { Variância do } \\
\text { conjunto total e } \\
\text { dados }\end{array}$ \\
\hline $1 \mathrm{Sul}$ & 95,34 & 90,26 & 457,96 & 50,94 \\
\hline $3 \mathrm{Sul}$ & 85,54 & 83,17 & 196,92 & 36,74 \\
\hline 1 Norte & 94,70 & 85,71 & 67,62 & 770,55 \\
\hline 3 Norte & 92,39 & 87,79 & 48,04 & 404,54 \\
\hline
\end{tabular}

Fonte: A autora

\subsection{5 Índice de correlação $\left(R^{2}\right)$}

As Figuras de 30 a 35 apresentam a relação entre as velocidades obtidas pelo sensor fixo do tipo laço indutivo e as coletadas da web. Para melhor interpretação dos resultados foi obtida a linha de tendência, considerando como ponto de intersecção o 0 , e o eixo de simetria, o qual corresponde ao resultado desejável.

Conforme esperado os dados que obtiveram a linha de tendência mais distante do eixo de simetria foram os referentes ao trecho 2 , os quais apresentaram valore de velocidade provenientes da concessionária muito abaixo dos referentes aos trechos 1 e 3 .

Considerando apenas os trechos 1 e 3 é possível notar que o sentido sul apresenta resultados melhores em comparação ao sentido norte, o que se evidencia pela maior proximidade entre as linhas de tendências obtidas e o eixo de simetria do gráfico. 
2 Dados de Tráfego Disponíveis na Web

Figura 30 - Velocidade obtida pelo sensor $\mathrm{x}$ velocidade obtida da web, no trecho 1 sul

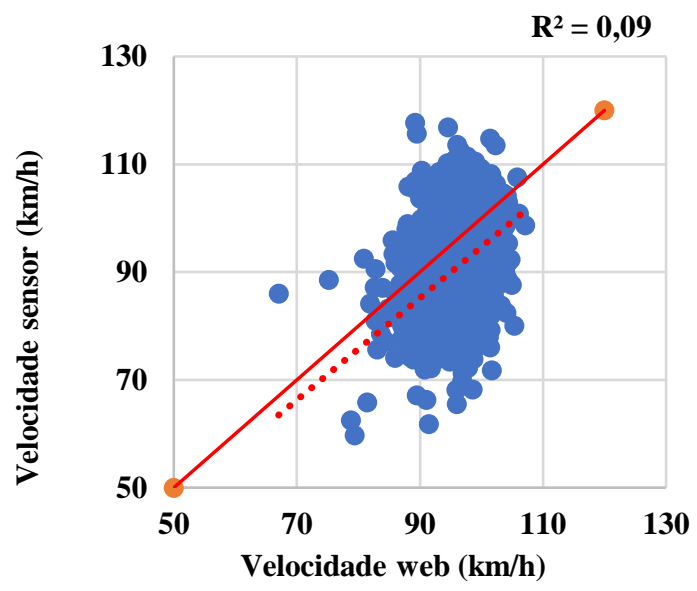

Fonte: A autora

Figura 32 - Velocidade obtida pelo sensor x velocidade obtida da web, no trecho 2 sul

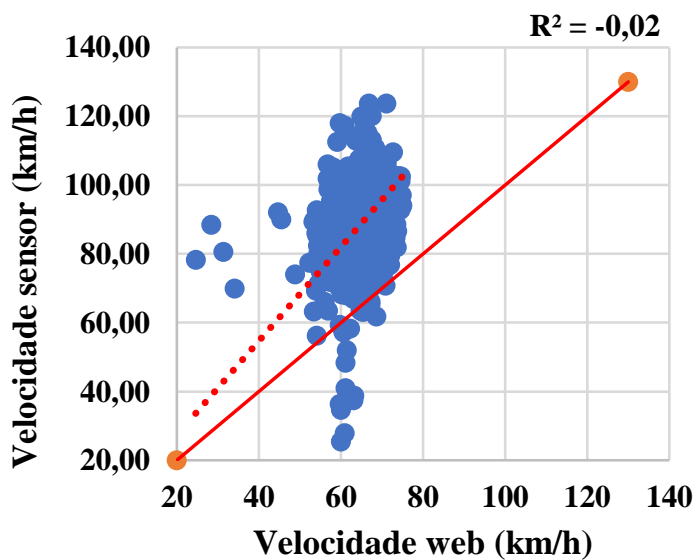

Fonte: A autora

Figura 34 - Velocidade obtida pelo sensor x velocidade obtida da web, no trecho 3 sul

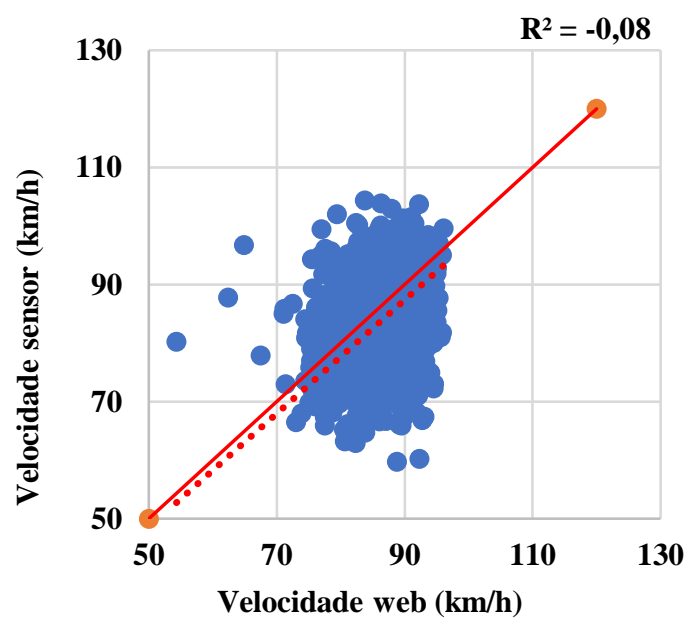

Fonte: A autora
Figura 31 - Velocidade obtida pelo sensor x velocidade obtida da web, no trecho 1 norte

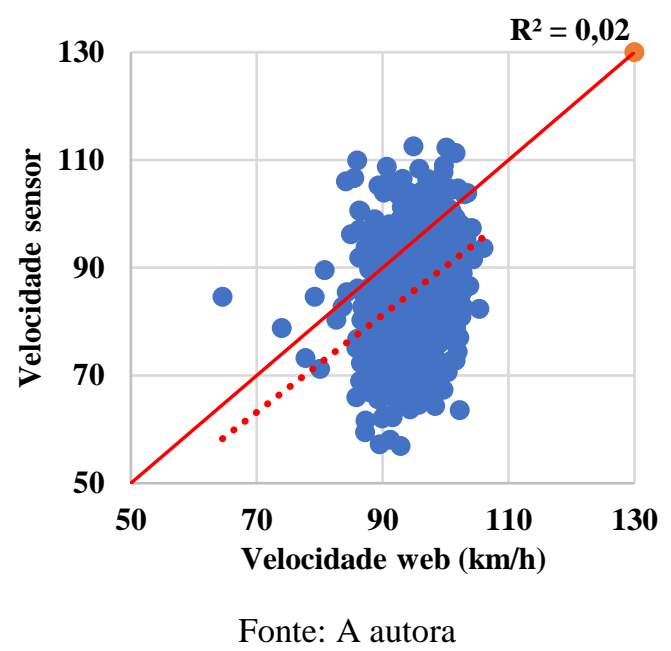

Figura 33 - Velocidade obtida pelo sensor x velocidade obtida da web, no trecho 2 norte

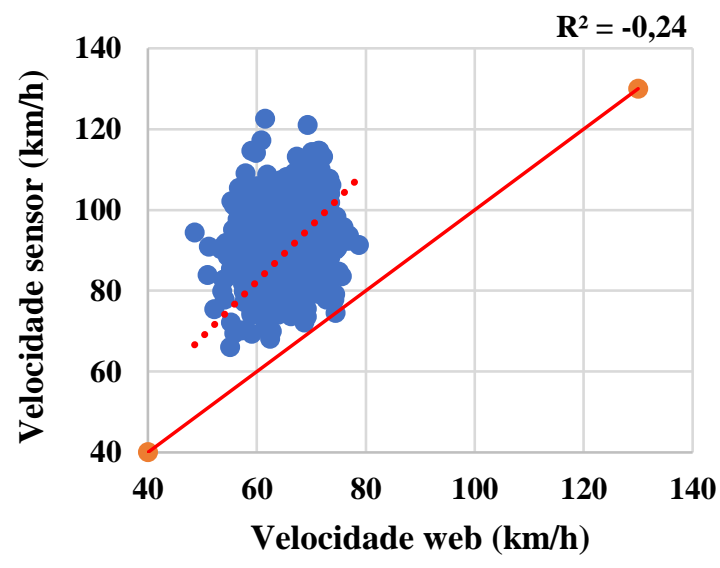

Fonte: A autora

Figura 35 - Velocidade obtida pelo sensor x velocidade obtida da web, no trecho 3 norte

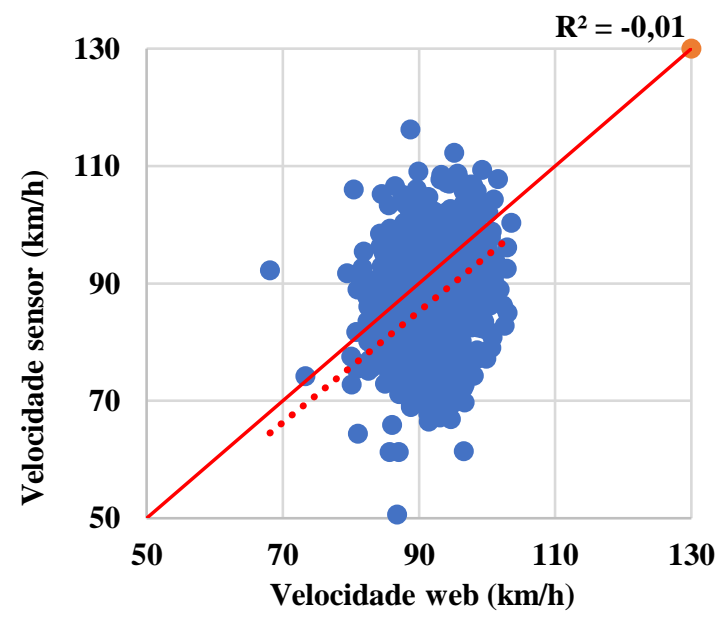

Fonte: A autora 
Embora as linhas de tendências obtidas, para ambos os sentidos, nos trechos 1 e 3 esteja próximo ao eixo de simetria do gráfico, os valores obtidos para o índice de correlação $\left(\mathrm{R}^{2}\right)$ foram baixos o que indica pouca correlação entre as velocidades obtidas pelo sensor e pela web.

\subsubsection{Testes estatísticos}

Por fim, foram realizados os testes não paramétricos Qui-quadrado $\left(X^{2}\right)$ e KolmogorovSmirnov, para avaliar a aderência entre as duas distribuições das amostras obtidas para cada trecho de estudo. Conforme exposto, os valores provenientes dos sensores se concentraram em algumas classes de frequência, de modo que as demais não apresentaram ocorrências. Por essa razão, não foi possível utilizar essa fonte de dados como sendo referente aos valores esperados, uma vez que, isso acarretaria em divisor nulo o que não é viável matematicamente. Desse modo, foi adotado como valor esperado os dados provenientes da API e como observado os coletados por sensor. Os valores obtidos para o teste em cada trecho são apresentados na Tabela 4.

Tabela 4 - Resultados obtidos para os testes estatísticos realizados

\begin{tabular}{lrrrrrrr}
\hline & \multicolumn{2}{c}{ Trecho 1 } & \multicolumn{2}{c}{ Trecho 2 } & \multicolumn{2}{c}{ Trecho 3 } \\
\cline { 2 - 9 } & \multicolumn{1}{c}{ Norte } & \multicolumn{1}{c}{ Sul } & Norte & \multicolumn{1}{c}{ Sul } & \multicolumn{2}{c}{ Norte } & Sul \\
\hline$X^{2}$ & 186,91 & 95,79 & 7893,69 & 3953,77 & 70,64 & 41,90 \\
\hline$X^{2}$ crítico & 16,92 & 16,92 & 5,99 & 16,92 & 18,31 & 16,92 \\
Kolmogorov-Smirnov & 0,51 & 0,40 & 0,97 & 0,93 & 0,31 & 0,21 \\
Kolmogorov-Smirnov crítico & 0,04 & 0,04 & 0,04 & 0,04 & 0,04 & 0,04 \\
\hline & \multicolumn{3}{c}{ Fonte: A autora } & & &
\end{tabular}

A hipótese nula $\left(\mathrm{H}_{0}\right)$ considerada, consiste na independência das amostras e em uma boa concordância entre as distribuições de frequência. Foi considerado alfa igual a 5\%. Para que a hipótese nula não seja refutada é necessário que os valores obtidos pelos testes sejam similares ou inferiores aos valores críticos determinados em função do número de observações (1.254) e da quantidade de categorias definidas nos histogramas.

Nos trechos 1 e 3 em que há mais de um sensor dentro de um mesmo link extraído da web, os testes estatísticos foram realizados considerando a média dos sensores internos a esses links. Conforme exposto na Tabela 4, a hipótese nula não foi refutada em nenhuma das análises realizadas. 


\subsection{CONCLUSÕES}

O presente capítulo apresentou as fontes de dados de tráfego em estudo, as quais consistem em um conjunto de informações coletadas por smartphones, equipamentos embarcados, sensores presentes em estruturas viárias, dentre outros. Esses dados são disponibilizados via web por meio de interfaces de programação de aplicativo.

As análises realizadas indicam que os dados em questão apresentam diferenças significativas em relação aos coletados por meio de sensores fixos do tipo laço indutivo. De modo geral, as amostras de velocidade da corrente de tráfego coletadas da web apresentam maior dispersão dos dados e valores abaixo dos coletados por meio do sensor, sendo que a maior parcela dos dados analisados apresentou diferença absoluta similar ou inferior a $10 \mathrm{~km} / \mathrm{h}$.

É importante destacar algumas diferenças fundamentais existentes entre a velocidade coletada por meio do sensor fixo e as extraídas a partir do GPS de smartphones e equipamentos embarcados. Enquanto a primeira é pontual, sendo a velocidade no tempo, a segunda refere-se a um trecho de via, representado no caso pelos links, podendo ser interpretada como a velocidade no espaço, a qual usualmente apresenta valores um pouco inferior. No entanto, conforme exposto, a diferença entre os valores obtidos por cada fonte não pode ser atribuída apenas ao fato de possuírem naturezas distintas, uma vez que a diferença observada entre os valores foi superior a atribuída a essa distinção.

Por fim é necessário ressaltar que embora as amostras coletadas pela fonte de dados em estudo apresente diferenças significativas em relação as amostras obtidas pelo sensor, sua maior facilidade de aquisição, ampla área de abrangência e período de coleta, bem como, seu baixo custo, principalmente quando comparado aos necessários a implantação e manutenção de sensores fixos e o fato de as diferenças entre as velocidades coletadas em cada amostra estarem dentro de níveis aceitáveis, torna bastante atrativa sua utilização. Além disso, estudos recentes como o projeto Mobile Century já indicam a necessidade de se questionar a adoção dos dados coletados por sensores como verdades absolutas, sendo evidenciado que, de modo geral, esse tipo fonte tende a superestimar os valores de velocidade coletados.

Por fim, ressalta-se as inúmeras possibilidades de estudos e aplicações a serem realizados a partir da fonte de dados aqui apresentada, como por exemplo, em análise de comportamento do tráfego, em estudos de mobilidade, dentre tantos outros. 


\section{MATRIZ SINTÉTICA}

Este capítulo tem por objetivo implementar um modelo/método de reconstrução de matriz OD sintética.

\subsection{CONTEXTUALIZAÇÃo}

A Matriz Origem Destino, ou Matriz OD, fornece o número de viagens realizadas entre cada origem $(i)$ e destino $(j)$ que compõe a rede de transporte em estudo, para um intervalo de tempo específico. Segundo Caceres et al. (2007), tais matrizes quantificam e sintetizam a mobilidade associada a produtos e pessoas na área em estudo. Os métodos de obtenção da matriz OD podem ser classificados como diretos e indiretos.

A obtenção por métodos diretos baseia-se no monitoramento das vias e de imagens, nas fotografias aéreas, no controle de placas e em entrevistas individuais (ORTÚZAR; WILLUMSEN, 1994). Já, a obtenção por métodos indiretos pode ocorrer com base em pesquisas domiciliares de origem e destino ou em função das atividades desempenhadas em cada região.

Tanto os métodos diretos quanto indiretos exigem elevados recursos financeiros, humanos e de tempo, o que dificulta sua adoção (WILLUMSEN, 1981). Além dessa questão, esses métodos observam apenas uma amostra. As estimativas realizadas por esses métodos apresentam alto potencial para erros de amostragem e de registro de dados, além de poderem variar de estudo para estudo, em decorrência das limitações do tamanho da amostra coletada e de sua aleatoriedade.

Uma alternativa derivada dos métodos diretos, porém menos onerosa, é a síntese da matriz OD a partir dos fluxos contabilizados nos arcos ou nós das redes de tráfego. Esse processo apresenta estratégia oposta à da alocação de tráfego e estima a demanda a partir dos volumes observados (WILLUMSEN, 1981).

A vantagem do uso das contagens de tráfego se deve ao fato de apresentarem custo relativamente acessível e de serem usualmente coletadas para diversos fins, como projeto de interseções, análises de acidentes, monitoramento do fluxo de veículos, dentre outros 
(WILLUMSEN, 1981). O volume de tráfego em vias pode ser computado, dentre outros métodos, por meio de pesquisadores in loco, sensores e pelo processamento das imagens de câmeras de monitoramento. Este último método tem se tornado cada vez mais atrativo devido ao surgimento dos Sistemas Inteligentes de Transportes (do inglês, Intelligent Transportation Systems - ITS), o que tornou habitual o uso de câmeras de vídeo e de circuitos fechados de televisão (CFTV), no monitoramento do tráfego viário (CUNHA, 2013).

De forma simplificada, o princípio dos métodos de sintetização da matriz OD consiste em identificar os pares de origem e destino e as rotas utilizadas nas viagens. Conforme exposto por Willumsen (1978), considerando que $Q_{i j}$ seja o número de viagens existentes entre a origem $i$ e o destino $j$, e $P_{i j}^{a}$, a proporção de viagens entre esse par OD, que utilizam o arco $a$, o volume observado no arco $a$ pode ser estimado pela equação [3.1].

$$
V_{a}=\sum P_{i j}^{a} \cdot Q_{i j}
$$

Nesse contexto, a matriz OD, observada no período da coleta das contagens, poderia ser reconstruída por meio da solução do sistema de equações [3.1], no entanto, tal sistema, normalmente, é altamente subespecificado, ou seja, o número de incógnitas, composto pelos fluxos que integram a matriz OD, é superior ao número de equações independentes, referente às contagens de tráfego coletadas nos links (ABRAHAMSSON, 1998; OLIVEIRA NETO et al., 2016)

Além disso, Timms (2001) mostrou que esses valores dificilmente coincidiriam, devido a uma série de questões como: a não correspondência com a realidade de algumas considerações e simplificações, a estimativa incorreta dos valores de $P_{i j}^{a}$, a desconsideração das viagens intrazonais, eventuais erros no processo de contagem e possível distinção entre o padrão de distribuição das viagens, observado na matriz semente utilizada, e os volumes contabilizados nos links.

Diferentes autores como Willumsen (1981), Abrahamsson (1998), Timms (2001) e Sherali et al. (2003) propõem categorias para a organização das vertentes existentes de estimação da matriz OD. Contudo, no presente trabalho, foi adotada a mesma subdivisão apresentada por Bertoncini (2010), a qual é composta pelas categorias: modelo gravitacional, inferências estatísticas e maximização da entropia. 


\subsubsection{Modelo gravitacional}

O modelo gravitacional busca estimar a matriz OD a partir do total de viagens produzidas, total de viagens atraídas e do custo atribuído às viagens. Sua aplicação demanda dados populacionais, muitos dos quais, obtidos por meio de pesquisas e entrevistas domiciliares (WILLUMSEN, 1981).

Schneider (1959) ressalta que embora o modelo gravitacional baseie-se no modelo newtoniano, sua nomeação não é a mais adequada, uma vez que o movimento dos veículos ocorre em função das intenções das pessoas, enquanto, no modelo de Newton, o movimento das partículas é influenciado pelo campo de força.

Segundo Willumsen (1981), o fluxo, entre a origem $i$ e o destino $j$, estimado pelo modelo gravitacional pode ser representado, de forma generalizada, conforme a equação [3.2]:

$$
Q_{i j}=b_{1} \cdot O_{i} \cdot D_{j} \cdot c_{i j}^{-d}
$$

em que,

$Q_{i j}:$ viagens entre o par OD $i j$

$b_{1}, d$ : parâmetros a serem calibrados;

$O_{i}:$ total de viagens originadas na zona $i$;

$D_{j}: \quad$ total de viagens atraídas pela zona $j$;

$c_{i j}$ : custo de viagem entre $i$ e $j$.

A utilização do modelo gravitacional apresenta como vantagem, por utilizar parâmetros populacionais, correlacionar as viagens com as características socioeconômicas dos indivíduos, agregadas por zonas.

Os parâmetros que devem ser considerados na elaboração do modelo são definidos pelo planejador. Tal característica garante uma parcela de subjetividade ao modelo e atribui caráter racionalista ao mesmo (TIMMS, 2001). A grande quantidade de dados, necessárias à sua calibração, torna os modelos gravitacionais menos atrativos, quando o objetivo é utilizar uma estratégia que dependa de poucas informações. 


\subsubsection{Inferências estatísticas}

Os métodos de inferências estatísticas partem do princípio que os fluxos apresentam distribuição aleatória e buscam estimar parâmetros que especifiquem sua distribuição (BERTONCINI, 2010).

O método de inferência Bayesiana toma os parâmetros como aleatórios e utiliza o teorema de Bayes (equação[3.3]) como estratégia para incorporar a informação inicial.

$$
P(\theta \mid y)=\frac{f(y \mid \theta) \cdot P(\theta)}{\int f(y \mid \theta) \cdot P(\theta) d \theta}
$$

em que,

$P(\theta)$ : densidade da probabilidade a priori do parâmetro $\theta$;

$f(y \mid \theta)$ : verossimilhança da observação $y$;

$P(\theta \mid y)$ : distribuição da probabilidade a posteriori de $y$.

Um dos primeiros estudos de estimação de viagens por meio da utilização dessa teoria foi proposto por Maher (1983) o qual, propunha a combinação da distribuição da média dos fluxos da matriz semente com a probabilidade normal multivariada.

O método proposto consiste em utilizar a teoria de Bayes para combinar as informações oriundas de duas fontes de dados distintas, a distribuição da probabilidade a priori da matriz OD $(\operatorname{Pr}(Q))$, obtida a partir da matriz OD semente, e as informações obtidas pela contagem de tráfego, cuja distribuição de probabilidade pode ser expressa por $\xi\left(V_{o b s} \mid Q\right)$. O resultado obtido é a probabilidade a posteriori $f\left(Q \mid V_{o b s}\right)$ conforme a equação [3.4].

$$
f\left(Q \mid V_{\text {obs }}\right) \approx \xi\left(V_{\text {obs }} \mid Q\right) \cdot \operatorname{Pr}(Q)
$$

Esse modelo é sensível à distribuição de probabilidade adotada a priori, o que exige do pesquisador um certo grau de certeza quanto a essas informações iniciais, principalmente quanto a acurácia da matriz semente. Por essa razão, Timms (2001) classifica tal modelo como subjetivo balanceado, uma vez que, depende mais da distribuição a priori da matriz semente, do que das contagens de tráfego. 


\subsubsection{Minimização das diferenças quadráticas}

O método de minimização das diferenças quadráticas parte do princípio que a partir da soma da matriz $\mathrm{OD}(Q)$ e de um termo atribuído ao erro probabilístico $(\eta)$, é possível obter a matriz OD semente, ou objetivo. Ou seja, $S=Q+\eta$.

O valor atribuído a $\eta$ geralmente é nulo, desde que a matriz OD (Q) seja definida pela média. Para tal é preciso definir as matrizes de variância e covariância que, para $\eta$, será M. O estimador de mínimos quadrados pode ser expresso, de forma genérica, conforme [3.5] (BERTONCINI, 2010):

$$
\min W=\frac{(S-Q) \cdot(S-Q)}{M}
$$

sujeito a

$$
Q_{i j} \geq 0
$$

em que,

$Q_{i j}:$ total de viagens entre a origem i e o destino j, pertencente a matriz OD $Q$.

A principal vantagem dessa estratégia é o conhecimento da distribuição de probabilidades dos resultados estimados, em contrapartida, esse método apresenta grande dependência da qualidade da matriz OD objetivo, ou semente, e da precisão das rotas utilizadas pelas viagens.

\subsubsection{Máxima verossimilhança}

Outro método de inferência estatística, a máxima verossimilhança, busca encontrar o valor máximo da multiplicação das probabilidades de um evento ocorrer.

Para tal, parte do princípio de que, sendo os valores obtidos pela contagem de tráfego $\left(V_{o b s}\right)$ e os volumes entre os pares OD $(Q)$ estatisticamente independentes, é possível obter uma função de verossimilhança a partir do conhecimento da distribuição de probabilidades dessas duas informações, conforme a equação [3.7] (BERTONCINI, 2010).

$$
L\left(\left\{V_{o b s}\right\},\left\{S_{i j}\right\} /\left\{Q_{i j}\right\}\right)=L\left(\left\{V_{o b s}\right\} /\left\{Q_{i j}\right\}\right) \cdot L\left(\left\{S_{i j}\right\} /\left\{Q_{i j}\right\}\right)
$$


Por meio da maximização da equação [3.7] é possível encontrar os valores mais prováveis para $\left\{Q_{i j}\right\}$ :

$$
Q_{i j}=\frac{S_{i j}}{\rho_{i j}+\sum_{a} P_{i j}^{a} \cdot K_{a}}
$$

em que,

$S_{i j}: \quad$ volume entre a origem i e o destino j na matriz semente;

$\rho_{i j}$ : fator de amostragem atribuído às contagens;

$K_{a}:$ fator de balanceamento.

O fator de balanceamento pode ser considerado nulo, caso as viagens na matriz OD semente forem internamente compatíveis com as contagens realizadas nos arcos da rede, o que permite a redução da equação anterior (BERTONCINI, 2010) na equação [3.9].

$$
Q_{i j}=\frac{S_{i j}}{\rho_{i j}}
$$

Spiess (1987), apresenta uma proposta de generalização do modelo para os casos em que a distribuição de probabilidades do volume observado (contagens) não for conhecida, conforme a equação [3.10].

$$
\min \left(\sum_{i j}\left(\rho_{i j} \cdot Q_{i j}-S_{i j} \cdot \log \left(Q_{i j}\right)\right)+\sum_{i j}\left(\rho_{a} \cdot V_{o b s}^{a}-K_{a} \cdot \log \left(V_{o b s}^{a}\right)\right)\right)
$$

em que,

$\rho_{a}:$ amostra de fluxo no $\operatorname{arco} a$;

$K_{a}$ : observações mutuamente independentes que seguem uma distribuição de Poisson.

Assim como alguns dos métodos citados anteriormente a máxima verossimilhança também apresenta certa dependência em relação a qualidade da matriz semente, visto que, o método multiplica a relação entre o fluxo observado no arco e o fluxo entre o par OD, pela relação entre o fluxo OD semente e o fluxo OD. 


\subsubsection{Modelos entrópicos}

Segundo Wilson (1970) o conceito de entropia é utilizado para representar os estados de um sistema, os quais podem ser definidos por meio de descrição completa, detalhada e microscópica.

Na física clássica o estado de um sistema gasoso é definido pelas coordenadas e velocidades de cada partícula do gás em cada período. Embora esse sistema possa ser detalhado a nível microscópico por meio da utilização da física Newtoniana, essa técnica já se mostra de difícil aplicação em situações onde há mais de duas partículas, o que evidencia o elevado grau de dificuldade de sua aplicação em situações usuais, em que o número de partículas de um gás é da ordem de $10^{23}$ (WILSON, 1970).

O desenvolvimento de estudos na área da mecânica estatística permitiu que físicos explicassem e previssem as propriedades do macroestado sem explicar o comportamento individual de cada partícula (WILSON, 1970).

Para Wilson (1970), os estados de um sistema gasoso podem ser representados em três níveis distintos:

- Macroestado - total de moléculas no sistema;

- Meso-estado - distribuição das moléculas no sistema;

- Microestado - combinação das moléculas.

Cada macroestado possui associado a ele um determinado número de meso-estado. Do mesmo modo, diferentes microestados podem estar associados a um determinado meso-estado. Considerando que a probabilidade de ocorrência é a mesma para todos os microestados, o mesoestado com maior probabilidade de ocorrência será aquele associado ao maior número de microestados. Este cálculo pode ser realizado sem a necessidade de qualquer conhecimento das viagens individuais. Sendo assim, Wilson (1970) propõe que para identificar o meso-estado de maior frequência basta calcular o número de microestados associado a cada meso-estado e sujeito a quaisquer restrições relevantes. $\mathrm{O}$ arranjo com maior probabilidade de ocorrer é também aquele de maior “desordem” (WILLUMSEN, 1978).

Wilson (1967) faz uma analogia entre o comportamento dos gases e dos sistemas urbanos e regionais e aplica a esses a mesma subdivisão em três níveis apresentada anteriormente. Nesse novo contexto porem, cada nível representa as seguintes informações: 
- Macroestado - Total de viagens em uma matriz OD;

- Meso-estado - Distribuição das viagens entre os pares OD;

- Microestado - Distribuição de cada viagem dentro da rede.

Para exemplificar a aplicação da entropia no estudo de sistemas urbanos e regionais, Wilson (1970), elabora a situação hipotética, em que trabalhadores desejam se deslocar de suas residências para seus locais de trabalho.

Como exposto por Wilson (1967) apenas três restrições são necessárias para realizar uma boa estimativa do volume entre uma origem $(i)$ e um destino $(j)$.

$$
\begin{gathered}
\sum_{j} Q_{i j}=O_{i} \\
\sum_{j} Q_{i j}=D_{j} \\
\sum_{i} \sum_{j} Q_{i j} \cdot c_{i j}=C
\end{gathered}
$$

em que,

$Q_{i j}:$ número de indivíduos que moram na zona $i$ e trabalham na zona $j$ (valor a ser estimado);

$O_{i}:$ número total de trabalhadores que moram na zona $i$;

$D_{j}$ : número total de postos de trabalho na zona $j$;

$c_{i j}$ : custo do deslocamento de $i$ para $j$;

$C$ : gasto total para realizar as viagens.

O objetivo é encontrar o meso-estado $Q_{i j}$ com o maior número de microestados a ele associados e sujeito apenas as restrições apresentadas nas equações [3.11], [3.12] e [3.13].

O número de microestados associado a um meso-estado pode ser obtido da seguinte forma. Suponhamos que $Q$ é o número total de trabalhadores, ou seja, $Q=\sum_{i} \sum_{j} Q_{i j}$. Primeiramente podemos selecionar $Q_{11}$ de $Q, Q_{12}$ de $Q-Q_{11}$, e assim em diante. Desse modo, o número de possíveis microestados atribuídos $\left(Z\left(Q_{i j}\right)\right)$ corresponde ao número de maneiras de selecionar 
$Q_{11}$ de, $Q,{ }^{T} C_{T_{11}}$, multiplicado pelo número de maneiras de selecionar $Q_{12}$ de, $Q-$ $Q_{11}{ }^{T-T_{11}} C_{T_{12}}$, etc (WILSON, 1970).

$$
\begin{gathered}
Z\left(Q_{i j}\right)=C_{Q_{11}}^{Q} \cdot C_{Q_{12}}^{Q-Q_{11}} \cdot C_{Q_{13}}^{Q-Q_{11}-Q_{12}} \ldots \\
Z\left(Q_{i j}\right)=\frac{Q !}{Q_{11} ! \cdot\left(Q-Q_{11}\right) !} \cdot \frac{\left(Q-Q_{11}\right) !}{Q_{12} ! \cdot\left(Q-Q_{11}-Q_{12}\right) !} \cdot \frac{\left(Q-Q_{11}-Q_{12}\right) !}{Q_{13} ! \cdot\left(Q-Q_{11}-Q_{12}-Q_{13}\right) !} \ldots \\
Z\left(Q_{i j}\right)=\frac{Q !}{\prod_{i j} Q_{i j} !}
\end{gathered}
$$

Em busca de tornar mais fácil a maximização, é aplicado o logaritmo natural na equação [3.16].

$$
\ln Z\left(Q_{i j}\right)=\ln \left(\frac{Q !}{\prod_{i j}\left(Q_{i j}\right)}\right)=\ln Q !-\sum_{i j} \ln Q_{i j} !
$$

A aproximação de Stirling é então utilizada como uma alternativa ao complexo processo de derivação de um logaritmo natural de fatorial, conforme exposto na equação [3.18].

$$
\ln X !=X \ln X-X
$$

A função de entropia passa a ser expressa, então, pela equação [3.19].

$$
Z\left(Q_{i j}\right)=Q \ln Q-Q-\sum_{i j}\left(Q_{i j} \ln Q_{i j}-Q_{i j}\right)
$$

Ao assumir $Q$ constante é possível simplificar a equação com a supressão de seus dos dois primeiros termos.

$$
Z\left(Q_{i j}\right)=-\sum_{i j}\left(Q_{i j} \ln Q_{i j}-Q_{i j}\right)
$$

A distribuição das viagens entre a origem i e o destino $\mathrm{j}\left(Q_{i j}\right)$ pode ser obtida por meio da maximização da equação [3.20] sujeita as três restrições apresentadas nas Equações [3.11] a [3.13]. 


\subsubsection{Maximização da entropia na estimação de matrizes origem destino a partir de contagens de tráfego}

Willumsen (1978) relaciona o conceito de entropia ao de "informação". Segundo o autor, o estado de máxima desordem é também o que contém uma quantidade mínima de informação. $\mathrm{O}$ potencial informativo de uma mensagem aumenta à medida que a sequência de símbolos nela contida se afasta de uma organização meramente aleatória.

A aplicação da maximização da entropia (ou minimização da informação) na obtenção da matriz OD mais provável e compatível com as contagens de veículos nos links da rede, pode ser descrita também, como a busca por explorar toda a informação contida nos volumes observados, para determinar a matriz OD compatível mais provável.

O modelo sintético de Willumsen (1978) modifica as restrições apresentadas por Wilson (1970). A utilização do total de viagens geradas e atraídas por cada zona é substituída pelo uso das contagens de trafego nos arcos da via. A nomenclatura atribuída ao modelo pelo autor se deve ao fato desse sintetizar a informação na estimação da matriz OD.

O modelo foi elaborado com base na associação do microestado referente as $\left(Z\left(Q_{i j}\right)\right)$, referente a distribuição de cada viagem dentro da rede, ao meso-estado $\left(Q_{i j}\right)$ que, no modelo de Wilson (1970), representa o número total de viagens entre cada par OD.

A representação deste modelo pode ser feita, com base nos fundamentos de análise combinatória, por meio da equação[3.20] (ORTÚZAR; WILLUMSEN, 2011). A equação [3.20] deve ser maximizada sujeita as três equações de restrição apresentadas a seguir:

$$
\begin{aligned}
& V_{o b s}^{a}=\sum_{i j} p_{i j}^{a} \cdot Q_{i j} \\
& Q_{i j} \geq 0 \quad \forall i, j \\
& Q=\sum_{i j} Q_{i j}
\end{aligned}
$$

As restrições [3.22] a [3.23] representam o cerne da proposta - relação entre os volumes observados e o fluxo entre cada par OD, garante a não existência de um número negativo de viagens entre o par OD e preserva a continuidade das viagens. 
A representação formal do modelo de Willumsen (1978) é apresentada na equação [3.24]. Para incorporar as restrições a função a ser maximizada é necessário o uso de multiplicadores de Lagrange $\left(\lambda_{a}\right)$.

$$
Q_{i j}=\prod_{i j}\left(\mathrm{e}^{-\lambda_{a}}\right)^{p_{i j}^{a}}
$$

O resultado obtido representa a matriz com maior probabilidade de ocorrer o que não quer dizer que seja a matriz que representa o deslocamento real do sistema, visto que o problema é indeterminado, ou seja, a indeterminação é superior à quantidade de informação.

Nesse contexto, Van Zuylen e Willumsen (1980) propõem a inserção de informação auxiliar no modelo, por meio da utilização da medida de informação de Brillouin (1956). Essa proposta assume o conhecimento a priori de uma viagem semente entre a origem $i$ e o destino $j$, a qual pode ser obtida a partir de uma antiga matriz OD.

De posse de um conjunto de volumes observados $\left(V_{o b s}\right)$, a medida da informação de Brillouin, modificada, para os links em que as contagens foram realizadas é dada pela equação [3.25].

$$
I_{a}=\ln V_{o b s}^{a} ! \prod\left[\frac{\left(\frac{s_{i j} p_{i j}^{a}}{\sum_{i j} s_{i j} p_{i j}^{a}}\right)^{Q_{i j} p_{i j}^{a}}}{Q_{i j} p_{i j}^{a} !}\right]
$$

sendo que,

$$
s_{i j}: \quad \text { viagem semente entre o par OD } i j
$$

Aplicando a aproximação de Stirling, a equação [3.25] pode ser expressa conforme a equação [3.26].

$$
I_{a}=\sum_{i j} Q_{i j} p_{i j}^{a} \ln \left[\frac{Q_{i j}\left(\sum_{i j} s_{i j} p_{i j}^{a}\right)}{V_{o b s}^{a} \cdot s_{i j}}\right]
$$

Considerando $\sum_{i j} s_{i j} p_{i j}^{a}=S$, a equação pode ser escrita como: 


$$
I_{a}=\sum_{a} \sum_{i j} Q_{i j} p_{i j}^{a} \ln \left(\frac{Q_{i j} . S}{V_{o b s}^{a} . S_{i j}}\right)
$$

A expressão formal para o modelo de minimização da quantidade de informação [3.28] pode ser obtida a partir da minimizando a equação [3.27] sujeita as restrições [3.21] e [3.22].

$$
Q_{i j}=s_{i j} \cdot \prod\left\{\frac{V_{o b s}^{a}}{S} \cdot e^{-\left(1+\lambda_{a}\right)}\right\}^{\frac{p_{i j}^{a}}{\sum_{a}^{a} p_{i j}^{a}}}
$$

Os modelos propostos por Willumsen (1978) e Van Zuylen (1980) apresentam similaridades, porém, sua principal distinção encontra-se no fato de que enquanto o meso estado de Willumsen (1978) é composto pelas viagens, no de Van Zuylen (1980) é composto pelas contagens de tráfego (BERTONCINI, 2010).

Van Zuylen e Willumsen (1980) propuseram a unificação de seus modelos em 1980, o qual, pode ser expresso formalmente pela equação [2.29]. O novo modelo considera a inserção de informação adicional ao modelo de Willumsen (1978). Essa informação adicional consiste na probabilidade a priori das contagens apresentarem uma viagem que ocorra entre o par OD $i, j$ (BERTONCINI, 2010).

$$
Z\left(Q_{i j}, s_{i j}\right)=\frac{Q !}{\prod_{i j}\left(Q_{i j} !\right)} \cdot \prod_{i j}\left(\frac{s_{i j}}{S}\right)^{Q_{i j}}
$$

em que,

$Q$ : soma das demandas que serão estimadas;

$Q_{i j}: \quad$ volume entre o par OD $i j$;

$s_{i j}$ : fluxo entre o par OD $i j$ obtido pela matriz semente

$S:$ total de viagens da matriz semente.

As demandas presentes na matriz OD são estimadas maximizando a Equação [3.30] sujeita às restrições típicas desse tipo de modelo, Equações [3.21] a [3.23].

$$
\ln Z\left(Q_{i j}, s_{i j}\right)=Q \cdot \ln Q-Q \cdot \ln S-\sum_{i j}\left(Q_{i j} \cdot \ln Q_{i j}-Q_{i j} \cdot \ln s_{i j}\right)
$$


O modelo de Van Zuylen e Willumsen (1980) pode ser expresso, formalmente, pela equação [3.31].

$$
Q_{i j}=s_{i j} \cdot \prod\left[\left(\sum_{i j} s_{i j}\right)^{\frac{1}{o}} \cdot \mathrm{e}^{-\lambda_{a}}\right]^{p_{i j}^{a}}
$$

em que,

$o$ : ao número total de links em que foram realizadas contagens de tráfego;

$\lambda_{a}:$ multiplicador lagrangeano.

A utilização de informação adicional oriunda de uma matriz antiga faz com que esse modelo, tenda a obter resultados mais precisos do que aqueles em que são consideradas apenas as contagens de tráfego. No entanto, a inserção dessa informação a priori também condiciona o resultado a qualidade da matriz semente utilizada, conforme exposto por Yang et al. (1992).

A utilização da matriz semente no processo de estimativa da matriz OD também apresenta o inconveniente de nem sempre estar disponível aos planejadores de transporte. Além disso, a distribuição do fluxo pode variar ao longo do tempo o que tornaria a utilização de uma matriz semente antiga inadequada em determinadas situações.

Uma alternativa para os casos em que não há matriz OD antiga é o uso de matriz semente uniforme, compostas apenas por valor unitário. A utilização desse tipo de informação, no entanto, anula a informação adicional relacionada a esse elemento, o que retorna o modelo a proposta inicial de Willumsen (1978).

A partir desse cenário, Bertoncini (2010) desenvolveu o Método das Médias Sucessivas com o objetivo de elaborar um modelo capaz de estimar, de forma adequada, a matriz OD, mas sem a necessidade de despender elevada quantidade de recursos.

\subsubsection{Método das médias sucessivas}

Conforme proposto por Bertoncini (2010), o método das médias sucessivas considera que o custo atribuído a cada arco está relacionado ao seu tempo de percurso, o qual dependerá da relação entre o volume e a capacidade observada no arco. Para estabelecer essa relação, foi 
utilizada a função de impedância proposta pelo Bureau of Public Rads - BPR, evidenciada na equação [3.32].

$$
t_{a}=T_{0}\left(1+\alpha \cdot\left(\frac{V_{o b s}^{a}}{C a p^{a}}\right)^{\beta}\right)
$$

em que,

$t_{a}:$ tempo gasto para percorrer o $\operatorname{arco} a$;

$T_{0}$ : tempo gasto para percorrer o arco $a$ na situação de fluxo livre;

$V_{o b s}^{a}:$ contagem de tráfego no arco $a$;

$\operatorname{Cap}^{a}$ : capacidade do arco $a$;

$\alpha$ e $\beta$ : constantes nos valores 0,15 e 4 , respectivamente.

Considerando um par OD hipotético, composto pela origem $i$ e o destino $j$, seu conjunto de caminhos mínimos $\left(C_{i j}^{\min }\right)$ é composto pelas rotas de menor tempo de percurso $\left(T_{i j}^{\min }\right)$. O custo atribuído ao trajeto é determinado pela soma do custo, ou tempo de percurso, de cada um dos $\operatorname{arcos} a$ que o compõe. A equação [3.33] expõe esta relação.

$$
T_{i j}^{\min }=\sum_{a \in C_{i j}^{\min }} t_{a}
$$

O início do método $(k=0)$ consiste em definir o custo de cada arco da rede na condição de fluxo livre, para, em seguida, serem definidos os conjuntos de caminhos mínimos entre cada par OD. Posteriormente, inicia-se a primeira etapa do método $(k=1)$, a qual é detalhada nos parágrafos a seguir.

Partindo do princípio que todas as viagens ocorrem pelo caminho mínimo, atribui-se valor 0 ou 1 para a probabilidade de determinado arco $a$ ser utilizado pelo fluxo de um par $\operatorname{OD}\left(Q_{i j}\right)$. Caso o arco $a$ integre o conjunto de caminhos mínimos do par OD $i j$, e se o fluxo $Q_{i j}$ utilizar tal arco, $P_{i j}^{a^{k}}=1$, caso contrário, $P_{i j}^{a^{k}}=0$.

A matriz OD é então estimada, com base no princípio da maximização da entropia, por meio da equação [3.34].

$$
Z\left(Q_{i j}\right)=\max \left[-\sum_{i j}\left(Q_{i j} \cdot \ln Q_{i j}-Q_{i j}\right)\right]
$$


sujeito a

$$
V_{o b s}^{a}=\sum_{i j} P_{i j}^{a^{k-1}} \cdot Q_{i j}
$$

Após a conclusão da estimativa da matriz $Q 1$, é preciso corrigir os erros de carregamento excessivo (etapa $k=2$ ). Para tal, é calculado o tempo de percurso referente a cada arco da rede, considerando o carregamento gerado pela etapa anterior $(k=1)$. Desse modo, obtém-se a matriz auxiliar $Q_{2}$, pelo mesmo processo utilizado na obtenção de $Q_{1}$, porém, considerando-se os novos custos obtidos.

A partir de $Q_{1}$ e $Q_{2}$, obtém-se uma terceira matriz, que consiste na média ponderada das matrizes, com peso $\left(1-\emptyset_{2}\right)$ para $Q_{1}$ e $\emptyset_{2}$ para $Q_{2}$. Essa operação corresponde a subtrair uma parcela de valor $\emptyset_{2} \cdot Q_{1}$ da primeira matriz estimada e adicionar uma parcela de $\emptyset_{2} \cdot Q_{2}$; ou seja, parte do fluxo $Q_{i j}$, alocada nos caminhos mínimos identificados na etapa $k=1$, é transferida para os caminhos mínimos identificados na etapa $k=2$.

Em redes não congestionadas, os conjuntos de caminhos mínimos, identificados nas etapas $k=1$ e $k=2$, são similares e, por essa razão, a parcela de fluxo subtraída é acrescentada ao mesmo trajeto.

No entanto, é importante ressaltar que nem sempre a parcela extraída será similar à adicionada, pois em redes congestionadas, geralmente, ocorre uma distinção entre as matrizes estimadas $Q_{1}$ e $Q_{2}$.

Conforme exposto por Bertoncini (2010), na $k$-ésima etapa, a subtração e o acréscimo podem ser realizados de acordo com o fator de ponderação $\emptyset_{k}\left(0 \leq \emptyset_{k} \leq 1\right)$, que é computado em função da etapa (k), como exposto na equação [3.36].

$$
\emptyset_{k}=\frac{1}{k}
$$

Desse modo, a matriz OD média será definida como:

$$
\bar{Q}_{k}=\left(1-\emptyset_{k}\right) \cdot \bar{Q}_{k-1}+\emptyset_{k} \cdot Q_{k}
$$

em que, 
$Q_{k}:$ matriz média de viagens estimada na etapa $k$.

Desta forma:

$$
\begin{gathered}
\bar{Q}_{1}=Q_{1} \\
\bar{Q}_{2}=\left(1-\emptyset_{2}\right) \cdot \bar{Q}_{1}+\emptyset_{2} \cdot Q_{2} \mathrm{e} \\
\bar{Q}_{3}=\left(1-\emptyset_{3}\right) \cdot \bar{Q}_{2}+\emptyset_{3} \cdot Q_{3}
\end{gathered}
$$

Adotando:

$$
\grave{\emptyset}_{k}=\left(1-\emptyset_{k}\right)
$$

Tem-se:

$$
\begin{gathered}
\grave{\emptyset}_{k} \cdot \grave{\emptyset}_{k-1} \ldots \grave{\emptyset}_{2} \cdot \bar{Q}_{1}=\grave{\emptyset}_{k} \cdot \grave{\emptyset}_{k-1} \ldots \emptyset_{2} \cdot Q_{1} \\
\grave{\emptyset}_{k} \cdot \grave{\emptyset}_{k-1} \ldots \grave{\emptyset}_{3} \cdot \bar{Q}_{2}=\grave{\emptyset}_{k} \cdot \grave{\emptyset}_{k-1} \ldots \bar{\emptyset}_{2} \cdot \bar{Q}_{1}+\grave{\emptyset}_{k} \cdot \grave{\emptyset}_{k-1} \ldots \grave{\emptyset}_{3} \cdot\left(1-\grave{\emptyset}_{2}\right) \cdot Q_{2} \\
\grave{\emptyset}_{k} \cdot \grave{\emptyset}_{k-1} \ldots \grave{\emptyset}_{4} \cdot \bar{Q}_{3}=\grave{\emptyset}_{k} \cdot \grave{\emptyset}_{k-1} \ldots \emptyset_{3} \cdot \bar{Q}_{2}+\grave{\emptyset}_{k} \cdot \grave{\emptyset}_{k-1} \ldots \grave{\emptyset}_{4} \cdot\left(1-\grave{\emptyset}_{3}\right) \cdot Q_{3} \\
\ldots \\
\grave{\emptyset}_{k} \cdot \bar{Q}_{k-1}=\grave{\emptyset}_{k} \cdot \grave{\emptyset}_{k-1} \cdot \bar{Q}_{k-2}+\grave{\emptyset}_{k} \cdot\left(1-\grave{\emptyset}_{k-1}\right) \cdot Q_{k-1} \\
\bar{Q}_{k}=\grave{\emptyset}_{k} \cdot \bar{Q}_{k-1}+\left(1-\grave{\emptyset}_{k}\right) \cdot Q_{k}
\end{gathered}
$$

Fazendo o somatório membro a membro, obtém-se a equação [3.47]:

$$
\begin{aligned}
\bar{Q}_{k}=\prod_{n=2}^{k} \grave{\emptyset}_{n} & \cdot Q_{1}+\prod_{n=3}^{k} \grave{\emptyset}_{n} \cdot\left(1-\grave{\emptyset}_{2}\right) \cdot Q_{2}+\ldots+\prod_{n=k-1}^{k} \grave{\emptyset}_{n} \cdot\left(1-\grave{\emptyset}_{k-2}\right) \cdot Q_{k-2} \\
& +\prod_{n=k}^{k} \grave{\emptyset}_{n} \cdot\left(1-\grave{\emptyset}_{k-1}\right) \cdot Q_{k-1}+\left(1-\grave{\emptyset}_{k}\right) \cdot Q_{k}
\end{aligned}
$$

Sabendo que: 


$$
\begin{gathered}
\emptyset_{2}=\frac{1}{2} \longrightarrow \grave{\emptyset}_{2}=\frac{1}{2} \\
\emptyset_{3}=\frac{1}{3} \longrightarrow \grave{\emptyset}_{2}=\frac{2}{3} \\
\emptyset_{4}=\frac{1}{4} \longrightarrow \grave{\emptyset}_{2}=\frac{3}{4} \\
\emptyset_{n}=\frac{1}{n} \longrightarrow \grave{\emptyset}_{n}=\frac{n-1}{n}
\end{gathered}
$$

Expressão generalizada da matriz média na $k$-ésima etapa:

$$
\bar{Q}_{k}=\frac{1}{k} \cdot \sum_{n=1}^{k} Q_{n}
$$

A matriz estimada em cada etapa corresponde à média aritmética das matrizes estimadas em cada uma das etapas realizadas até o momento.

\subsection{MÉtodo Proposto}

Conforme exposto, este capítulo tem por objetivo a implementação de um método/modelo de reconstrução de matriz OD a partir de contagens de tráfego. Para tal, foi selecionado o método de Bertoncini (2010) devido ao fato desse ser não complexo, prescindir uma matriz OD e ter obtido resultados superiores aos de programas da área, tais como TransCAD e QueensOD.

A rotina computacional do método das médias sucessivas foi realizada na linguagem de programação de alto nível Python. Essa linguagem foi lançada por Guido Rossum em 1991 e possui como características o fato de ser interpretada, imperativa, orientada a objetos, funcional e de tipagem dinâmica.

A escolha pela linguagem Python no desenvolvimento do estudo deve-se a sua facilidade de aprendizagem e leitura, ser de uso livre (opensource) e a disponibilidade de grande número de bibliotecas e módulos. Tais módulos e bibliotecas contém funções previamente escritas e 
avaliadas que permitem simplificar o processo de escrita do código, como exemplo podem ser citados os pacotes $S c i P y^{21}$ e $N u m P y^{22}$.

\subsubsection{Implementação do MEMS}

O propósito desta etapa é codificar em linguagem Python o Método das Médias Sucessivas (MEMS), até então, realizado apenas por meio do programa Microsoft Excel. Para tal, foram utilizadas as mesmas rede e demanda consideradas por Bertoncini (2010), para que fosse permitida a comparação dos resultados obtidos.

A rede utilizada é composta por 9 nós, todos do tipo origem e destino, e 24 arcos orientados. A Figura 36 apresenta a rede em questão.

Figura 36 - Rede de transporte utilizada para o experimento de implementação do MEMS na linguagem Python

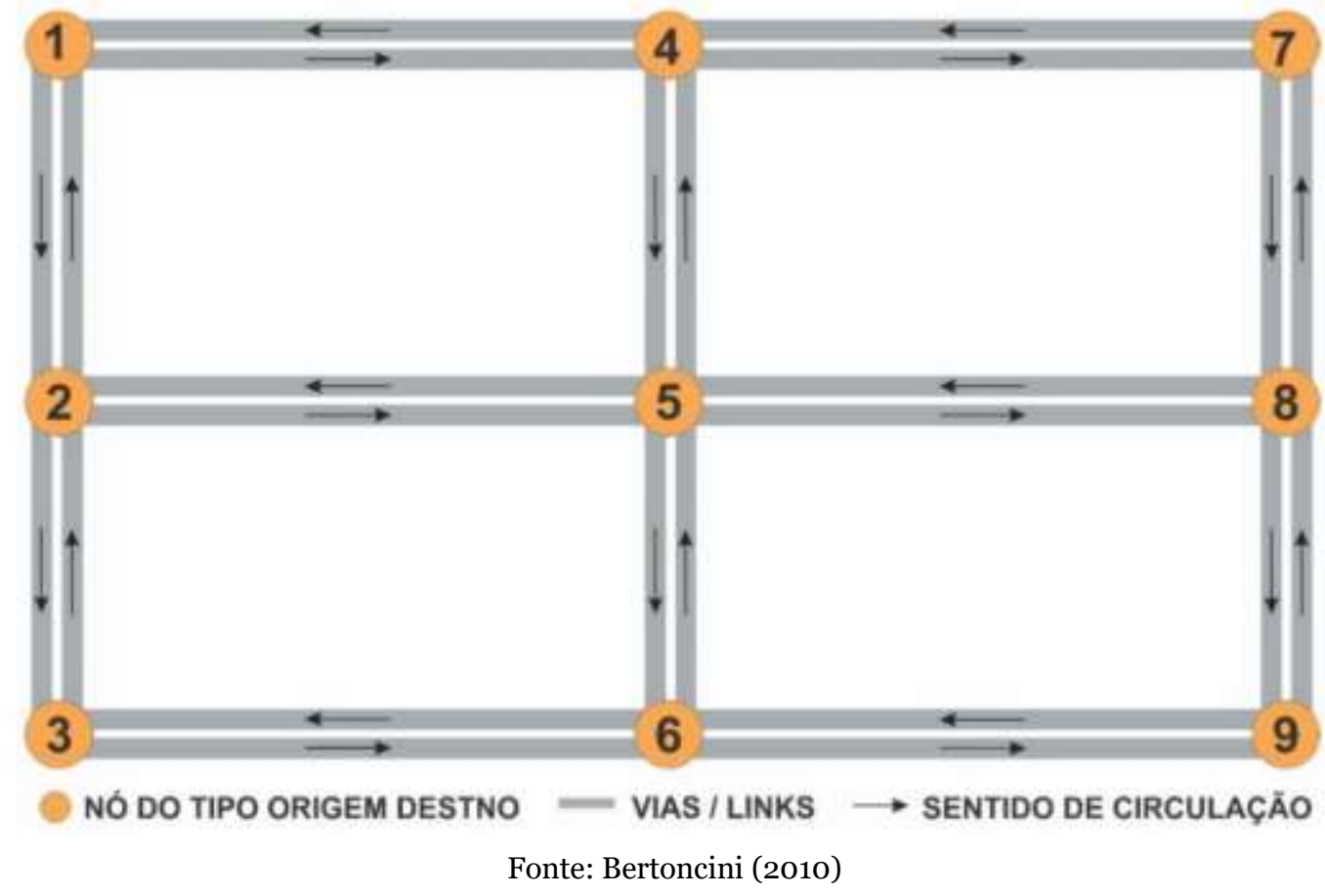

${ }^{21}$ https://www.scipy.org/

${ }^{22} \mathrm{http}: / /$ www.numpy.org/ 
Tabela 5 - Matriz OD "real" definida em Bertoncini (2010)

\begin{tabular}{ccccccccccc}
\hline $\mathrm{O} / \mathrm{D}$ & 1 & 2 & 3 & 4 & 5 & 6 & 7 & 8 & 9 & Total \\
\hline 1 & - & 406 & 464 & 330 & 418 & 175 & 276 & 159 & 371 & 2.599 \\
2 & 204 & - & 386 & 415 & 233 & 225 & 416 & 219 & 484 & 2.582 \\
3 & 176 & 377 & - & 351 & 419 & 187 & 245 & 246 & 288 & 2.289 \\
4 & 334 & 203 & 309 & - & 487 & 231 & 204 & 213 & 210 & 2.191 \\
5 & 337 & 414 & 246 & 184 & - & 199 & 466 & 260 & 328 & 2.434 \\
6 & 455 & 462 & 226 & 371 & 311 & - & 165 & 320 & 353 & 2.663 \\
7 & 407 & 428 & 179 & 172 & 347 & 451 & - & 323 & 434 & 2.741 \\
8 & 284 & 282 & 275 & 359 & 475 & 265 & 401 & - & 326 & 2.667 \\
9 & 444 & 268 & 364 & 350 & 476 & 477 & 310 & 298 & - & 2.987 \\
\hline Total & 2.641 & 2.840 & 2.449 & 2.532 & 3.166 & 2.210 & 2.483 & 2.038 & 2.794 & 23.153 \\
\hline \multicolumn{7}{c}{ Fonte: Bertoncini (2010) }
\end{tabular}

Os valores, considerados como contagens nos links, foram os obtidos por Bertoncini (2010), por meio do método de alocação por médias sucessivas, realizado em uma rotina criada em planilha Microsoft Excel. A Figura 37 apresenta os valores atribuídos à contagem em cada link.

Figura 37 - Fluxos alocados aos arcos pelo método das médias sucessivas

1.834

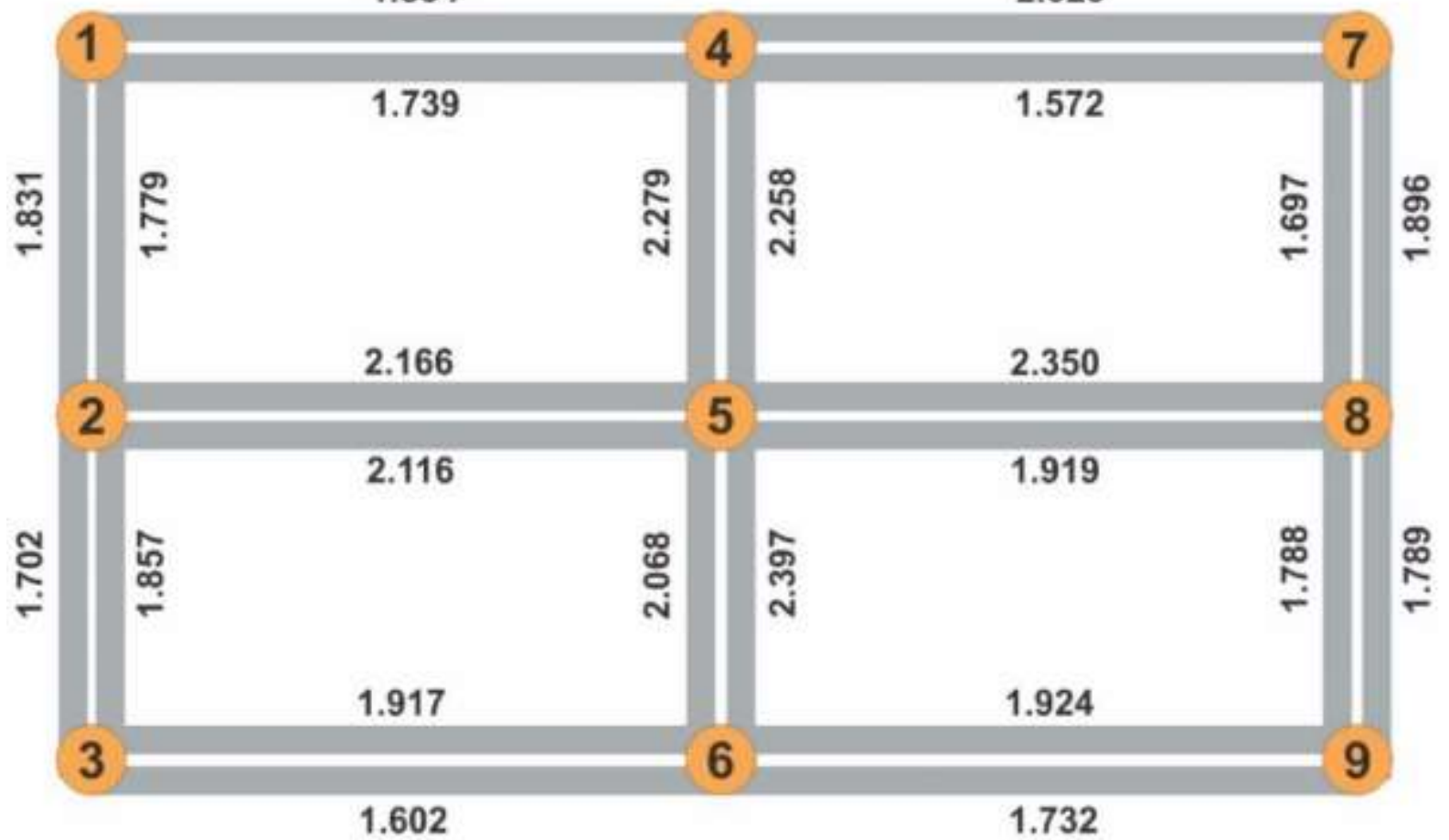

Fonte: Bertoncini (2010)

A capacidade considerada foi extraída do experimento de Bertoncini (2010), assim como o custo inicial atribuído a cada link que, conforme exposto na revisão bibliográfica, está relacionado apenas ao tempo gasto para percorrer o trecho (Figura 38).

Para realização do experimento na linguagem Python, a rede foi inserida na forma de dígrafo. As características como custo e capacidade foram inseridas na forma de matriz de adjacência, na qual as células referentes à linha $i$ e à coluna $j$ recebem valores distintos de nulo, apenas se 
existir o link entre os vértices $i$ e $j$. No caso específico da matriz de custos, os valores nulos foram convertidos em 1.000 como uma estratégia para indicar a inviabilidade de o caminho mínimo ser realizado pelos links inexistentes.

Embora a seleção do caminho mínimo tenha sido realizada por meio do algoritmo de Dijkstra (1959), o uso da programação computacional permite que, no futuro, sejam testados outros algoritmos de caminhos mínimos, que possam se mostrar mais eficientes ou rápidos. Os demais algoritmos não serão abordados neste estudo, por não ser esse o objetivo central do experimento.

Figura 38 - Tempo de deslocamento no fluxo livre e a capacidade viária considerados para cada trecho da rede

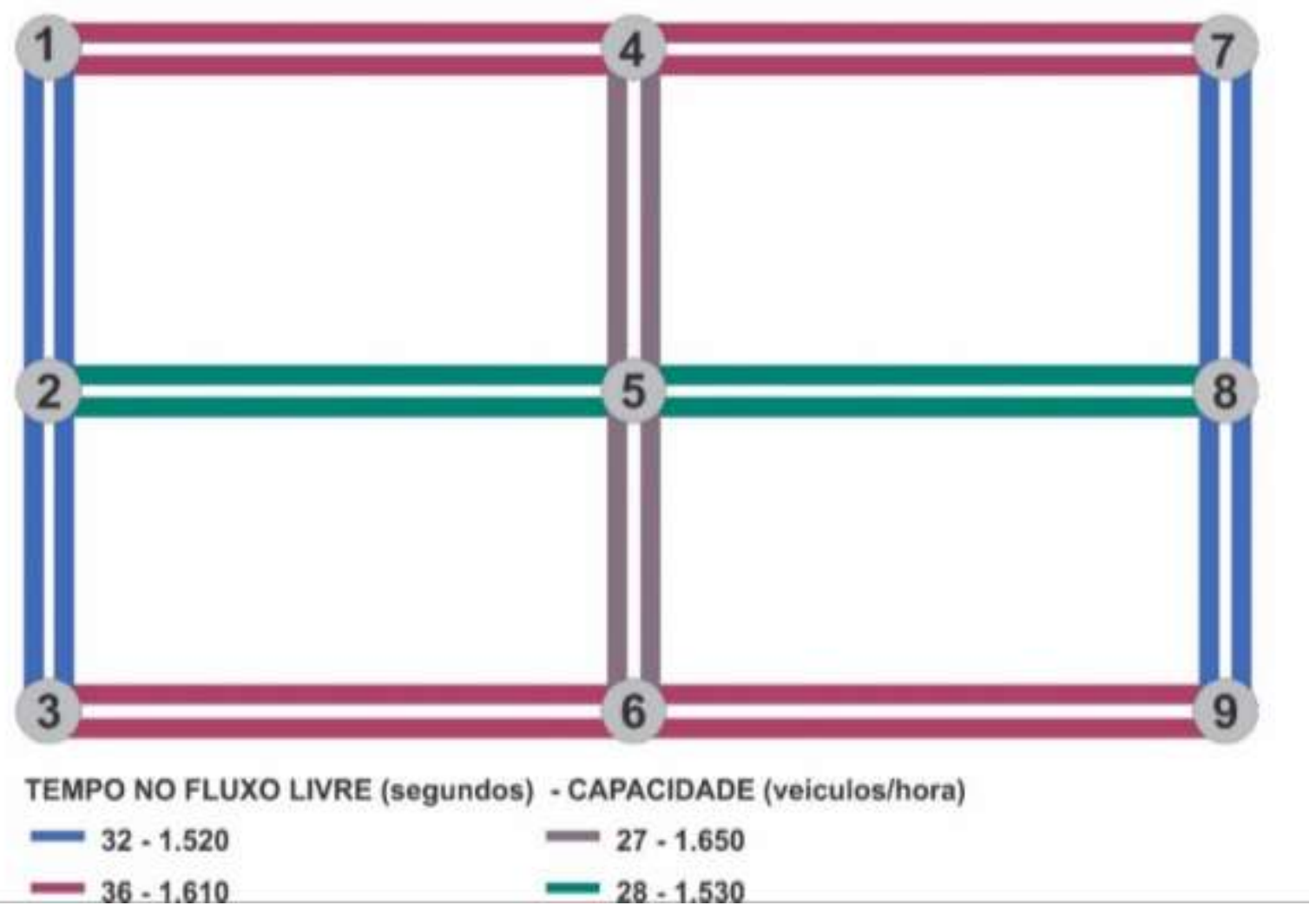

Fonte: A autora

As várias matrizes geradas por Bertoncini (2010), ao longo do método das médias sucessivas, foram obtidas pela maximização da entropia e pelos algoritmos de otimização presentes no suplemento Solver do Microsoft Excel. Atualmente, o Solver oferece apenas três opções de otimização: GRG não linear, Simplex LP e Evolutionary.

Em contrapartida, o pacote de otimização scipy.optimize, da linguagem Python, oferece quatorze opções de algoritmos de otimização (SCIPY, 2018). Foi selecionado o método SLSQP (do inglês, Sequential Least Square Programming) o qual faz uso da rotina de otimização SLSQP originalmente desenvolvida por Kraft (1988). Esse método utiliza a programação de 
Mínimos Quadrados Sequenciais para minimizar uma função composta por diversas variáveis, com qualquer combinação de limites e sujeitas a restrições do tipo equação e inequação. A possibilidade de utilizar restrições expressas por meio de equações e inequações foi um dos fatores determinantes na escolha do método SLSQP.

No processo de maximização da entropia realizado internamente ao MEMS, são impostas restrições dos dois tipos. As do tipo equação estão relacionadas a relação de igualdade entre a soma dos volumes dos pares OD cujos caminhos passa por determinado link e o volume obtido pela contagem no local. Já a restrição do tipo inequação refere-se a impossibilidade de existirem viagens negativas o que torna necessária a imposição de que os valores atribuídos aos pares OD sejam iguais ou superiores a zero.

O método SLSQP possui um conjunto de parâmetros passíveis de serem alterados de acordo com o problema tratado e o objetivo que se deseja alcançar. Dentre esses, destaca-se o número máximo de iterações e a tolerância. Para garantir que o processo de otimização utilizado durante a fase de maximização da entropia não fosse interrompido antes do resultado ótimo considerado pelo programa, foi estabelecido valor de limite de 1000 iterações. A adequabilidade do valor adotado foi verificada por meio da realização de replicações com valores de limite de interação significativamente abaixo do estabelecido, sendo observada a manutenção do resultado da operação de otimização.

O parâmetro tolerância exigiu um tratamento mais cuidadoso em sua determinação. As primeiras operações realizadas apresentaram valores que podem ser considerados inadequados no que se diz respeito a uma matriz OD em que o resultado obtido consistia em matrizes espelhadas e o processo de otimização não chegava a ser de fato realizado. Esse resultado ocorreu devido a utilização de valor de tolerância mínimo, no caso zero, para o não atendimento às restrições estabelecidas, o que não é esperado para o tipo de problema de otimização tratado nesta pesquisa.

Para escolha do valor mais adequado para o parâmetro de tolerância foram realizadas replicações com diferentes valores, sendo avaliado em seguida o desempenho do resultado obtido por meio da comparação da matriz OD final do código com a obtida por Bertoncini (2010), após a aplicação do MEMS em planilha Excel, e a matriz OD real considerada. Os resultados e comparações em questão serão apresentados na seção 3.3 Resultados do presente capítulo. 
Foi definido como critério de parada para a rotina computacional implementada a obtenção de valor inferior ou igual a 0,01 para todas as células da matriz resultante da subtração da última matriz média estimada pela anterior, como forma de identificar a convergência entre essas matrizes.

\subsubsection{Validação do método MEMS implementado}

A avaliação dos resultados obtidos pela implementação do método MEMS, na linguagem Python, foi realizada de forma semelhante à efetuada por Bertoncini (2010), com o objetivo de permitir a comparação entre os novos resultados alcançados e os obtidos pelo autor.

Embora Bertoncini (2010) tenha avaliado a influência do acréscimo de informações, por meio da contagem realizada nos nós, o presente estudo avaliou apenas os experimentos compostos pelas contagens nos links, por ser essa a informação que se consegue aferir da API Here Traffic.

As três formas de análises dos resultados obtidos serão:

- Análise comparativa das diferenças entre as viagens das matrizes OD "real" e estimada;

- Análise da diferença absoluta média;

- Análise da distribuição de frequências das diferenças relativas.

\subsection{ResUltados}

A Tabela 6 até a Tabela 11 apresentam as matrizes OD obtidas pela rotina computacional implementada considerando a adoção de diferentes valores de tolerância para o processo de otimização utilizado na maximização da entropia. A matriz OD obtida por Bertoncini (2010) por meio da execução do MEMS em planilha eletrônica é apresentada na Tabela 11 apenas a título de comparação.

O teste do parâmetro de tolerância foi realizado por meio da utilização de valores distintos para esse parâmetro na função de otimização. Após descartar o uso do valor zero para tolerância por se inadequado para solução do problema, foi considerado o valor 1. A partir desse foram testados progressivamente os valores referentes as dezenas de modo a encontrar o intervalo que continha o valor específico a partir do qual o acréscimo no número referente a tolerância não acarretava qualquer mudança no resultado obtido pela rotina computacional. Encontrado esse intervalo foram testados cada um de seus valores até ser identificado que do $33 \mathrm{em}$ diante o aumento da tolerância não ocasiona qualquer alteração nos resultados. Por essa razão, são 
apresentadas a seguir as matrizes referentes aos valores de tolerância igual a 1, 10, 20, 30, 32 e 33.

Tabela 6 - Matriz OD obtida pela rotina computacional elaborada considerando de nível de tolerância 1 durante processo de otimização

\begin{tabular}{c|ccccccccc|c}
\hline $\mathrm{O} / \mathrm{D}$ & 1 & 2 & 3 & 4 & 5 & 6 & 7 & 8 & 9 & Total \\
\hline 1 & 0 & 1 & 63 & 3 & 58 & 519 & 122 & 411 & 849 & $\mathbf{2 0 2 6}$ \\
2 & 6 & 0 & 5 & 59 & 5 & 59 & 389 & 64 & 398 & $\mathbf{9 8 5}$ \\
3 & 65 & 6 & 0 & 543 & 58 & 6 & 849 & 417 & 139 & $\mathbf{2 0 8 3}$ \\
4 & 5 & 59 & 514 & 0 & 4 & 79 & 6 & 58 & 524 & $\mathbf{1 2 4 9}$ \\
5 & 61 & 5 & 62 & 4 & 0 & 3 & 59 & 5 & 60 & $\mathbf{2 5 9}$ \\
6 & 560 & 60 & 1 & 116 & 5 & 0 & 548 & 58 & 5 & $\mathbf{1 3 5 3}$ \\
7 & 33 & 389 & 839 & 5 & 58 & 517 & 0 & 0 & 63 & $\mathbf{1 9 0 4}$ \\
8 & 379 & 64 & 382 & 60 & 5 & 58 & 0 & 0 & 2 & $\mathbf{9 5 0}$ \\
9 & 839 & 389 & 52 & 521 & 58 & 6 & 63 & 0 & 0 & $\mathbf{1 9 2 8}$ \\
\hline Total & $\mathbf{1 9 4 8}$ & $\mathbf{9 7 3}$ & $\mathbf{1 9 1 8}$ & $\mathbf{1 3 1 1}$ & $\mathbf{2 5 1}$ & $\mathbf{1 2 4 7}$ & $\mathbf{2 0 3 6}$ & $\mathbf{1 0 1 3}$ & $\mathbf{2 0 4 0}$ & $\mathbf{1 2 7 3 7}$ \\
\hline
\end{tabular}

Fonte: A autora

Tabela 7 - Matriz OD obtida pela rotina computacional elaborada considerando de nível de tolerância 10 durante processo de otimização

\begin{tabular}{c|ccccccccc|c}
\hline $\mathrm{O} / \mathrm{D}$ & 1 & 2 & 3 & 4 & 5 & 6 & 7 & 8 & 9 & Total \\
\hline 1 & 0 & 0 & 264 & 28 & 95 & 515 & 365 & 340 & 730 & $\mathbf{2 3 3 7}$ \\
2 & 0 & 0 & 0 & 89 & 19 & 75 & 328 & 143 & 336 & $\mathbf{9 9 0}$ \\
3 & 264 & 0 & 0 & 535 & 84 & 2 & 728 & 366 & 326 & $\mathbf{2 3 0 5}$ \\
4 & 30 & 97 & 523 & 0 & 27 & 304 & 0 & 86 & 545 & $\mathbf{1 6 1 2}$ \\
5 & 76 & 20 & 77 & 0 & 0 & 1 & 75 & 29 & 76 & $\mathbf{3 5 4}$ \\
6 & 544 & 102 & 28 & 340 & 27 & 0 & 569 & 88 & 22 & $\mathbf{1 7 2 0}$ \\
7 & 56 & 329 & 706 & 111 & 86 & 487 & 0 & 39 & 257 & $\mathbf{2 0 7 1}$ \\
8 & 321 & 143 & 324 & 103 & 24 & 89 & 9 & 0 & 0 & $\mathbf{1 0 1 3}$ \\
9 & 710 & 327 & 63 & 551 & 90 & 40 & 273 & 12 & 0 & $\mathbf{2 0 6 6}$ \\
\hline Total & $\mathbf{2 0 0 1}$ & $\mathbf{1 0 1 8}$ & $\mathbf{1 9 8 5}$ & $\mathbf{1 7 5 7}$ & $\mathbf{4 5 2}$ & $\mathbf{1 5 1 3}$ & $\mathbf{2 3 4 7}$ & $\mathbf{1 1 0 3}$ & $\mathbf{2 2 9 2}$ & $\mathbf{1 4 4 6 8}$ \\
\hline
\end{tabular}

Fonte: A autora

Tabela 8 - Matriz OD obtida pela rotina computacional elaborada considerando de nível de tolerância 20 durante processo de otimização

\begin{tabular}{c|ccccccccc|c}
\hline O/D & 1 & 2 & 3 & 4 & 5 & 6 & 7 & 8 & 9 & Total \\
\hline 1 & 0 & 0 & 309 & 71 & 114 & 517 & 414 & 375 & 762 & $\mathbf{2 5 6 2}$ \\
2 & 47 & 0 & 33 & 104 & 27 & 85 & 366 & 148 & 362 & $\mathbf{1 1 7 2}$ \\
3 & 314 & 0 & 0 & 530 & 112 & 0 & 757 & 378 & 387 & $\mathbf{2 4 7 8}$ \\
4 & 21 & 105 & 526 & 0 & 31 & 303 & 0 & 93 & 532 & $\mathbf{1 6 1 1}$ \\
5 & 86 & 26 & 89 & 26 & 0 & 11 & 89 & 33 & 89 & $\mathbf{4 4 9}$ \\
6 & 534 & 120 & 80 & 334 & 37 & 0 & 547 & 100 & 71 & $\mathbf{1 8 2 3}$ \\
7 & 87 & 359 & 746 & 129 & 106 & 503 & 0 & 59 & 303 & $\mathbf{2 2 9 2}$ \\
8 & 360 & 148 & 362 & 122 & 33 & 106 & 33 & 0 & 40 & $\mathbf{1 2 0 4}$ \\
9 & 741 & 365 & 89 & 523 & 108 & 71 & 321 & 36 & 0 & $\mathbf{2 2 5 4}$ \\
\hline Total & $\mathbf{2 1 9 0}$ & $\mathbf{1 1 2 3}$ & $\mathbf{2 2 3 4}$ & $\mathbf{1 8 3 9}$ & $\mathbf{5 6 8}$ & $\mathbf{1 5 9 6}$ & $\mathbf{2 5 2 7}$ & $\mathbf{1 2 2 2}$ & $\mathbf{2 5 4 6}$ & $\mathbf{1 5 8 4 5}$ \\
\hline
\end{tabular}

Fonte: A autora 
3 Matriz Sintética

Tabela 9 - Matriz OD obtida pela rotina computacional elaborada considerando de nível de tolerância 30 durante processo de otimização

\begin{tabular}{c|ccccccccc|c}
\hline O/D & 1 & 2 & 3 & 4 & 5 & 6 & 7 & 8 & 9 & Total \\
\hline 1 & 0 & 0 & 309 & 78 & 114 & 516 & 414 & 372 & 755 & $\mathbf{2 5 5 8}$ \\
2 & 48 & 0 & 34 & 104 & 26 & 89 & 360 & 148 & 359 & $\mathbf{1 1 6 8}$ \\
3 & 314 & 0 & 0 & 529 & 112 & 0 & 747 & 375 & 387 & $\mathbf{2 4 6 4}$ \\
4 & 21 & 110 & 525 & 0 & 30 & 306 & 0 & 95 & 532 & $\mathbf{1 6 1 9}$ \\
5 & 89 & 26 & 89 & 27 & 0 & 11 & 92 & 32 & 90 & $\mathbf{4 5 6}$ \\
6 & 534 & 120 & 81 & 336 & 37 & 0 & 547 & 102 & 71 & $\mathbf{1 8 2 8}$ \\
7 & 87 & 355 & 733 & 137 & 106 & 501 & 0 & 61 & 303 & $\mathbf{2 2 8 3}$ \\
8 & 359 & 148 & 359 & 122 & 35 & 106 & 33 & 0 & 40 & $\mathbf{1 2 0 2}$ \\
9 & 735 & 365 & 89 & 523 & 108 & 78 & 321 & 36 & 0 & $\mathbf{2 2 5 5}$ \\
\hline Total & $\mathbf{2 1 8 7}$ & $\mathbf{1 1 2 4}$ & $\mathbf{2 2 1 9}$ & $\mathbf{1 8 5 6}$ & $\mathbf{5 6 8}$ & $\mathbf{1 6 0 7}$ & $\mathbf{2 5 1 4}$ & $\mathbf{1 2 2 1}$ & $\mathbf{2 5 3 7}$ & $\mathbf{1 5 8 3 3}$ \\
\hline
\end{tabular}

Fonte: A autora

Tabela 10 - Matriz OD obtida pela rotina computacional elaborada considerando de nível de tolerância 32 durante processo de otimização

\begin{tabular}{ccccccccccc}
\hline $\mathrm{O} / \mathrm{D}$ & 1 & 2 & 3 & 4 & 5 & 6 & 7 & 8 & 9 & Total \\
\hline 1 & 0 & 1 & 308 & 83 & 114 & 505 & 406 & 337 & 708 & $\mathbf{2 4 6 2}$ \\
2 & 64 & 0 & 56 & 105 & 29 & 96 & 319 & 145 & 324 & $\mathbf{1 1 3 8}$ \\
3 & 313 & 0 & 0 & 520 & 112 & 1 & 709 & 343 & 382 & $\mathbf{2 3 8 0}$ \\
4 & 23 & 115 & 515 & 0 & 47 & 345 & 2 & 99 & 522 & $\mathbf{1 6 6 8}$ \\
5 & 91 & 26 & 91 & 31 & 0 & 19 & 93 & 35 & 92 & $\mathbf{4 7 8}$ \\
6 & 524 & 120 & 85 & 376 & 58 & 0 & 537 & 102 & 74 & $\mathbf{1 8 7 6}$ \\
7 & 88 & 318 & 685 & 163 & 106 & 488 & 0 & 70 & 303 & $\mathbf{2 2 2 1}$ \\
8 & 316 & 145 & 316 & 122 & 36 & 110 & 35 & 0 & 42 & $\mathbf{1 1 2 2}$ \\
9 & 691 & 319 & 116 & 513 & 108 & 90 & 320 & 39 & 0 & $\mathbf{2 1 9 6}$ \\
\hline Total & $\mathbf{2 1 1 0}$ & $\mathbf{1 0 4 4}$ & $\mathbf{2 1 7 2}$ & $\mathbf{1 9 1 3}$ & $\mathbf{6 1 0}$ & $\mathbf{1 6 5 4}$ & $\mathbf{2 4 2 1}$ & $\mathbf{1 1 7 0}$ & $\mathbf{2 4 4 7}$ & $\mathbf{1 5 5 4 1}$ \\
\hline
\end{tabular}

Fonte: A autora

Tabela 11 - Matriz OD obtida pela rotina computacional elaborada considerando de nível de tolerância 33 durante processo de otimização

\begin{tabular}{c|ccccccccc|c}
\hline O/D & 1 & 2 & 3 & 4 & 5 & 6 & 7 & 8 & 9 & Total \\
\hline 1 & 0 & 259 & 486 & 544 & 209 & 415 & 934 & 35 & 340 & $\mathbf{3 2 2 2}$ \\
2 & 194 & 0 & 210 & 187 & 17 & 152 & 64 & 21 & 48 & $\mathbf{8 9 3}$ \\
3 & 460 & 229 & 0 & 435 & 200 & 457 & 343 & 27 & 946 & $\mathbf{3 0 9 7}$ \\
4 & 513 & 217 & 428 & 0 & 299 & 520 & 418 & 157 & 436 & $\mathbf{2 9 8 8}$ \\
5 & 114 & 17 & 107 & 236 & 0 & 184 & 136 & 17 & 120 & $\mathbf{9 3 1}$ \\
6 & 443 & 231 & 548 & 592 & 331 & 0 & 501 & 180 & 542 & $\mathbf{3 3 6 8}$ \\
7 & 945 & 62 & 303 & 658 & 186 & 389 & 0 & 197 & 486 & $\mathbf{3 2 2 6}$ \\
8 & 89 & 21 & 81 & 234 & 17 & 198 & 294 & 0 & 276 & $\mathbf{1 2 1 0}$ \\
9 & 316 & 68 & 938 & 461 & 191 & 585 & 510 & 202 & 0 & $\mathbf{3 2 7 1}$ \\
\hline Total & $\mathbf{3 0 7 4}$ & $\mathbf{1 1 0 4}$ & $\mathbf{3 1 0 1}$ & $\mathbf{3 3 4 7}$ & $\mathbf{1 4 5 0}$ & $\mathbf{2 9 0 0}$ & $\mathbf{3 2 0 0}$ & $\mathbf{8 3 6}$ & $\mathbf{3 1 9 4}$ & $\mathbf{2 2 2 0 6}$ \\
\hline
\end{tabular}

Fonte: A autora

A matriz OD obtida por Bertoncini (2010) é apresentada na Tabela 12 apenas a título de comparação. Seus valores também serão considerados como referência durante as análises dos resultados obtidos. 
Tabela 12 - Matriz OD obtida por Bertoncini (2010)

\begin{tabular}{c|cccccccccc}
\hline O/D & 1 & 2 & 3 & 4 & 5 & 6 & 7 & 8 & 9 & Total \\
\hline 1 & 0 & 371 & 391 & 174 & 287 & 340 & 281 & 295 & 509 & $\mathbf{2 6 4 8}$ \\
2 & 244 & 0 & 190 & 233 & 163 & 218 & 310 & 100 & 276 & $\mathbf{1 7 3 4}$ \\
3 & 128 & 122 & 0 & 405 & 235 & 190 & 483 & 252 & 380 & $\mathbf{2 1 9 5}$ \\
4 & 190 & 253 & 464 & 0 & 190 & 358 & 134 & 175 & 371 & $\mathbf{2 1 3 5}$ \\
5 & 154 & 196 & 248 & 190 & 0 & 116 & 247 & 501 & 174 & $\mathbf{1 8 2 6}$ \\
6 & 364 & 245 & 169 & 380 & 190 & 0 & 381 & 207 & 190 & $\mathbf{2 1 2 6}$ \\
7 & 380 & 341 & 417 & 190 & 278 & 359 & 0 & 331 & 115 & $\mathbf{2 4 1 1}$ \\
8 & 344 & 105 & 403 & 380 & 190 & 271 & 190 & 0 & 154 & $\mathbf{2 0 3 7}$ \\
9 & 495 & 353 & 219 & 611 & 298 & 111 & 380 & 200 & 0 & $\mathbf{2 6 6 7}$ \\
\hline Total & $\mathbf{2 2 9 9}$ & $\mathbf{1 9 8 6}$ & $\mathbf{2 5 0 1}$ & $\mathbf{2 5 6 3}$ & $\mathbf{1 8 3 1}$ & $\mathbf{1 9 6 3}$ & $\mathbf{2 4 0 6}$ & $\mathbf{2 0 6 1}$ & $\mathbf{2 1 6 9}$ & $\mathbf{1 9 7 7 9}$ \\
\hline
\end{tabular}

Fonte: Bertoncini (2010)

O número de iterações necessárias para conclusão da rotina computacional, para cada uma das matrizes obtidas é apresentado na Tabela 13, assim como o número de iterações utilizadas pelo autor do método.

Tabela 13 - Número de iterações necessárias para obtenção de cada matriz

\begin{tabular}{lrrrrrrr}
\hline Matriz & Bertoncini & Tol. 1 & Tol. 10 & Tol. 20 & Tol. 30 & Tol. 32 & Tol. 33 \\
\hline $\mathrm{N}^{\circ}$ de iterações & 250 & 245 & 209 & 104 & 106 & 178 & 89 \\
\hline
\end{tabular}

Fonte: A autora

A Tabela 13 evidencia uma tendência a redução no número de iterações necessárias para que o método alcance a convergência a medida que o nível de tolerância do processo de otimização aumenta. A exceção está para os experimentos realizados com valores de tolerância 30 e 32, os quais requerem número de iterações acima do teste realizado considerando tolerância de 20 . O número total iterações varia em função do método numérico empregado. No caso de Bertoncini (2010) a utilização do processo de otimização do solver Excel pode ser o responsável pelo maior número de iterações devido a sua simplicidade.

Conforme exposto anteriormente, a partir do valor 33 o acréscimo da tolerância do processo de otimização não acarreta mudança no resultado obtido, sendo mantido também o valor de 89 iterações necessárias para obter a convergência do código implementado.

\subsubsection{Total de viagens estimadas}

O Figura 39 apresenta a relação entre o total de viagens estimadas e o total de viagens reais para cada uma das matrizes resultado obtidas. Para comparação, a relação otida por Bertoncini (2010) também é apresentada. 
Todas as matrizes obtidas apresentarama uma subestimação do resultado em relação ao total de viagens da matriz "real". O teste que apresentou melhor resultado, nesse quesito, foi o teste com valor de tolerancia igual a 33, o qual subestimou apenas em $4 \%$ o número total de viagens. O pior resultado foi obtido pelo teste 1 que apresentou número total de viagens estimadas $45 \%$ abaixo do valor "real".

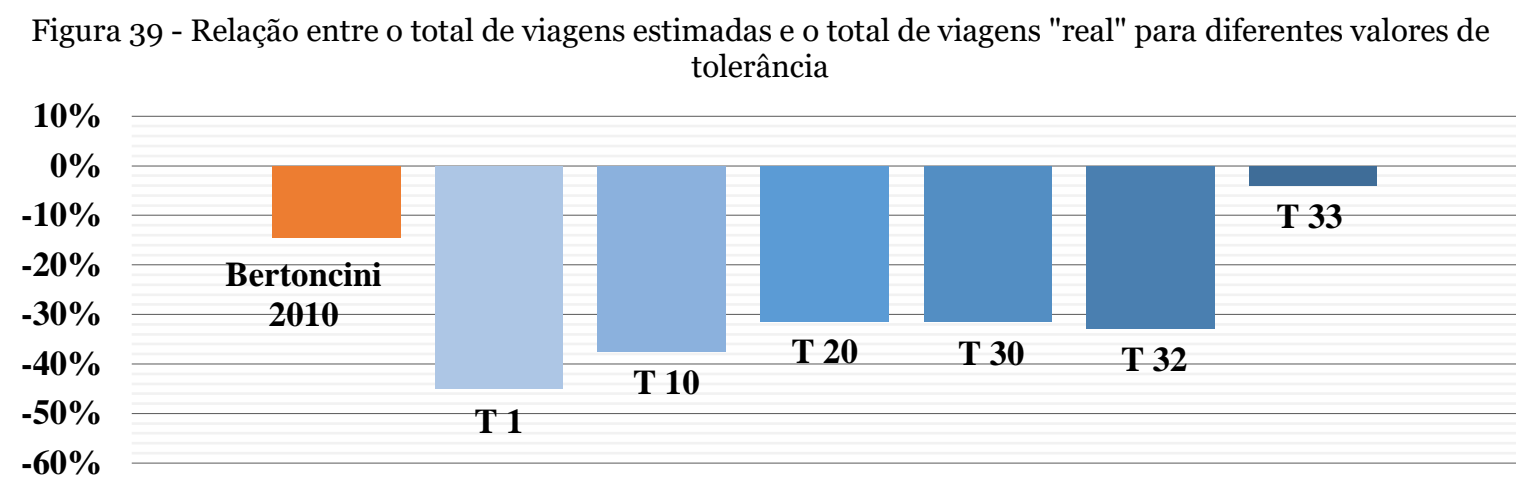

Fonte: A autora

\subsubsection{Viagens estimadas em cada par $O D$}

Apenas o número total de viagens não pode ser considerado como parâmetro para determinar a adequação da matriz OD gerada, uma vez que, o total de viagens pode estar próximo ao "real", porém a distribuição desse volume entre os pares OD pode estar completamente incorreta. Por essa razão é necessária a análise das viagens estimadas em cada par OD.

A Figura 40 até a Figura 44 apresentam a relação entre os valores reais referentes a cada par OD e os valores obtidos por meio da rotina computacional elaborada a partir do método das medias sucessivas. A Figura 45 apresenta a mesma relação, porém considerando o resultado obtido anteriormente por Bertoncini (2010) em seu experimento T8.

Para melhor interpretação dos resultados foi obtida a linha de tendência, considerando o 0 como ponto de interseção, e o eixo de simetria qual corresponde ao resultado ideal. Quanto mais próxima do eixo de simetria estiver a linha de tendência mais adequados estarão os resultados. 
Figura 40 - Viagens reais $\mathrm{x}$ viagens estimadas por par OD, tolerância 1

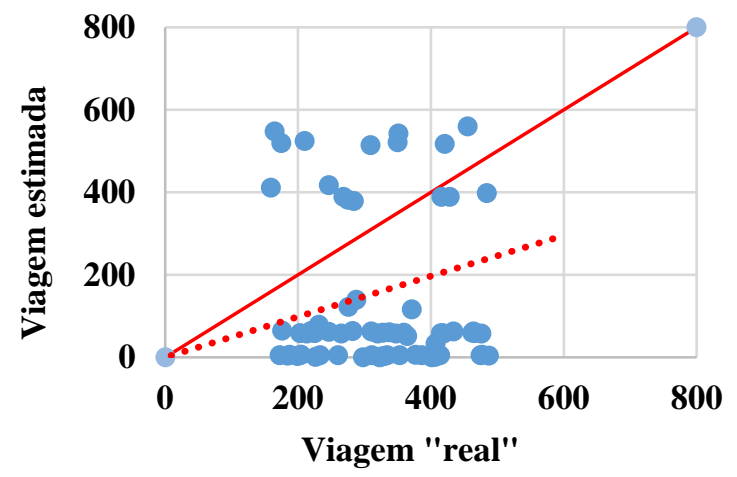

Fonte: A autora

Figura 42 - Viagens reais x viagens estimadas por par OD, tolerância 20

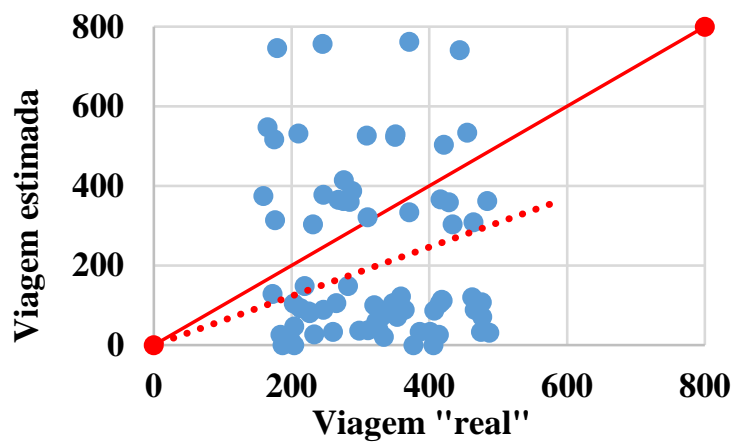

Fonte: A autora

Figura 44 - Viagens reais x viagens estimadas por par OD, tolerância 33

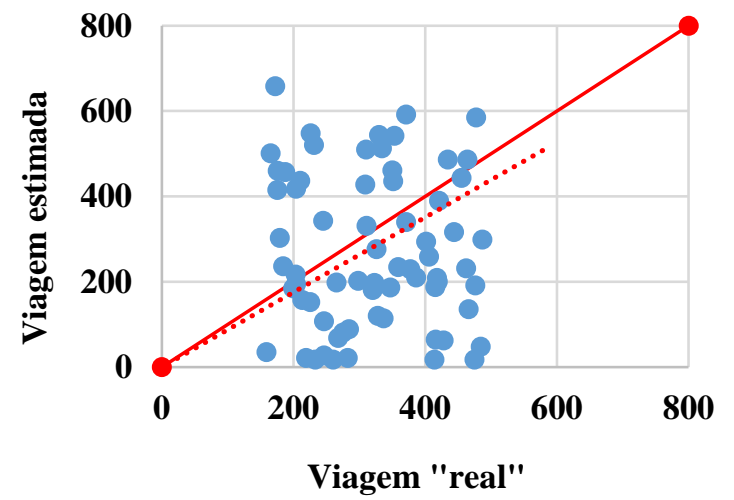

Fonte: A autora
Figura 41 - Viagens reais x viagens estimadas por par OD, tolerância 10

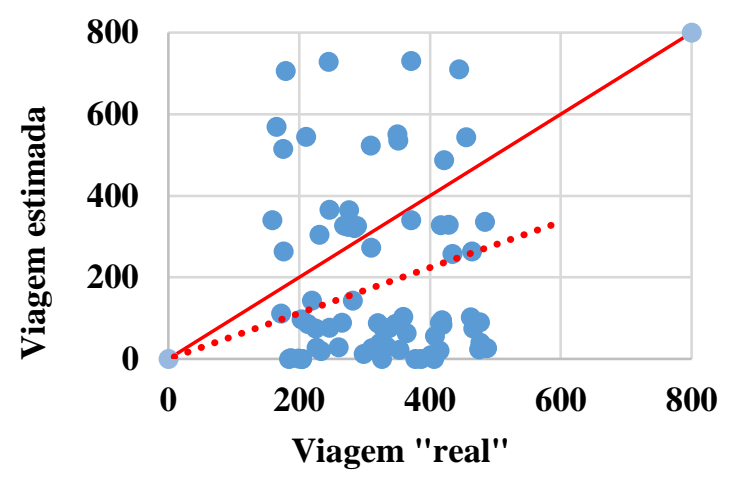

Fonte: A autora

Figura 43 - Viagens reais x viagens estimadas por par OD, tolerância 30

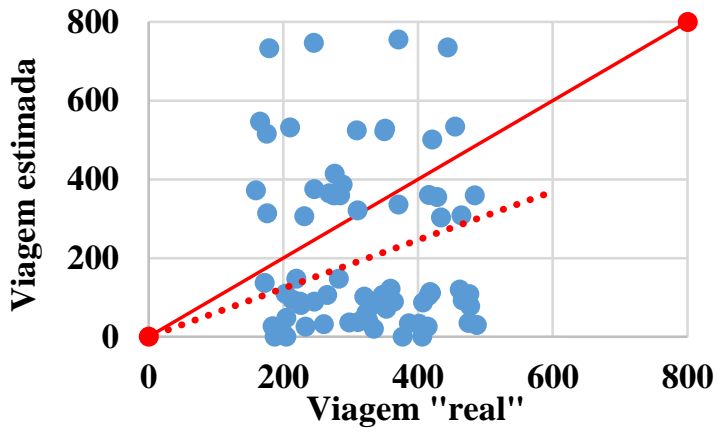

Fonte: A autora

Figura 45 - Viagens reais x viagens estimadas por par OD

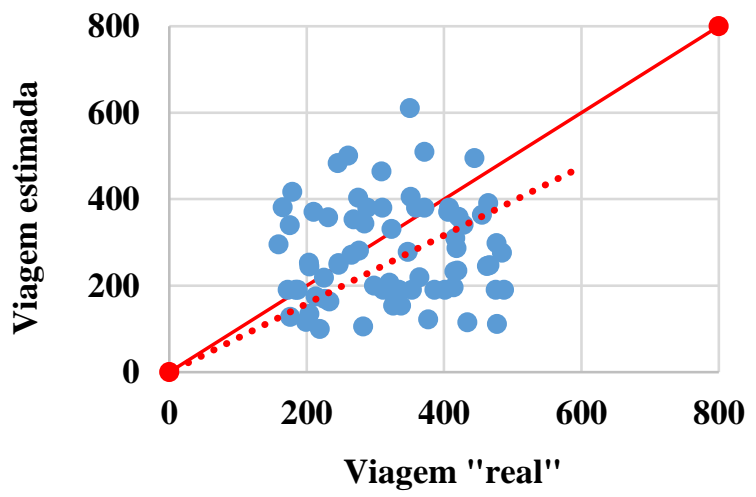

Fonte: Bertoncini (2010)

Os dados estimados que obtiveram linha de tendência mais próxima ao eixo de simetria foram os obtidos a partir do código implementado com o uso do valor de tolerância igual a 33, mesmo quando comparado com o resultado obtido por Bertoncini (2010). 


\subsubsection{Diferença absoluta}

A Tabela 14 evidência que para a rotina computacional proposta o aumento da tolerância acarretou uma redução da diferença absoluta média, as quais, no entanto, ainda se encontram distantes do valor obtido pelo autor do método. O maior e o menor erro obtidos também foram superiores aos obtidos por Bertoncini (2010).

Tabela 14 - Diferença absoluta média e erro absoluto

\begin{tabular}{lrrrrrr}
\hline Tolerância & \multicolumn{1}{c}{1} & \multicolumn{1}{c}{10} & 20 & 30 & 33 & Bertoncini (2010) \\
\cline { 2 - 7 } Diferença absoluta média & 0,86 & 0,74 & 0,71 & 0,69 & 0,64 & 0,39 \\
Maior erro absoluto & 660 & 527 & 567 & 506 & 658 & 366 \\
Menor erro absoluto & 27 & 31 & 11 & 5 & 10 & 2 \\
\hline
\end{tabular}

Fonte: A autora

Analisando a distribuição de frequência relativa dos erros absolutos (Figura 46) observa-se que o resultado obtido por Bertoncini (2010) apresenta maior frequência de erros entre 50 e 100 viagens enquanto o resultado obtido pela rotina computacional implementada apresenta maiores ocorrências de erros em torno de 250 e 300 viagens. É possível observar também que a rotina implementada obteve alguns erros significativamente elevados, o que não ocorreu no experimento de Bertoncini (2010).

Figura 46 - Distribuição de frequência dos erros absolutos obtidos para o experimento T8 de Bertoncini (2010) e para o código implementado com tolerância 33.

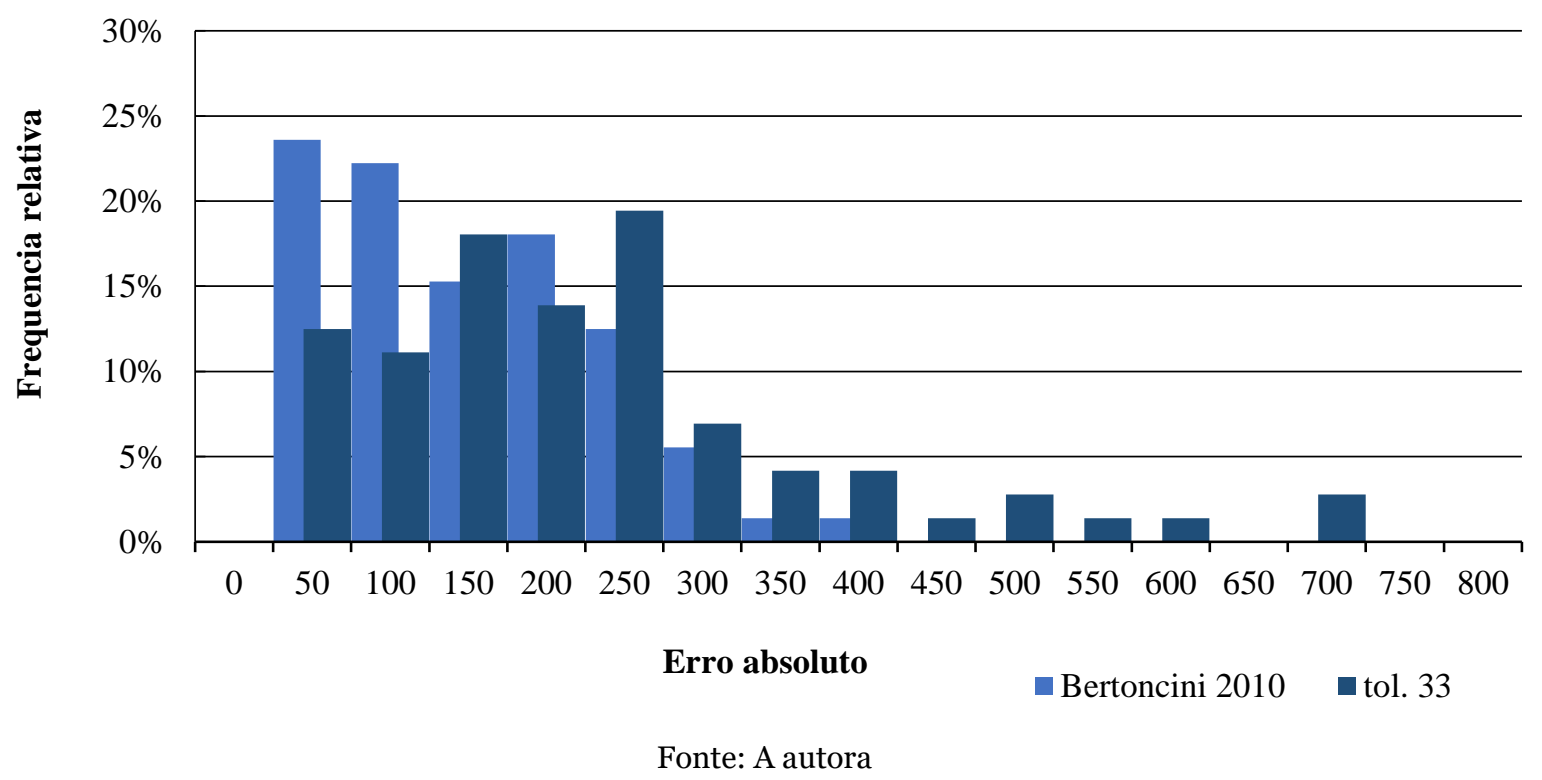




\subsection{CONCLUSÕES}

A rotina computacional elaborada obteve desempenho superior ao alcançado por Bertoncini (2010) com relação ao número de viagens totais estimadas e a linha de tendência obtida no gráfico de dispersão de valores estimados x reais em cada par OD, a qual se mostrou mais próxima ao eixo de simetria, que corresponde ao resultado ideal. Em contrapartida, os valores obtidos pelo código implementado apresentaram maior frequência de valores elevados de erro, quando comparado ao obtido por Bertoncini (2010) o qual apresentou maior ocorrência de erros entre 50 e 100 viagens.

A rotina computacional elaborada apresenta potencial para melhoria do seu desempenho por meio do estudo mais detalhado dos pacote de otimização utilizado. O scipy optimize apresenta elevado número de algoritmos e variáveis, as quais não foram todas plenamente testadas durante o desenvolvimento do código.

Além do MEMS, Bertoncini (2010) propôs a realização de contagens nos nós como uma estratégia para aumentar a quantidade de informações e assim reduzir a indeterminação do problema. Os melhores resultados obtidos pelo autor foram na aplicação do MEMS juntamente com a utilização de contagens nos nós. Esses cenários não foram retratados nesta pesquisa, pois os dados disponibilizados pela API são referentes aos links. 


\section{MATRIZ SINTÉTICA A PARTIR DE DADOS DA}

WEB

Este capítulo tem por objetivo reconstruir matriz origem destino sintética a partir de dados de tráfego disponíveis na web.

\subsection{ESTUDO DE CASO}

A rede real selecionada para o experimento exploratório de reconstrução da matriz OD a partir de dados fornecidos pela web, é composta pelas Rodovias Presidente Dutra, Ayrton Senna, Governador Carvalho Pinto, Pedro I e Acesso Nicola Capucci e encontra-se entre os municípios de São Paulo e São José dos Campos (Figura 47).

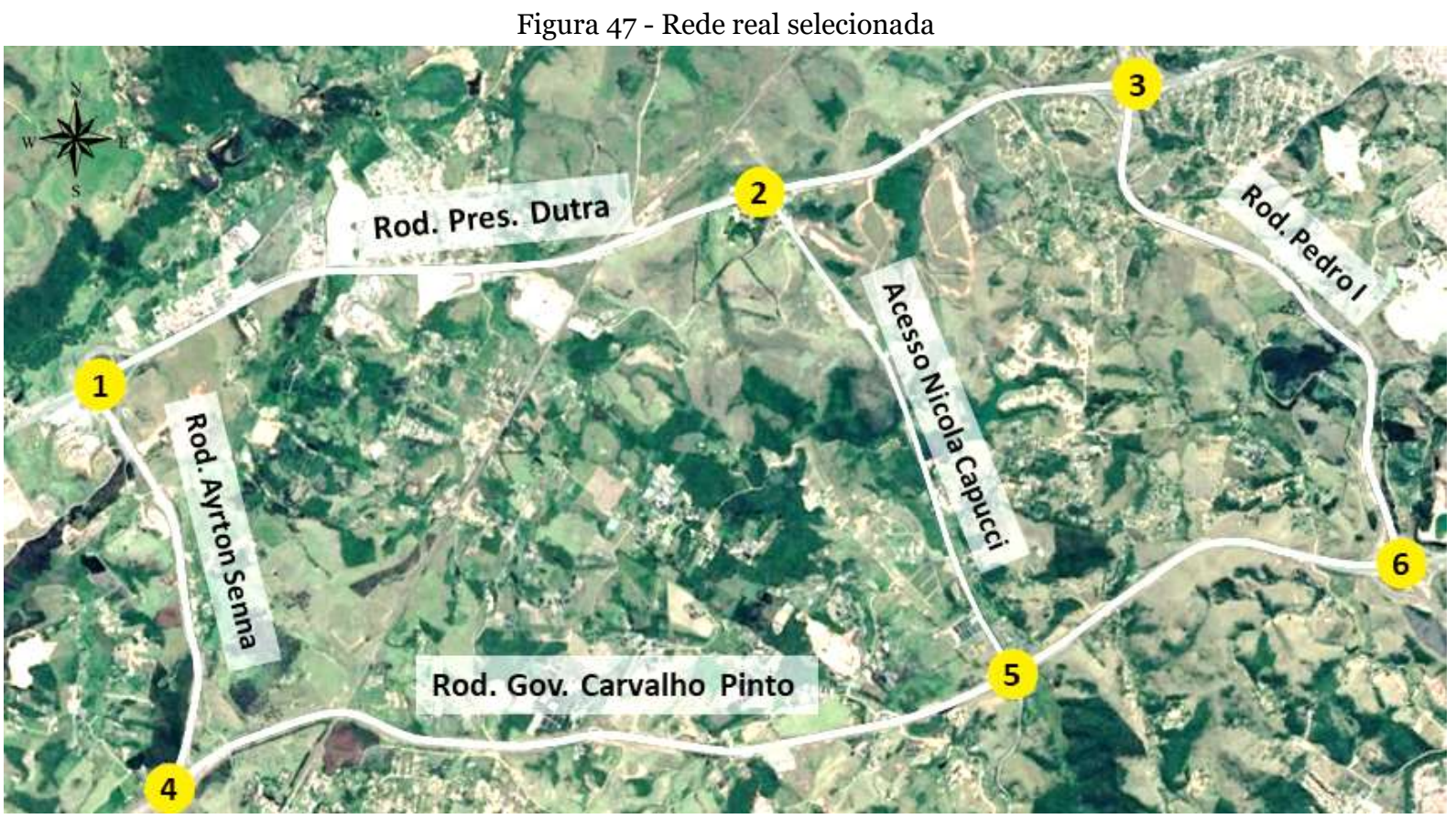

Fonte: A autora sobre imagem do Google Earth

Os seis nós que compõem a rede desempenham função de origem e destino de viagens e foram numerados conforme Figura 47. A coleta dos dados ocorreu por meio da Here Traffic API, conforme descrito no Capítulo 2. 


\subsection{MÉtodo PROPOSTO}

O objetivo central desta pesquisa foi testar a hipótese referida anteriormente: $E$ possivel reconstruir uma matriz $O D$ a partir de dados disponíveis na web? Para tal, foi desenvolvido um método composto por três etapas conforme exposto na Figura 48.

Figura 48 - Método elaborado para reconstrução da Matriz OD a partir de dados da web.

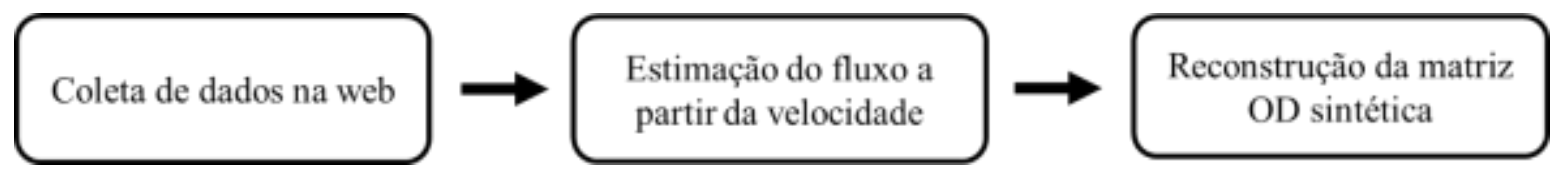

Fonte: A autora

\subsubsection{Etapa 1: Coleta de dados de tráfego da web}

Nesta etapa foi elaborada uma rotina computacional para extração, de forma automática, dos dados provenientes da Here Traffic API. Para que o código de extração funcione é necessário que o usuário adquira um APP ID e um APP CODE por meio de licença obtida no site da Here, a qual é gratuita para o período de 3 meses, não apresenta limites de extração e conta com suporte técnico da empresa.

Além dos dados de registro, deve ser delimitada a área de estudo por meio das coordenadas dos vértices que formam o retângulo do bounding box. Neste experimento foram inseridas as coordenadas referentes ao retângulo que abrange as quatro rodovias e o acesso em estudo.

A rotina desenvolvida acessou os dados da Here Traffic API a cada 1 (um) minuto e os salvou em pasta predefinida pelo usuário, adotando como nomenclatura dos arquivos a hora, o minuto e o segundo em que a extração ocorreu. Para esse experimento foram extraídos os dados referentes ao intervalo entre $19 \mathrm{~h} 00 \mathrm{~min}$ e $20 \mathrm{~h} 00 \mathrm{~min}$ do dia 25 de novembro de 2016. Os arquivos salvos encontram-se no formato JSON e cada um apresentou os dados de todos os links internos ao bouding box apresentado.

Para facilitar o tratamento e visualização dos dados, foi elaborada uma segunda rotina computacional que tem como função acessar cada um dos arquivos salvos pela rotina precedente e organiza-los em planilhas eletrônicas. Essa rotina permitiu escolher o link e as informações que se deseja obter dos todos os arquivos.

O resultado final desta etapa foi um conjunto de planilhas eletrônicas, uma para cada link, em que cada linha se refere a um minuto do intervalo de tempo pesquisado e cada coluna a uma 
informação do link tais como ID, nome, extensão, velocidade limitada, velocidade não limitada, fator de congestionamento, dentre outras.

\subsubsection{Etapa 2: Estimação do fluxo a partir da velocidade}

Conforme exposto no Capítulo 2 do presente estudo, a Here Traffic API não fornece o volume de tráfego - entrada primordial a execução do modelo MEMS. Por essa razão, a etapa 2 do método proposto dedica-se apenas a obtenção do fluxo a partir da velocidade, por ser um dos dados disponíveis na web.

Como este trabalho consiste em uma abordagem exploratória da utilização dos dados disponíveis na web para a reconstrução de uma matriz OD sintética, é proposta a obtenção do volume a partir da fórmula de impedância elaborada pela BPR (do inglês, Bureau of Public Roads) e utilizada no MEMS para calcular o "custo" atribuído a cada link.

$$
t_{a}=T_{0}\left(1+\alpha \cdot\left(\frac{V_{o b s}^{a}}{C a p^{a}}\right)^{\beta}\right)
$$

em que,

$t_{a}:$ tempo gasto para percorrer o $\operatorname{arco} a$;

$T_{0}$ : tempo gasto para percorrer o arco $a$ na situação de fluxo livre;

$V_{o b s}^{a}: \quad$ contagem de tráfego no $\operatorname{arco} a$;

$\mathrm{Cap}^{a}$ : capacidade do $\operatorname{arco} a$;

$\alpha$ e $\beta$ : constantes nos valores 0,15 e 4 , respectivamente.

A equação [4.1] obtém o tempo gasto para percorrer o arco em função da relação entre volume e capacidade e do tempo gasto para percorrê-lo em uma situação de fluxo livre. A Here Traffic API fornece a extensão do link e a velocidade média no trecho para determinado intervalo de tempo o que permite calcular o tempo gasto para percorrê-lo. O tempo gasto para percorrer o link em uma situação de fluxo livre pode ser obtido em função da velocidade regulamentada na via.

Por fim, a capacidade de cada trecho pode ser adotada em função da configuração e do tipo de via. Embora esse não seja o processo mais adequado de obtenção da capacidade da via, é considerado adequado para o presente experimento, por se tratar de uma técnica exploratória ainda em processo desenvolvimento. 
Sendo assim, isolando o volume na equação [4.1] é possível obter a equação [4.2] a qual permite estimar o volume na via a partir da velocidade, com base no tempo gasto para percorrer o trecho.

$$
V_{o b s}^{a}=\sqrt[\beta]{\frac{t_{a}-T_{0}}{\alpha \cdot T_{0}}} \cdot \operatorname{Cap}^{a}
$$

Para o presente experimento optou-se por utilizar a menor velocidade presente no intervalo de estudo, as quais são apresentadas na Figura 49.

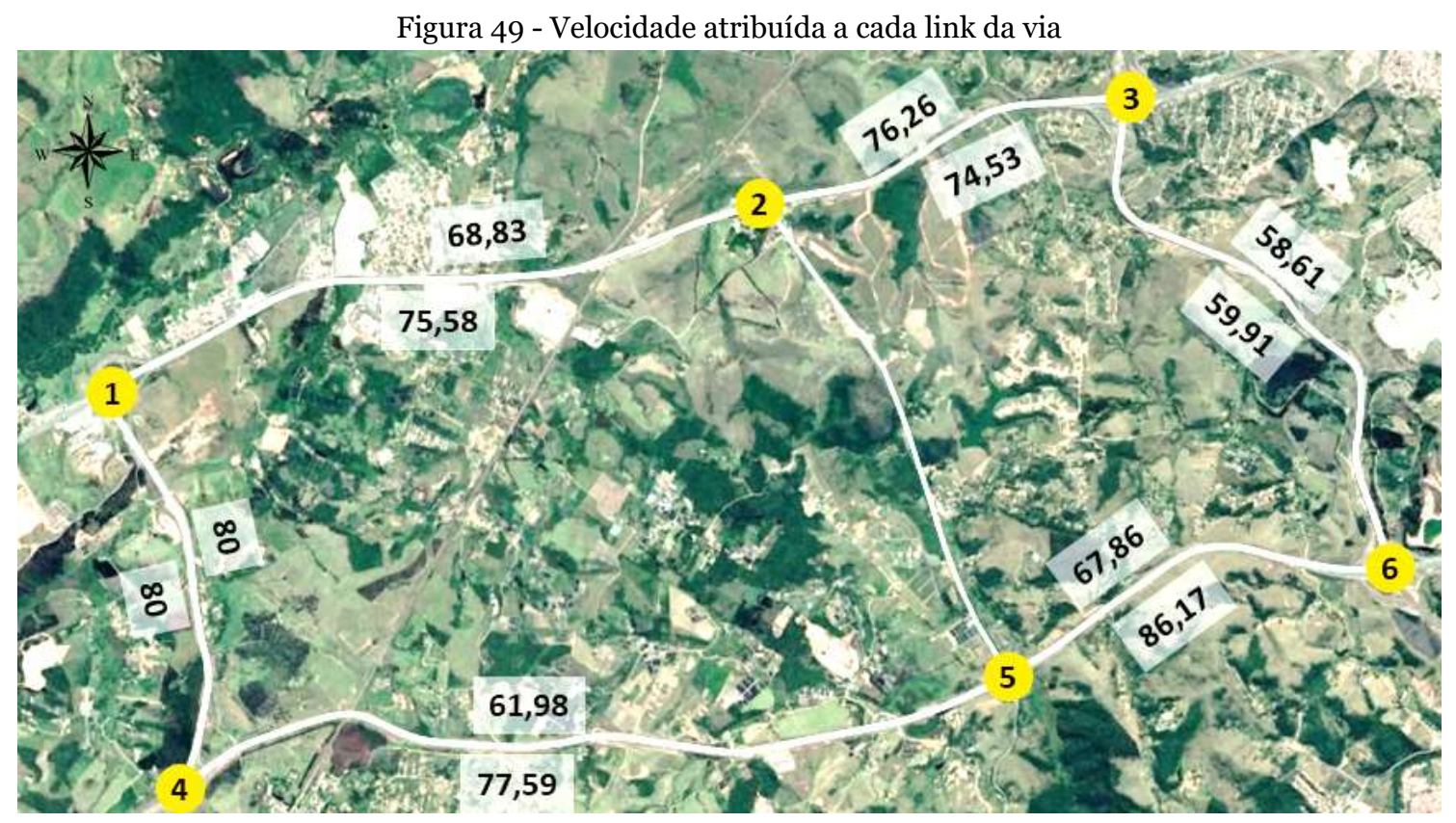

Fonte: A autora sobre imagem do Google Earth

A capacidade de uma via pode ser determinada em função da velocidade de fluxo livre. Em vias expressas, para uma velocidade de fluxo livre de $110 \mathrm{~km} / \mathrm{h}$, a capacidade considerada pode ser de $2.350 \mathrm{ucp} / \mathrm{h} / \mathrm{faixa}$. Para rodovias de pista simples, a capacidade tende a ser de $1.700 \mathrm{cp} / \mathrm{h} /$ faixa (DEMARCHI, 2009), podendo chegar, em segmentos genéricos a $3.200 \mathrm{cp} / \mathrm{h}$ em ambos os sentidos (DEMARCHI e SETTI, 20--).

Em estudos de tráfego o ideal é que seja realizada a calibração da curva fluxo-velocidade e obtida a capacidade real de cada via ou trecho. No entanto, por não ser o objetivo central do presente estudo, optou-se por utilizar valores padrão para a capacidade das vias que compõem a rede viária em estudo.

As rodovias Governador Carvalho Pinto, Presidente Dutra, Pedro I e Ayrton Senna apresentam infraestrutura composta por pista dupla com duas faixas de circulação por sentido, nos trechos 
4 Matriz Sintética a Partir de Dados da Web

em estudo. Por apresentarem características de vias expressas foi atribuído a elas capacidade de $2.350 \mathrm{cp} / \mathrm{h} /$ faixa. O acesso Nicola Capucci apresenta infraestrutura composta por pista simples com um faixa de circulação por sentido. Por essa razão, foi atribuída capacidade de 1.700 ucp/h/faixa. A capacidade atribuída a cada link da rede é apresentada na Figura 50.

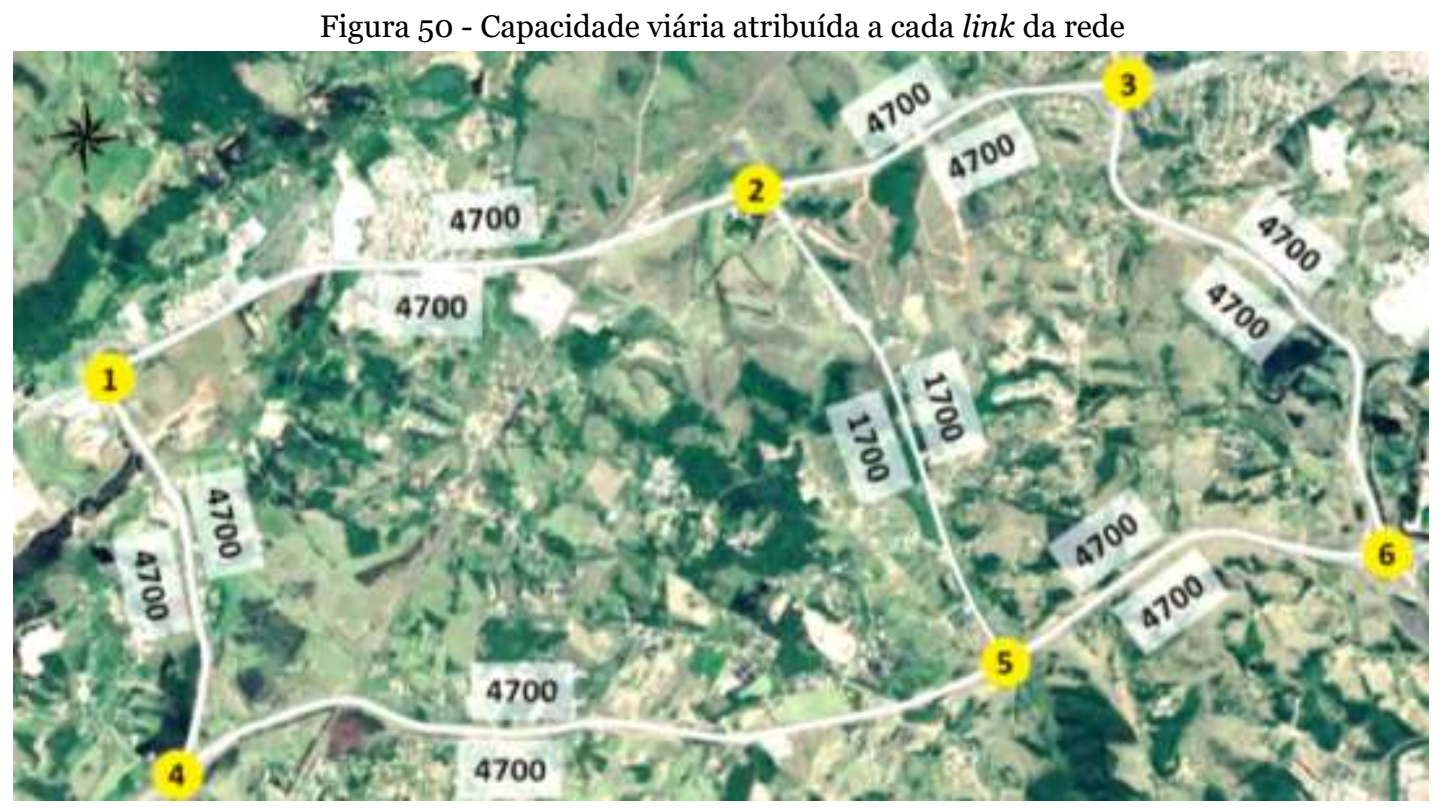

Fonte: A autora sobre imagem do Google Earth

Aplicando os valores considerados na equação [4.2] obtém-se os volumes nos links conforme Figura 51. Por não existirem os dados referentes a velocidade nos links do acesso Nicola Capucci não foi estimado o fluxo presente no mesmo, sendo adotado que não houve contagem na via em questão.

Figura 51 - Volumes estimados a partir da velocidade no link fornecida pela API

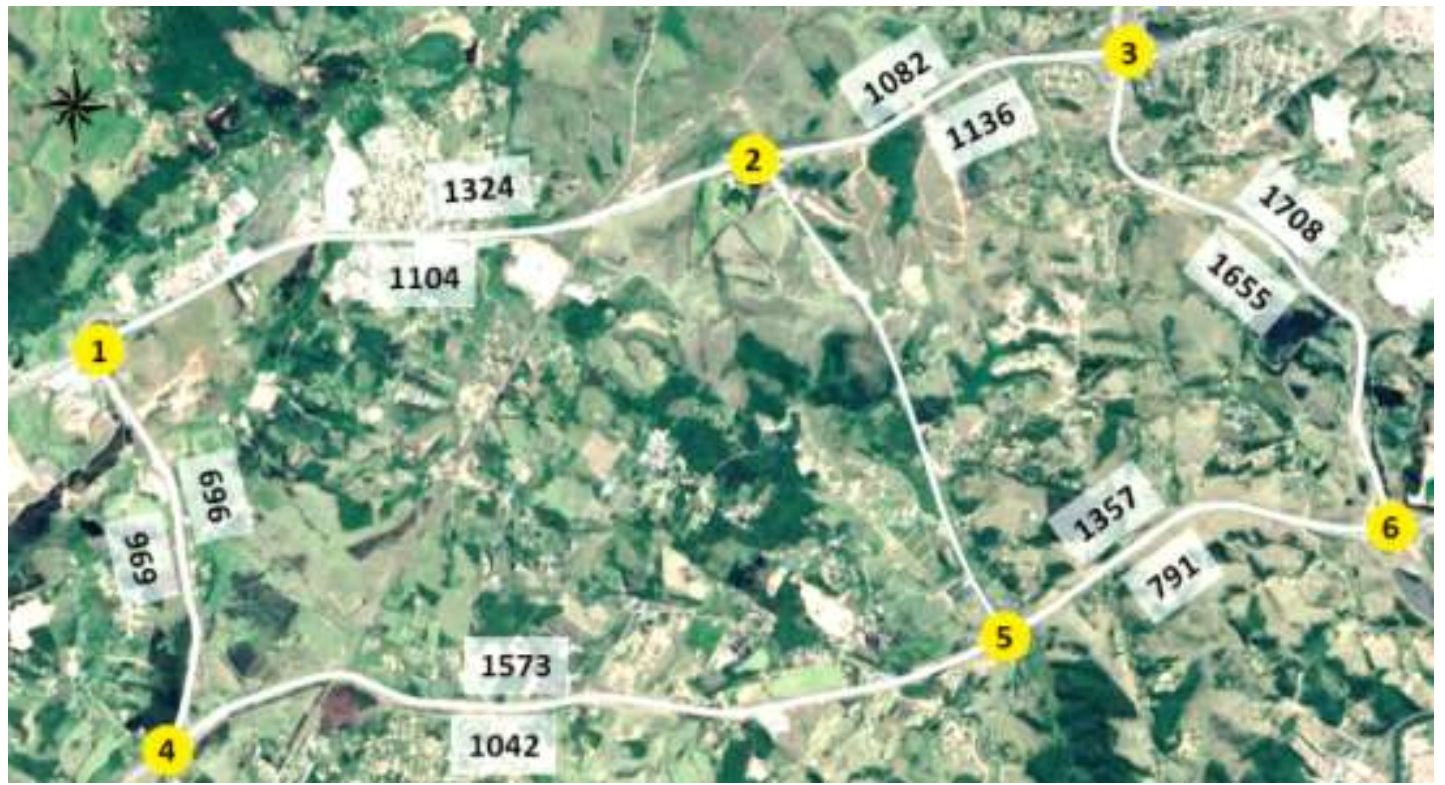

Fonte: A autora sobre imagem do Google Earth 
Comparando os volumes estimados com os obtidos pelos sensores da CCR, presentes na rodovia Presidente Dutra é possível observar que a maior diferença relativa obtida foi de $22 \%$ abaixo do volume real no trecho entre o acesso Nicola Capucci e a Rodovia Ayrton Senna (Tabela 15). A comparação em questão foi realizada apenas para os trechos da rodovia Presidente Dutra devido a inexistência das informações referentes as demais vias.

\begin{tabular}{llll}
\multicolumn{4}{c}{ Tabela 15 - Comparação entre os volumes estimados e reais para os trechos da rodovia Presidente Dutra. } \\
\hline \multirow{2}{*}{ Link $1-2$} & Real & Estimado & Diferença relativa \\
\cline { 2 - 4 } Link $2-1$ & 1478 & 1324 & $10 \%$ \\
Link $2-3$ & 1417 & 1104 & $22 \%$ \\
Link $3-2$ & 1333 & 1082 & $19 \%$ \\
\hline
\end{tabular}

Fonte: A autora

O processo de estimação do volume presente no link a partir da velocidade foi implementado em linguagem computacional e inserido no início na rotina elaborada para reconstrução da matriz OD. Os dados de entrada a serem inseridos são a velocidade, a extensão e capacidade dos links, os quais devem estar no formato de matriz de adjacências.

\subsubsection{Etapa 3: Reconstrução da matriz OD sintética}

A etapa 3 consiste na aplicação da rotina computacional elaborada no Capítulo 3 desta pesquisa incluindo a função desenvolvida na etapa 2 do método. Uma vez que os dados de entrada foram inseridos na etapa 2, não é necessário agregar qualquer nova informação nesta etapa.

Para este experimento foi utilizado na função de otimização valor de tolerância igual a 15, pois não foi observada alteração do resultado ao aumentar esse valor.

É possível acompanhar as etapas intermediárias do MEMS e dos métodos propostos através da do interpretador de linha de comando ou outras interfaces utilizadas para processar a rotina. $\mathrm{O}$ resultado obtido é salvo na forma de matriz em uma planilha eletrônica.

\subsection{Resultados}

A matriz OD sintética obtida pelo método a partir dos valores de capacidade e velocidade expostos é apresentada na Tabela 16. 
4 Matriz Sintética a Partir de Dados da Web

Tabela 16 - Matriz OD obtida para a rede real em estudo.

\begin{tabular}{c|cccccc|c}
\hline $\mathrm{O} / \mathrm{D}$ & 1 & 2 & 3 & 4 & 5 & 6 & Total \\
\hline 1 & 0 & 162 & 158 & 16 & 266 & 518 & $\mathbf{1 1 2 0}$ \\
2 & 248 & 0 & 19 & 271 & 15 & 346 & $\mathbf{8 9 9}$ \\
3 & 384 & 126 & 0 & 407 & 424 & 350 & $\mathbf{1 6 9 1}$ \\
4 & 19 & 130 & 126 & 0 & 244 & 516 & $\mathbf{1 0 3 5}$ \\
5 & 336 & 15 & 19 & 368 & 0 & 262 & $\mathbf{1 0 0 0}$ \\
6 & 410 & 153 & 20 & 443 & 66 & 0 & $\mathbf{1 0 9 2}$ \\
\hline Total & $\mathbf{1 3 9 7}$ & $\mathbf{5 8 6}$ & $\mathbf{3 4 2}$ & $\mathbf{1 5 0 5}$ & $\mathbf{1 0 1 5}$ & $\mathbf{1 9 9 2}$ & $\mathbf{6 8 3 7}$ \\
\hline
\end{tabular}

Fonte: A autora

De modo geral, os volumes atribuídos a cada par OD apresentaram valores adequados variando entre 150 e 500 veículos. No entanto, algumas células apresentaram valores muito baixos tais como 19 e 15 veículos. A ocorrência de valores baixos em determinadas células também foi observada na replicação do MEMS apresentada no capítulo 3.

Uma vez que a capacidade foi uma variável utilizada tanto no processo de estimativa do volume quanto no de reconstrução da matriz OD no cálculo do custo atribuído a cada link, foi realizada uma análise de sensibilidade para observar como os valores de capacidade inseridos interferem no resultado. Para tal foram realizadas novamente as etapas 2 e 3 do método adotando capacidade igual a 4000 veículos/hora para todos os links da rede e a metade da capacidade considerada anteriormente. As matrizes obtidas são apresentadas na Tabela 17 e na Tabela 18.

Tabela 17 - Matriz OD obtida para a rede real em estudo considerando capacidade igual a 4.ooo veículos/hora para todos os links.

\begin{tabular}{c|cccccc|c}
\hline O/D & 1 & 2 & 3 & 4 & 5 & 6 & Total \\
\hline 1 & 0 & 136 & 132 & 13 & 224 & 436 & $\mathbf{9 4 0}$ \\
2 & 338 & 0 & 17 & 356 & 15 & 291 & $\mathbf{1 0 1 7}$ \\
3 & 194 & 17 & 0 & 212 & 358 & 295 & $\mathbf{1 0 7 6}$ \\
4 & 17 & 108 & 103 & 0 & 205 & 436 & $\mathbf{8 7 0}$ \\
5 & 282 & 15 & 17 & 311 & 0 & 221 & $\mathbf{8 4 7}$ \\
6 & 345 & 645 & 790 & 373 & 55 & 0 & $\mathbf{2 2 0 7}$ \\
\hline Total & $\mathbf{1 1 7 6}$ & $\mathbf{9 2 1}$ & $\mathbf{1 0 5 9}$ & $\mathbf{1 2 6 6}$ & $\mathbf{8 5 6}$ & $\mathbf{1 6 7 9}$ & $\mathbf{6 9 5 8}$ \\
\hline
\end{tabular}

Tabela 18 - Matriz OD obtida para a rede real em estudo considerando a metade da capacidade adotada inicialmente.

\begin{tabular}{c|cccccc|c}
\hline $\mathrm{O} / \mathrm{D}$ & 1 & 2 & 3 & 4 & 5 & 6 & Total \\
\hline 1 & 0 & 78 & 77 & 8 & 130 & 256 & $\mathbf{5 5 0}$ \\
2 & 196 & 0 & 18 & 208 & 15 & 170 & $\mathbf{6 0 7}$ \\
3 & 113 & 18 & 0 & 125 & 209 & 171 & $\mathbf{6 3 6}$ \\
4 & 18 & 63 & 62 & 0 & 119 & 255 & $\mathbf{5 1 6}$ \\
5 & 165 & 15 & 18 & 180 & 0 & 128 & $\mathbf{5 0 5}$ \\
6 & 203 & 377 & 461 & 218 & 31 & 0 & $\mathbf{1 2 8 9}$ \\
\hline Total & $\mathbf{6 9 5}$ & $\mathbf{5 5 1}$ & $\mathbf{6 3 5}$ & $\mathbf{7 3 9}$ & $\mathbf{5 0 4}$ & $\mathbf{9 8 0}$ & $\mathbf{4 1 0 4}$ \\
\hline
\end{tabular}

Fonte: A autora 
Ao analisar o número total de viagens estimadas é possível observar a forte influência da capacidade no resultado obtido, devido ao fato de ser utilizada tanto no processo de obtenção dos volumes quanto na função do custo atribuído aos links. A matriz OD estimada com valores de capacidade iguais a metade dos valores utilizados para obtenção da Tabela 16, apresentou uma redução significativa no total de viagens estimadas. No entanto, essa redução não foi proporcional a redução aplicada aos valores de capacidade.

Por meio da comparação dos valores estimados em cada par OD nas três matrizes é possível observar que os valores baixos apresentados na Tabela 16 nos pares 2_3, 2_5, 4_1, 5_2 e 5_3 se mantem baixos ou similares na Tabela 17 e na Tabela 18. Essa ocorrência indica que não há relação entre a capacidade adotada e a ocorrência de volumes significativamente abaixo do esperado em alguns pares OD, o que também foi observado durante a implementação do código a partir de uma rede hipotética realizada no Capítulo 3.

A matriz estimada considerando metade da capacidade adotada inicialmente apresenta maior concentração de valores nas faixas entre 100 e 300 viagens por hora, quando comparada as demais, e nenhuma ocorrência de valores acima 550.

As matrizes obtidas a partir da capacidade inicial considerada e da capacidade de 4.000 veículos/hora para todos os links apresentaram frequências aproximadas de valores entre 100 e 450 viagens. A matriz estimada com capacidade similar para todos os links foi a única a estimar valores acima de 600 viagens por hora, o que pode estar relacionado a estimada de volume mais elevado em cada link. 


\section{CONSIDERAÇÕES FINAIS}

\subsection{CONCLUSÕES}

O amplo uso de equipamentos dotados de GPS, tais como telefones celulares e computadores embarcados possibilitou o surgimento de uma nova fonte de dados de tráfego. Empresas como Here Maps, Google, dentre outras coletam dados dos usuários de suas ferramentas em tempo real e disponibilizam parte dessas informações de forma gratuita por meio de suas APIs.

O objetivo central deste trabalho foi explorar o uso dessas novas fontes de dados e aplicar as informações coletadas na reconstrução de uma matriz OD sintética. Para tal, foram propostos três objetivos específicos:

I. Comparar as velocidades obtidas a partir da web com as aferidas por sensores fixos do tipo laço indutivo;

II. Construir um modelo de reconstrução de matriz OD;

III. Implementar o modelo e verificar sua aderência a realidade.

Os dados selecionados para avaliação e aplicação no experimento são provenientes da Here Traffic API. Para avaliar a adequação do conteúdo coletado foi realizada a comparação entre as velocidades obtidas a partir da web e as aferidas por meio de sensores fixos. Os resultados atingidos evidenciam diferenças entre os dados obtidos pelas duas fontes com maior dispersão e valores mais baixos dos dados coletados da web em comparação aos provenientes de sensores. É importante destacar que as velocidades coletadas por meio de sensores fixo e as extraídas a partir do GPS de smartphones e equipamentos embarcados, possuem naturezas distintas. A primeira refere-se a velocidade média no tempo e é extraída apenas em um ponto da via enquanto a segunda refere-se a velocidade média no espaço e representa a velocidade em um trecho, neste caso em um link. Embora usualmente a velocidade no espaço apresenta valores um pouco inferiores aos obtidos para a velocidade no tempo, as análises realizadas indicam que a diferença entre as velocidades obtidas pelas duas fontes de dados não se deve apenas ao fato de possuírem naturezas distintas.

Além disso, a maioria dos dados obtidos da web apresentou diferença absoluta similar ou inferior a $10 \mathrm{~km} / \mathrm{h}$ quando comparado aos valores aferidos pelo sensor, pode ser considerada 
baixa uma vez que a média das velocidades médias dos sensores, desconsiderando o trecho 2 , em ambos os sentidos foi de aproximadamente $90 \mathrm{~km} / \mathrm{h}$. Sendo assim a maior parcela dos dados obteve erro inferior a $11 \%$.

A facilidade de acesso aos dados provenientes da web, o fato de cobrir praticamente todas as vias principais e, em alguns casos vias locais, de sistemas viários urbanos e rurais, bem como o baixo custo de aquisição em comparação a outras fontes de dados torna essa uma opção atrativa para os gestores de tráfego.

A implementação de uma rotina computacional, a partir do Método das Médias Sucessivas de Bertoncini (2010) foi realizada de forma adequada e o resultado apresentou desempenho superior em algumas análises ao obtido pelo autor do método em seu experimento T8, que considerava contagens apenas nos links. No entanto, a rotina ainda precisa ser aprimorada por meio do estudo mais aprofundado da ferramenta de otimização utilizada.

O experimento de reconstrução da matriz OD de uma rede viária real por meio do uso de dados oriundos da web foi devidamente realizado. Para tal, foi necessário estimar o volume presente na via a partir da velocidade da corrente de tráfego. Os volumes obtidos apresentaram diferença relativa máxima de $22 \%$ quando comparado a contagem real do tráfego, realizada por meio de sensores fixos, o que corresponde a aproximadamente 300 veíc/h. Em um contexto rodoviário, em que o volume da via é próximo de 1400 veículos por hora, como neste estudo, esse valor pode ser considerado pouco impactante. No entanto, em um contexto urbano tais diferenças podem ser consideradas inaceitáveis.

A matriz OD obtida apresentou elevada dependência dos valores de capacidade adotado, os quais são utilizados no processo de estimação do volume e no cálculo do custo atribuído a cada link. Uma vez que a capacidade é uma característica relacionada a estrutura física e a configuração da via, não sendo alterada por fatores como volume e horário, é possível estimala para uma determinada rede e a partir desse valor fixo reconstruir as matrizes referentes a diferente horários e datas, por meio da velocidade fornecida pela web.

Conforme exposto na introdução, foi proposta a seguinte hipótese: É possível reconstruir uma matriz $O D$ a partir de dados disponíveis na web. Os resultados obtidos evidenciam que, por meio do método apresentado, é possível reconstruir uma matriz OD a partir dos dados disponíveis na web. Embora ainda seja necessário aprimorar o método proposto, o baixo custo e o fato de não ser necessário realizar contagens ou pesquisas devido a vasta disponibilidade de dados disponíveis na web, o torna bastante atrativo. 


\subsection{SUgESTÕES de TRABALHOS FutUROS}

Como sugestão de trabalhos futuros é proposta a utilização da fonte de dados apresentada em outras aplicações, tais como o estudo do comportamento do tráfego, avaliação do desempenho das vias, análise da topologia da rede viária, dentre outras. Bem como a análise das velocidades e demais informações de tráfego obtidas apenas de links que não possuem interconexões.

Com relação ao método de reconstrução de matriz OD implementado, é proposto o estudo de diferentes algoritmos de caminhos mínimos e otimização de modo a avaliar a influência desses sobre o desempenho geral do método. Do mesmo modo, sugere-se a avaliação do uso de outras equações de custo.

No que se refere a adaptação dos dados extraídos é indicada a necessidade de avaliar a melhor forma de obter o volume no trecho de via a partir dos dados fornecidos pelas APIs. Sugere-se a avaliação da obtenção do fluxo a partir da velocidade fornecida pelas APIs por meio da obtenção de valores mais adequados da capacidade dos links em estudo, como por exemplo o método do Highway Capacity Manual (HCM).

Relacionado a obtenção de matriz OD a partir das velocidades de trafego disponíveis na web, propõe-se a aplicação do modelo de reconstrução de matriz OD para cada uma das fontes consideradas, contagem por meio de sensores do tipo laço indutivo e volumes estimados a partir da velocidade de tráfego disponível na web, de forma independente e posterior comparação entre as matrizes obtidas por cada fonte. Essa análise não pode ser realizada no presente estudo devido a obtenção de dados de contagem de tráfego referentes apenas a uma das cinco vias que compunham a rede viária em estudo. Além disso, pode ser realizada a análise da relação entre os resultados obtidos para cada célula da matriz OD reconstruída e a distância entre os respectivos pares OD.

Por fim, sugere-se a aplicação do método proposto em redes urbanas em que a disposição de dados é significativamente superior, sendo possível obter informações de vias expressas e até mesmo locais, para algumas cidades e em redes maiores do que a considerada neste estudo. 


\section{REFERÊNCIAS BIBLIOGRÁFICAS}

ABRAHAMSSON, T. Estimation of Origin-Destination Matrices Using Traffic Counts - A Literature Survey. In: International Institute of Applied Systems Analysis, Interim Report IR-98-021, Austria, 1998.

HERRERA, J. C.; WORK, D. B.; HERRING, R.; BANB X.; JACOBSON, Q.; BAYEN, A. M.; Evaluation of Traffic Data Obtained via GPS-enabled Mobile Phones: the Mobile Century field experiment. In: Transportation Research C, 2009.

BECKER, R. A.; CACERES, R.; HANSON, K.; LOH, J. M.; URBANEK, S.; VARSHAVSKY, A.; VOLINSKY, C. Route Classification using Cellular Handoff Patterns. In: UbiComp' 11 Proceedings of the 13th international conference on Ubiquitous computing. p. 123-132, 2011.

BERTONCINI, B. V. Uma proposta de Estimação da matriz OD a partir de fluxos de tráfego observados nas interseções de rede de transportes. 2010. 231 p. Tese de doutorado. Escola de Engenharia de São Carlos (EESC), Universidade de São Paulo (USP), São Carlos, 3 mar. 2011.

BING MAPS. 2018. Disponível em: <https://www.bing.com/maps>. Acesso em: jan. 2018.

CACERES, N.; WIDEBERG, J. P.; BENITEZ, F. G. Deriving origin-destination data from mobile network. In: The Institution of Engineering and Technology, Intelligent Transport System, pp. 15-26, 2007.

CADE O ÔNIBUS? 2018. Disponível em: <http://www.cadeoonibus.com.br/>. Acesso em: jan. 2018.

CALABRESE, F.; DI LORENZO, G.; LIU, L.; RATTI, C. Estimating origin destination flows using mobile phone location data. In: IEEE Pervasive Computing, v. 10, pp. 36-44, 2011.

CANALTECH. 2018. 5 aplicativos para acompanhar ônibus em tempo real. Disponível em: $<$ https://canaltech.com.br/apps/5-aplicativos-para-acompanhar-onibus-em-tempo-real/>. Acesso em: jan. 2018.

CITTAMOBI. 2018. Disponível: <https://www.cittamobi.com.br/home/>. Acesso em: jan. 2018

CUNHA, A. L. B. N. Sistema automático para obtenção de parâmetros do tráfego veicular a partir de imagens de vídeo usando OpenCV. 2013. 128 p. Tese de doutorado. Escola de Engenharia de São Carlos (EESC), Universidade de São Paulo (USP), São Carlos, 29 nov. 2013.

DEMARCHI, S. H. Análise de capacidade e nível de serviço de rodovias de pista simples. Universidade Estadual de Maringá, 2009.

DEMARCHI, S. H.; SETTI, J. R. A. Análise de capacidade e nível de serviço de rodovias do tipo pista dupla expressa (freeway). 20--. 
DIJKSTRA, E. W. A note on two problems in conexions with graphs. Numerische Mathematik, v. 1, n. 1, pp. $269271,1959$.

EASY TAXI. 2018. Disponível em: <http://www.easytaxi.com/br/>. Acesso em: jan. 2018.

FLAMMIA, G.; RABINOWICZ, A. Turning Transportation Planning Data into Effective Web Sites. In: 9th TRB Conference on the Application of Transportation Planning Methods, Batons Rouge, Los Angeles, 2003.

GERLOUGH, D. L.; HUBER, M. J. Traffic flow theory: a monograph. In: Transportation Research Board, Special Report 165. U. S. National Research Council, Washington, DC, EUA, 1976.

GOOGLE MAPS. 2018. Disponível em: <https://www.google.com.br/maps>. Acesso em: jan. 2018.

. 2018. Pricing. Disponível em: $<$ https://cloud.google.com/maps-platform/pricing/?hl=ptbr>. Acesso em: jan. 2018.

HERE. Here Traffic API. 2018. Disponível em: $<$ https://developer.here.com/documentation/traffic/topics/request-constructing.html $>$. Acesso em: jan. 2018 $\overline{26 \text { p., } 2014 .}$

TrafficML 3.1 Real-time Flow Feed Specification - Here Implementation. Version 1.8.

KLEIN, L. A. Sensor Technologies and Data Requirements for ITS. Boston: Artech House. 550 p., 2001. ISBN: 1-58053-077-X.

KRAFT, D. A software package for sequential quadratic programming. Tech. Rep. DFVLR-FB 88-28, DLR German Aerospace Center -Institute for Flight Mechanics, Koln, Germany, 33 p., 1988.

MAHER, M. J. Inferences on trip matrices from observations on link volumes: A Bayesian statistical approach. Transportation Research Part B, v. 17, n. 6, p. 435-447, 1983.

MAP QUEST. 2018. Disponível em: <https://www.mapquest.com/>. Acesso em: jan. 2018.

MOOVIT. 2018. Disponível em: <https://moovit.com/>. Acesso em: jan. 2018.

MORGUL, E. F.; YANG, H.; KURKCU, A.; OZBAY, K.; BARTIN, B.; KAMGA, C.; SALLOUM, R. Virtual sensors: Web-based real-time data collection methodology for transportation operation performance analysis. Transportation Research Record, v. 2442(1), p. 106-116, 2014.

NEXTBUS. 2018. Disponível em: <https://www.nextbus.com/>. Acesso em: jan. 2018.

NUMPY. 2018. Disponível em: <http://www.numpy.org/>. Acesso em: jan. 2018.

OLIVEIRA NETO, F. M.; PITOMBEIRA NETO, A. R.; LOUREIRO, C. F. G.; BERTONCINI, B. V. Discussão conceitual sobre método de reconstrução de matrizes origem-destino estáticas em redes de transportes. Transportes, v. 24, p. 107-119, 2016. 
OPENSTREETMAP. 2018. Disponível em: <https://www.openstreetmap.org/\#map=4/-15.13/53.19>. Acesso em: jan. 2018.

ORTÚZAR, J. D.; WILLUMSEN, L. G. Modelling transport (4ª ed.). Wiley, Chichester, 2011.

PAN, B.; ZHENG, Y.; WILKIE, D.; SHAHABI, C. Crowd Sensing of Traffic Anomalies based on Human Mobility and Social Media. In: Proceedings of the 21st ACM SIGSPATIAL International Conference on Advances in Geographic Information Systems. ACM, p. 344-353, Orlando, Florida, USA, 2013.

BRUS, J.; VONDRAKOVA, A.; VOZENILEK, V. Modern Trends in Cartography. Selected Papers of CARTOCON 2014. Springer International Publishing Switzerland, 2015.

PYTHON. 2018. Disponível em: https://www.python.org/ Acesso em: jan. 2018.

RIBEIRO, E. R.; CUNHA, A. L. B. N. Análise exploratória de método para definição de dia típico utilizando transformada wavelet e análise de agrupamento. In: XXX Congresso de Pesquisa e Ensino em Transporte (ANPET), 30, 2016, Rio de Janeiro. Anais... 2016.

SCHNEIDER, M. Gravity Models and Trip Distribution Theory. Papers and proceedings of the Regional Science Association, v. 5, p. 51-56, 1959

SCIPY. 2018. Disponível em: <https://docs.scipy.org/doc/scipy/reference/tutorial/optimize.html>. Acesso em: jan. 2018.

SHERALI, H. D.; NARAYANAN, A.; SIVANANDAN, R. Estimation of origin-destination triptables based on a partial set of traffic link volumes. Transportation Research Part B, n 37, p. 815-836, 2003.

SPIESS, H. A Maximum Likelihood Model For Estimating Origin-Destination Matrices. Transportation Research Part B, n. 21B, p. 395-412, 1987.

TIMMS, P. A philosophical context for methods to estimate origin-destination trip matrices using link counts. Transport Reviews, v. 21, n. 3, p. 269-301, 2001.

THOMAS, D., LAWRENCE, J; RETTIG. J. T.R.A.F.F.I.C. 2012.

TOMTOM. 2018. Disponível em: <https://www.tomtom.com/pt_br/>. Acesso em: jan. 2018.

UBER. 2018. Disponível em: <https://www.uber.com/pt-BR/>. Acesso em: jan. 2018.

VÁ DE ÔNIBUS. 2018. Disponível em: <http://www.vadeonibus.com.br>. Acesso em: jan. 2018.

VAN ZUYLEN, H. J.; WILLUMSEN, L. G. The most likely trip matrix estimated from traffic counts. Transportation Research Part B, n. 14, p. 281-293, 1980.

WANG, F.; XU, Y. Estimating O-D Travel Time Matrix by Google Maps API: Implementation, Advantages, and Implications. Annals of GIS, v. 17, n. 4, p. 199-209, 2011. 
WANG, P.; HUNTER, T.; BAYEN, A. M.; SCHECHTNER, K.; GONZÁLEZ, M. C. Understanding Road Usage Patterns in Urban Areas. Scientific Reports, v. 2, 2012. Art. ID. 1001.

WANG, Y.; ZHENG, Y.; XUE, Y. Travel time estimation of a path using sparse trajectories. In: 20th ACM SIGKDD international conference on Knowledge discovery and data mining, n. 5, p. 25-34, 2014.

WAZE MOBILE. Waze Connected Citizens, 2016. Disponível em: https://www.waze.com/ptBR/ccp. Acesso em: out. 2016.

WELCH, T. J.; TUFTE, K.; MCCOURT, R. S.; BERTINI, R. L.; SNOOK, A. Implementing a UserOriented Web-based Traffic Data Management and Archive System. In: 86th Annual Meeting of Transportation Research Board, Washington, D. C., 2007.

WILLUMSEN, L. G. Estimation of an O-D matrix from traffic counts - A Review. Institute of Transport Studies. Working paper 99, Leeds University, 1978.

1981.

. Simplified Transport Models Based Traffic Counts. Transportation, v. 10, p. 257-278,

WILSON, A. G. A statistical theory of spatial distribution models, Transportation Research, v. 1 p. 253-269, 1967.

. Entropy in urban and regional modeling. Pion, London, 1970.

YANG, H.; SASAKI, T.; IIDA, Y.; ASAKURA, Y. Estimation of Origen-Destination matrices from link traffic counts on congested network. Transportation Research B, n. 26, p. 417-434, 1992.

ZHANG, Y.; QIN, X.; DONG, S.; RAN, B. Daily OD matrix estimation using cellular probe data. In: 89th Annual Meeting Transportation Research Board, v. 9, 2010.

ZHENG, X.; CHEN, W.; WANG, P.; SHEN, D.; CHEN, S.; WANG, X.; YANG, L. Big Data for Social Transportation. IEEE Transactions on intelligent Transportation Systems, v. 17, n 3, p. 620-630, 2016.

99TAXI. 2018. Disponível em: <https://99app.com/>. Acesso em: jan. 2018. 